FEAUSP - FACULDADE DE ECONOMIA, ADMINISTRAÇÃO E CONTABILIDADE DA UNIVERSIDADE DE SÃO PAULO DEPARTAMENTO DE ADMINISTRAÇÃO PROGRAMA DE PÓS GRADUAÇÃO EM ADMINISTRAÇÃO

Edgard Rasquini Arnas

Gestão da Inovação em Medicina Diagnóstica: um Estudo de Caso 
Prof. Dr. Marco Antonio Zago

Reitor da Universidade de São Paulo

Prof. Dr. Adalberto Américo Fischmann

Diretor da Faculdade de Economia, Administração e Contabilidade Prof. Dr. Roberto Sbragia Chefe do Departamento de Administração

Prof. Dr. Moacir de Miranda Oliveira Júnior

Coordenador do Programa de Pós-Graduação em Administração 
Edgard Rasquini Arnas

\section{Gestão da Inovação em Medicina Diagnóstica: um Estudo de Caso}

Dissertação apresentada ao Programa de Pós-Graduação em Administração do Departamento de Administração da Faculdade de Economia, Administração e Contabilidade da Universidade de São Paulo, como requisito parcial para a obtenção do título de Mestre em Ciências

Orientador:

Prof. Dr. Marcelo Caldeira Pedroso

Versão Corrigida

(versão original disponível na Faculdade de Economia, Administração e Contabilidade)

São Paulo 
AUTORIZO A REPRODUÇÃO E A DIVULGAÇÃO TOTAL OU PARCIAL DESTE TRABALHO PARA FINS DE ESTUDOS ACADÊMICOS E CIENTÍFICOS DESDE QUE CIDADA A FONTE

\section{FICHA CATALOGRÁFICA}

Elaborada pela Seção de Processamento Técnico do SBD/FEA/USP

Arnas, Edgard Rasquini

Gestão da inovação em medicina diagnóstica: um estudo de caso / Edgard Rasquini Arnas. -- São Paulo, 2017.

$161 \mathrm{p}$.

Dissertação (Mestrado) - Universidade de São Paulo, 2017.

Orientador: Marcelo Caldeira Pedroso.

1. Inovação 2. Gestão da inovação 3. Serviços de saúde 4. Medicina diagnóstica I. Universidade de São Paulo. Faculdade de Economia, Administração e Contabilidade. II. Título.

CDD -658.4 
Dedico este mestrado à toda minha querida família que me incentivou a buscar meus sonhos e vencer desafios 



\section{AGRADECIMENTOS}

Agradeço primeiramente a Deus, criador do universo e de todos os mistérios que o ser humano, por meio da ciência, busca revelar. Minha gratidão pelo amor infinito demonstrado dia a dia em toda a natureza. Minha certeza de que cada passo até aqui foi guiado por Ele.

Aos meus pais, Edgard Romaneli Arnas e Eliana Rasquini Romaneli Arnas, que são a base da minha formação e valores. Obrigado por me ensinarem que o conhecimento é um bem valioso e eterno.

À minha querida esposa Paula Lacorte Arnas, pelos abraços e palavras de incentivo dados a mim nos momentos mais difíceis. Pela sua compreensão na mudança de nossa rotina durante este período, em especial o tempo dispendido aos estudos durante as noites e finais de semana. Por se envolver ao final, ajudando nas revisões ortográficas e compreensão de texto. Você foi muito especial.

Ao meu orientador Prof. Marcelo Caldeira Pedroso, cuja trajetória profissional e acadêmica serve de inspiração e incentivo para mim. Muito obrigado pelo conhecimento compartilhado, os ensinamentos e valiosas contribuições concedidas.

Aos meus gestores Patrícia Maeda e Hans Lenk que, no papel de gestores, flexibilizaram minhas horas de trabalho, permitindo completar todas as exigências do meio acadêmico.

À todos os meus amigos e colegas que de forma direta ou indireta colaboraram com o sucesso deste trabalho. 



\section{RESUMO}

Este trabalho busca responder a pergunta de pesquisa: como ocorre a gestão da inovação em uma empresa de Medicina Diagnóstica? Para isso teve como objetivo aprofundar a compreensão sobre a gestão da inovação nesta empresa, entendendo as etapas do processo de inovação (ideação, conversão e difusão), entendendo como a estratégia da inovação se insere no processo de gestão da inovação, e entendendo como que pessoas e organização se inserem na gestão da inovação.

Esta pesquisa fez uso de uma abordagem de natureza teórico-prática de enfoque qualitativo e objetivos de caráter exploratório por meio de um estudo de caso único em um centro de medicina diagnóstica de grande porte, reconhecido por práticas de gestão e inovação. Foram utilizadas as técnicas de entrevistas semiestruturadas, observação direta na empresa, e análise de documentos. Para a etapa de entrevista foi elaborado um protocolo semiestruturado com questões orientadoras conforme pesquisa bibliográfica a respeito de gestão da inovação, o setor de saúde e medicina diagnóstica. Foram entrevistados 12 líderes da empresa envolvidos com a gestão da inovação. Todas as fontes de dados foram analisadas e trianguladas chegando à apresentação e discussão de resultados do caso.

Como resultados, a pesquisa evidenciou a importância da inovação em medicina diagnóstica, podendo reduzir custos e aumentar a qualidade, além de gerar valor para o restante da cadeia.

A estratégia da inovação é alinhada à estratégia corporativa em diversos elementos e possui um processo de definição de drivers que direcionam a companhia no processo de inovação.

O processo de inovação é influenciado por atores encontrados na literatura como órgãos reguladores, médicos, pacientes, fornecedores, universidades e operadoras. Além destes, outros foram citados, como órgãos representativos e o Ministério da Ciência e Tecnologia.

Dois processos estruturados de inovação foram evidenciados: de novos produtos e de novos processos. O processo de novos produtos é alinhado ao modelo de stage gates, enquanto que o processo de novos processos é mais amplo seguindo o modelo hegemônico. A etapa de ideação ocorre com geração de ideias tanto por fontes internas como externas, sendo as principais fontes os médicos e técnicos assessores, e os colaboradores. Técnicas como brainstorming, observação do comportamento dos clientes, e pesquisas acadêmicas são utilizadas. Na etapa de conversão, a seleção e avaliação é feita de maneira colegiada ou individual, por meio de fóruns presenciais ou virtuais. Os critérios de seleção são o alinhamento estratégico, as análises financeiras, técnicas e comerciais. No desenvolvimento e implantação, destaca-se a aplicação de pilotos e testes antes da efetiva implantação da inovação, treinamentos e acompanhamentos da implantação. Por fim, a etapa de difusão ocorre externamente, por meio da equipe comercial junto às operadoras, e com a equipe de médicos e técnicos assessores, junto aos clientes médicos, além dos canais de divulgação como eventos e congressos. A divulgação com clientes finais se dá por meio dos sites, redes sociais, e revistas. Já internamente, a comunicação ocorre principalmente na forma de murais e portais virtuais de comunicação, na atualização de documentos técnicos, e por meio de eventos internos de divulgação do conhecimento, premiação e reconhecimento.

Em pessoas e organização, a pesquisa evidenciou que a cultura influencia o processo de gestão da inovação, sendo formada historicamente sobre os pilares de geração de conhecimento e relacionamento acadêmico nas universidades. Objetiva-se gerenciar os recursos humanos capturando pessoas alinhadas ao valor da inovação desde a fase de contratação, passando por treinamentos, avaliação anual de desempenho, premiação e reconhecimento. Não somente os colaboradores internos recebem incentivos e reconhecimentos, como também há incentivos a fornecedores, médicos e universitários por meio de programas específicos.

\section{Palavras-chave}

Gestão da inovação; inovação em serviços de saúde; medicina diagnóstica 


\begin{abstract}
This master thesis seeks to answer the research question: how works the management of innovation in a case of Diagnostic Medicine? The purpose of this study was to deepen the understanding of innovation management in a diagnostic medicine company, understanding the stages of the innovation process (ideation, conversion and diffusion), understanding how the innovation strategy is embedded in the process of innovation management, and understanding how people and organizations are involved in managing innovation.

This research made use of a theoretical-practical approach of qualitative approach and exploratory objectives through a case study in a large diagnostic medicine center, recognized by management and innovation practices. The techniques of semi-structured interviews, direct observation in the company, and document analysis were used. For the interview stage, a semistructured protocol was developed with orienting questions according to bibliographic research regarding innovation management, the health sector and diagnostic medicine. We interviewed 12 company leaders involved in innovation management. All data sources were analyzed and triangulated, arriving at the presentation and discussion of the results of the case. The research highlighted the importance of innovation in diagnostic medicine, which can reduce costs and increase quality, and generate value for the rest of the chain.

The innovation strategy is aligned with the corporate strategy in several elements and has a process of definition of drivers that guide the company in the process of innovation.

The innovation process is influenced by several stakeholders found in the literature. Besides these others were cited as representative bodies, and the ministry of science and technology.

Two structured innovation processes were evidenced: process of new products and new processes. The process of new products is aligned with the stage gates model, while the process of new processes is broader following the hegemonic model. The stage of ideation occurs with the generation of ideas by both internal and external sources, the main sources being the doctors and technical advisors, and collaborators. Techniques such as brainstorming, customer behavior observation, and academic research are used. In the conversion stage, the selection and evaluation can be done collegially or individually, through forums that can be even virtual. The selection criteria are strategic alignment, financial, technical and commercial analysis. In the development and implementation, we highlight the application of pilots and tests before the effective implementation of the innovation, the training and follow-up of the implementation. Finally, the diffusion stage occurs externally, through the commercial team with the operators, and with the team of medical and technical advisors, with the medical clients, in addition to the channels of dissemination such as events, congresses. Publicity with end customers is through websites, social networks, and magazines. Already internally the communication occurs mainly in the form of virtual murals and portals of communication, in the updating of technical documents, and through internal events of dissemination of knowledge, awards and recognition. In people and organization, the research evidenced that culture influences the process of innovation management, being historically formed on the pillars of knowledge generation and academic relationship in universities. It aims to manage human resources by capturing people aligned with the value of innovation from the hiring stage, through training, annual performance evaluation, awards and recognition. Not only do internal collaborators receive incentives and recognition, but there are also incentives to suppliers, doctors and university students through specific programs.
\end{abstract}

\title{
Key-words
}

Innovation Management, Healthcare Services Innovation; Diagnostic Medicine, Laboratory Medicine 


\section{LISTA DE FIGURAS}

Figura 1: Lacuna de conhecimento na saúde .....................................................25

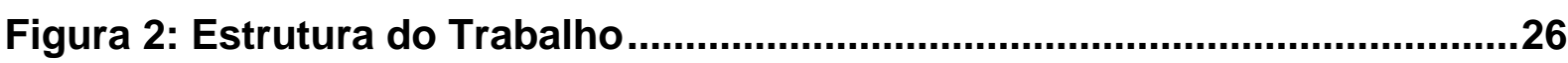

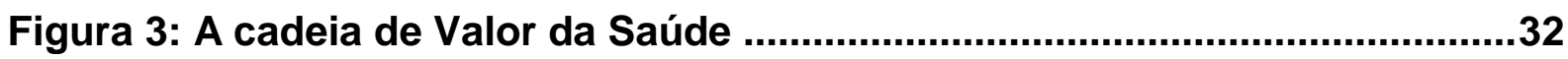

Figura 4: A cadeia de valor da prestação de serviços de saúde em uma

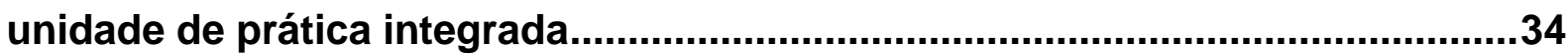

Figura 5: Cadeia de valor do setor de medicina diagnóstica no Brasil:

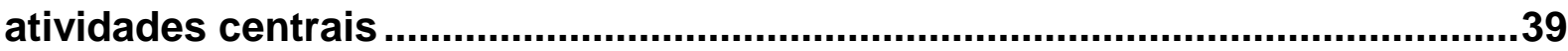

Figura 6: Tipos de serviços de medicina diagnóstica .......................................42

Figura 7: Experiência dos clientes em serviços de medicina diagnóstica ........44

Figura 8: As três atividades de Produção de Serviços ........................................53

Figura 9: Driving Forces Behind Service Innovations ........................................55

Figura 10: Relationship between process, technical characteristics and service characteristics in the Saviotti-Metcalfe framework

Figura 11: Operationalized model with user-facing competences and back office competences.......................................................................................58

Figura 12: A Conceptual Framework for Innovation in Healthcare .....................63

Figura 13: O processo de inovação em saúde ...................................................64

Figura 14: Modelo do Funil da Inovação de Wheelwright e Clark........................67

Figura 15: Modelo stage gates de Cooper ..........................................................69

Figura 16: Modelo Pentathlon da Inovação de Goffin e Mitchell..........................71

Figura 17: 0 modelo da Cadeia de Inovação de Hansen e Birkinshaw ...............74

Figura 18: 0 modelo de processo de inovação de Varkey, Horne, Bennet........75

Figura 19: Estrutura conceitual considerado na pesquisa..................................84

Figura 20: Presença das marcas do Grupo Fleury no Brasil...............................92

Figura 21: Público alvo das marcas do Grupo Fleury por região .......................93

Figura 22: Histórico de aquisições do Grupo Fleury ..........................................94

Figura 23: Estrutura Societária do Grupo Fleury ................................................94

Figura 24: Estrutura Organizacional do Grupo Fleury.......................................95

Figura 25: Marcos de Inovação do Grupo Fleury ............................................96

Figura 26: Mapa de competências do Grupo Fleury ……................................102

Figura 27: Diferenciais competitivos do Grupo Fleury .....................................103 
Figura 28: Definição da Estratégia da Inovação 105

Figura 29: Desdobramento das tendências da saúde .................................... 106

Figura 30: Implicações das tendências mapeadas ......................................... 107

Figura 31: Estrutura Organizacional de P\&D ...............................................118 


\section{LISTA DE GRÁFICOS}

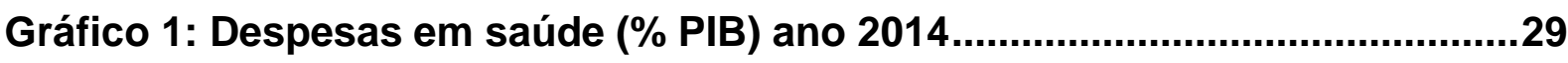

Gráfico 2: Beneficiários de Plano de Saúde Privado no Brasil (Milhões) ..........30

Gráfico 3: Beneficiários por modalidade de operadora em dezembro de 2016 (Milhões)

Gráfico 4: Variação em 12 meses do número de pessoas ocupadas e de beneficiários de planos coletivos .31

Gráfico 5: Número de novos produtos lançados ...............................................97

Gráfico 6: Número de Consultorias Médicas Realizadas (em milhares) ..........129 


\section{LISTA DE QUADROS}

Quadro 1: Entrevistados da Pesquisa ............................................................ 90

Quadro 2: Síntese dos achados da visão geral da inovação na empresa ........ 100

Quadro 3: Missão, visão e valores do Grupo Fleury ........................................ 101

Quadro 4: Síntese dos achados em Estratégia de Inovação ............................ 109

Quadro 5: Síntese dos achados em Processos de Novos Produtos ............... 134

Quadro 6: Síntese dos achados em Processos de Novos Processos ............. 136

Quadro 7: Síntese dos achados em Pessoas e Organização ............................ 144 


\section{LISTA DE TABELAS}

Tabela 1: Estabelecimentos por Região e Esfera Administrativa em outubro de 2015

Tabela 2: Estabelecimentos com Tipo de Atendimento Prestado - SADT em outubro 2015

Tabela 3: Gastos com despesa assistencial em 2015 na Saúde Suplementar ..38

Tabela 4: Atores Chave do Processo de Inovação em Saúde 62 


\section{LISTA DE ABREVIATURAS E SIGLAS}

AC - Análises Clínicas

ANS - Agência Nacional de Saúde Suplementar

ANVISA - Agência Nacional de Vigilância Sanitária

BSC - Balance Scorecard

CAP - College of American Pathologists

CD - Centro Diagnóstico

$\mathrm{Cl}$ - Central de Ideias

CNES - Cadastro nacional de estabelecimentos de saúde

EOL - End of Life

FAP - Fóruns de Aprovação de Projetos

FINEP - Financiadora de Estudos e Projetos

IBGE - Instituto Brasileiro de Geografia e Estatística

IESS - Instituto de Estudos de Saúde Suplementar

IG - Instrução Gera de Exames

INAMPS - Instituto Nacional de Assistência Médica e Previdência Social

IQPC - International Quality Productivity Center

ISO - International Organization for Standardization

ITR - Instrução de Trabalho

MS - Ministério da Saúde

OCDE - Organização para a Cooperação e Desenvolvimento Económico

OMS - Organização Mundial de Saúde

ONA - Organização Nacional de Acreditação

OPS - Operadores de Plano de Saúde

P\&D - Pesquisa e Desenvolvimento

PALC - Programa de Acreditação de Laboratórios Clínicos

PERC - Programa de Excelência em Relacionamento com a Cadeia de

Fornecedores

PIB - Produto Interno Bruto

PIF - Prêmio de Inovação do Grupo Fleury

POP - Procedimento Operacional Padrão

PROEX - Programa de Excelência Médica

PROMED - Programa de Reconhecimento Médico 
$\mathrm{RH}$ - Recursos Humanos

SADT - Serviços auxiliares de diagnóstico e terapêutica

SBPC/ML - Sociedade Brasileira de Patologia Clínica/Medicina Laboratorial

SOCESP - Sociedade de Cardiologia do Estado de São Paulo

SUS - Sistema Único de Saúde

TI - Tecnologia da Informação

TUSS - Terminologia Unificada da Saúde Suplementar

USP - Universidade de São Paulo 



\section{SUMÁRIO}

1 INTRODUÇÃO

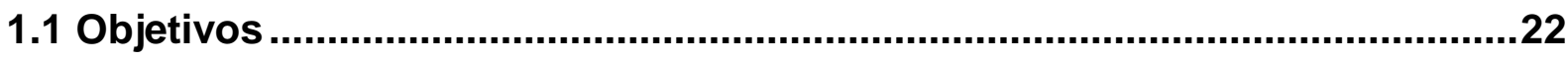

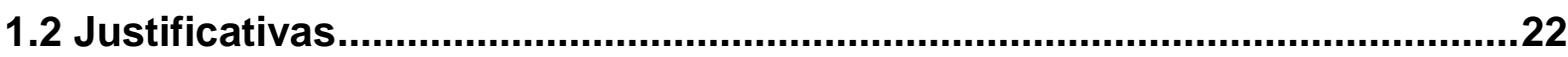

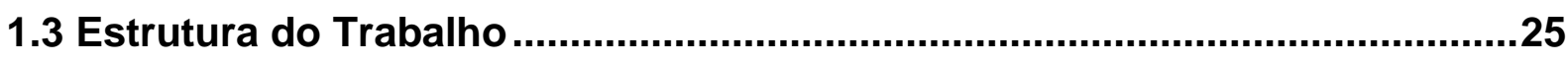

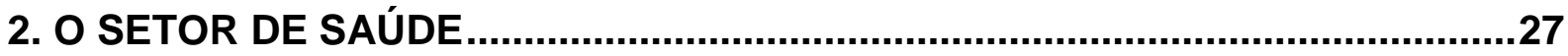

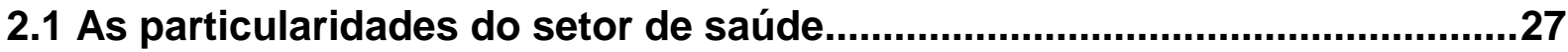

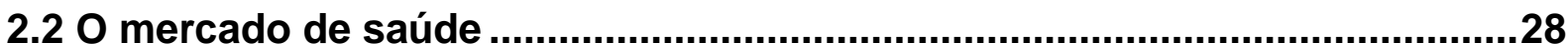

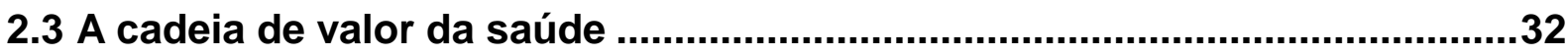

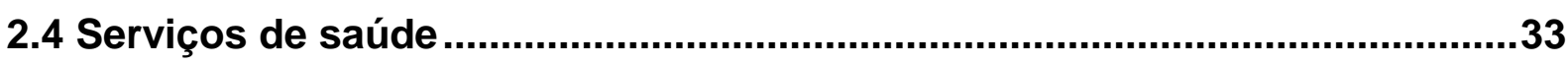

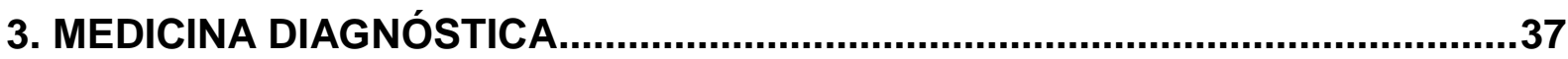

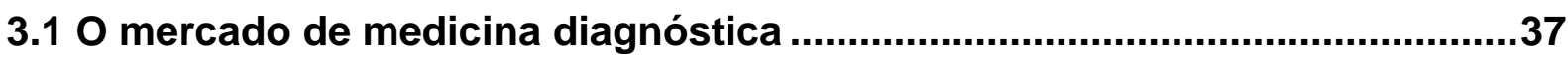

3.2 A cadeia de valor de medicina diagnóstica .....................................................39

3.3 Produtos e serviços em medicina diagnóstica...............................................40

3.4 A experiência dos clientes de medicina diagnóstica .......................................43

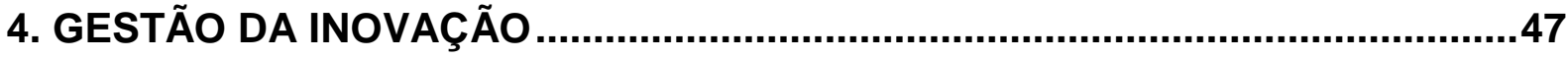

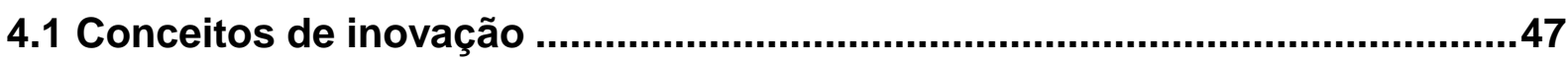

4.2 Gestão de operações de serviços ...............................................................

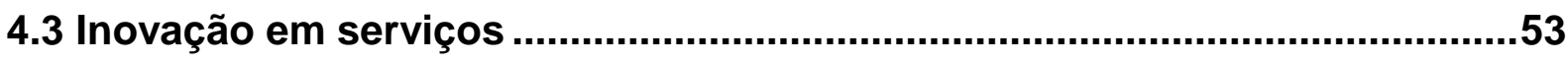

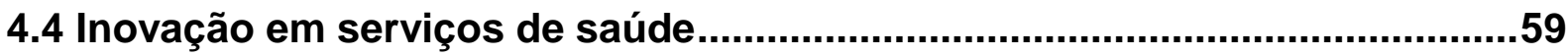

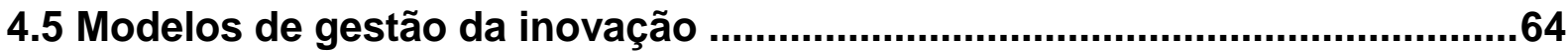

4.6 Considerações sobre o material pesquisado .................................................76

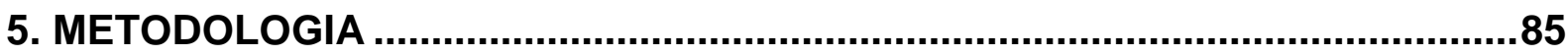

6 APRESENTAÇÃO E DISCUSSÃO DOS RESULTADOS …................................

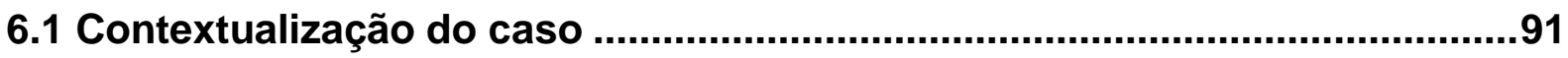

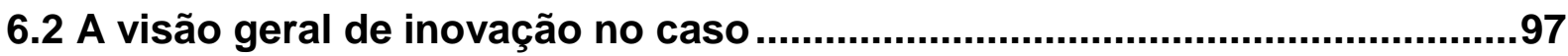

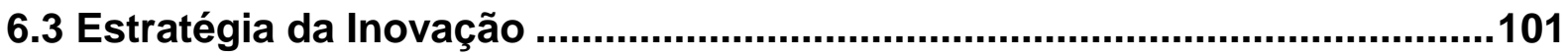

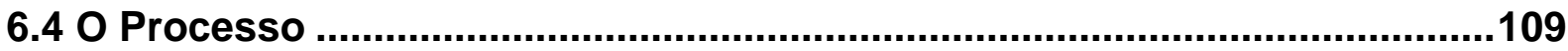

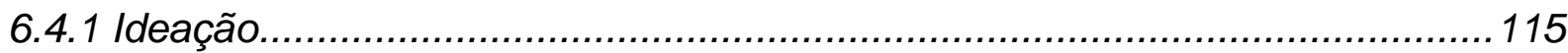

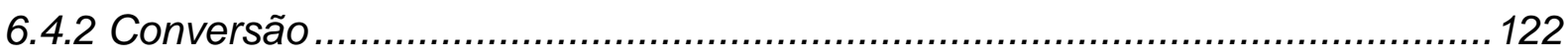

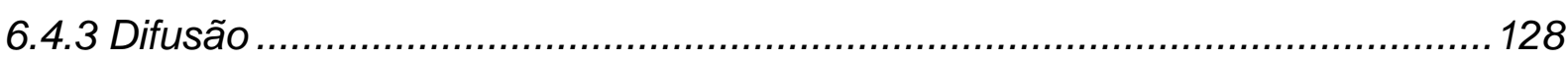

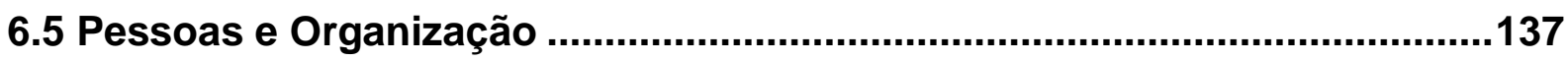

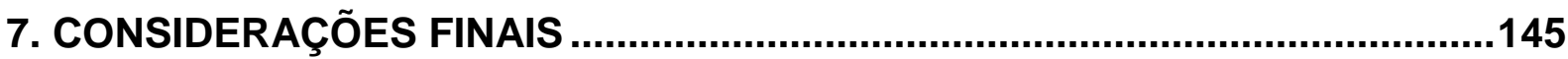


REFERÊNCIAS BIBLIOGRÁFICAS 


\section{INTRODUÇÃO}

Em ambiente cada vez mais competitivo, inovar acabou se tornando um imperativo para aquelas empresas que desejam sobreviver no mercado. Corporações que não inovam acabam sucumbindo frente aos seus concorrentes, por conta das mudanças do próprio mercado, eventualmente desaparecendo dele. Desse modo, inúmeras empresas veem a inovação como o elemento vital de sua sobrevivência e garantia de seu futuro no mercado. (DAVILA, EPSTEIN, SHELTON, 2007).

Neste sentido, Baregheh, Rowley e Sambrook (2009) consideram a inovação como um processo de várias etapas através das quais as organizações transformam ideias em produtos novos/melhorados, serviços ou processos, a fim de avançar, competir e se diferenciar com sucesso em seu mercado.

Davila, Epstein e Shelton (2007) também entendem a inovação como um processo que deve ser gerido. Tidd e Bessant (2015) apontam que quando este processo é gerido, é possível influenciar o resultado final, garantindo a sobrevivência já comentada.

Esta visão de gerenciar o processo de inovação pode alavancar os resultados da empresa, sendo fundamental compreender cada parte que o compõe. Neste sentido, muitos modelos de gestão da inovação foram propostos, mas ainda há pouca informação sobre o a gestão de inovação focados no setor de saúde (OMACHONU; EINSPRUCH, 2010; VARKEY; HORNE; BENNET, 2008). O setor de saúde possui importante relevância econômica para o Brasil, representando $10,1 \%$ do produto interno bruto, ou $R \$ 557$ bilhões no ano de 2014 (IESS, 2016). Dentro do setor de saúde os serviços de medicina diagnóstica representam $21 \%$ do total de despesas assistenciais, representando o segundo maior gasto em saúde (ANS, 2015).

Neste sentido chegamos a seguinte questão de pesquisa: Como ocorre a gestão da inovação em uma empresa de medicina diagnóstica? 


\subsection{Objetivos}

Partimos então da questão de pesquisa: Como ocorre a gestão da inovação em uma empresa de medicina diagnóstica? Apresentada a questão de pesquisa, o objetivo deste trabalho é aprofundar a compreensão sobre a gestão da inovação em uma empresa de medicina diagnóstica, buscando avançar no conhecimento de cada etapa do processo de gestão da inovação. Neste sentido, partindo de uma abordagem processual, tomando como base as etapas do processo de gestão da inovação encontrados na literatura, o estudo visa três objetivos específicos:

- Entender o processo de ideação, conversão e difusão da inovação em Medicina Diagnóstica

- Entender como a estratégia de inovação se insere no processo de gestão da inovação

- Entender como pessoas e organização se inserem no processo de gestão da inovação

\subsection{Justificativas}

Joseph Schumpeter (1984) propôs a inovação como sendo o diferencial competitivo entre empresas e o motor do crescimento econômico. Desde então cresceu a necessidade de estudar como as empresas organizam suas práticas de inovação com o objetivo de alavancarem a sua competitividade.

Davila, Epstein e Shelton (2007) destacam que a longo prazo, o único fator realmente capaz de garantir o futuro de qualquer empresa é sua capacidade de inovar melhor e de forma mais contínua por mais tempo que as concorrentes.

Em um cenário econômico cada vez mais desafiador, as empresas têm buscado formas de se diferenciar competitivamente com o objetivo de manter seu mercado atual e buscar a abertura de novos mercados (SCHUMPETER, 1984; DRUCKER, 2003; OCDE, 2004; PROENÇA et al, 2015; TIDD; BESSANT, 2015). Portanto, estudar a inovação é importante para compreender a manutenção da posição competitiva das empresas ou ampliação das fronteiras competitivas, seja no mercado que atua, ou pela abertura de novos mercados. 
Dentro deste contexto de inovação, a gestão da inovação é uma atividade muito importante, e entender suas partes e influenciar o resultado final é essencial. (PANTLEÃO;ANTUNES JÚNIOR; PELLEGRIN, 2007; TIDD; BESSANT, 2015; BAREGHEH; ROWLEY; SAMBROOK, 2009; HANSEN; BIRKINSHAW, 2007; GOFFIN; MITCHELL, 2005). Portanto é fundamental estudar a gestão da inovação.

Neste cenário econômico desafiador, a atividade de serviços veio crescendo ao longo dos anos no Brasil e hoje já representa 73,3\% do PIB Brasileiro (IBGE, 2016). Apesar da importância no cenário econômico tanto nacional quanto mundial, estudos de gestão da inovação em serviços ainda são pouco abordados (GALLOUJ; WINDRUM, 2009; GALLOUJ; SAVONA, 2009). Um dos setores de serviços é o serviço de saúde, considerado complexo e que ainda demanda estudos (CHRISTENSEN; GROSSMAN; HWANG, 2009; PORTER; TEISBERG, 2007).

Muito tem sido escrito sobre modelos e processos de inovação. Mas ainda há pouca informação sobre a gestão de inovação focados no setor de saúde (OMACHONU; EINSPRUCH, 2010; VARKEY; HORNE; BENNET, 2008).

Ao olharmos o lado de custos, o setor de saúde brasileiro vem sendo pressionado. A despesa no sistema de saúde brasileiro em 2014 atingiu o valor de $10,1 \%$ do produto interno bruto, ou $\mathrm{R} \$ 557$ bilhões (IESS, 2016). Em dezembro de 2016, cerca de $25,4 \%$ da população ( 47,8 milhões de beneficiários) tinham acesso ao Sistema de Saúde Suplementar, e corresponderam a $50 \%$ dos gastos totais com a saúde no Brasil (ANS, 2017). Christensen, Grossman e Hwang (2009) reforçam que a inovação, pode reduzir custos e melhorar a qualidade e acessibilidade à saúde. Porter e Teisberg (2004) entendem que o que deve ser feito é buscar estrategicamente inovações que aumentem o valor para o paciente (resultado obtido por capital investido) ao longo da cadeia de prestação de serviços, olhando de maneira holística. Estas inovações devem ser altamente recompensadas e há imensas oportunidades de obtê-las avançando nos campos de conhecimento de estratégias, estruturas organizacionais, instalações, processos e parcerias (PORTER; TEISBERG, 2007).

Dentro do setor de saúde temos os serviços de medicina diagnóstica. Segundo dados do IBGE (2010), os estabelecimentos exclusivos de SADT, ou ditos de medicina diagnóstica, representam $20,5 \%$ do total de estabelecimentos de saúde do país sendo que $90,8 \%$ destes são estabelecimentos particulares. Mesmo na esfera pública, a relevância dos estabelecimentos particulares fica ainda mais evidente dado que quase $40 \%$ dos estabelecimentos que atendem o SUS são privados. Auriemo e Rosenfeld 
(2006) apontam que a evolução tecnológica e as necessidades de operação a custos reduzidos vêm transformando os modelos organizacionais da medicina diagnóstica.

Os gastos com exames complementares totalizaram mais de 25 bilhões de reais e representam $21 \%$ do total de despesa assistencial. É o segundo maior gasto em Saúde Suplementar (ANS, 2015).

Campana, Oplustil e Gonzalez (2011) apontam que o envelhecimento da população brasileira levará a um maior consumo pelos serviços de medicina diagnóstica. De fato, há maior prevalência de doenças crônicas em idades mais elevadas, elevando a necessidade por exames nesta população. A maior utilização dos serviços de saúde pela população idosa projeta um aumento nos gastos das operadoras de saúde e consequentemente, maior pressão por redução de custos sob os prestadores de serviços.

Estudar o setor de Medicina Diagnóstica, justifica-se além da importância social e econômica atribuída ao setor. Forsman, (1996), Auriemo e Rosenfeld (2006), e Campana, Oplustil e Gonzalez (2011) relatam que mais de 70\% das decisões médicas estão apoiadas em informações provenientes da medicina diagnóstica. Porter e Teisberg (2007), reforçam que um diagnóstico preciso têm um importante impacto na geração de valor da cadeia de serviços de saúde.

Quando se estuda a gestão da inovação em serviços de saúde, há estudos focados em hospitais (DJELLAL; GALLOUJ, 2005; VARGAS, 2006; DJELLAL; GALLOUJ, 2007), mas há escassez de estudos focados em Medicina Diagnóstica.

De fato, ao realizar a busca no Science Direct em português pelas palavras "gestão da inovação" e "medicina diagnóstica" ou "Medicina laboratorial" ou "SADT" o resultado é 0 . Ao buscar em inglês pelas palavras "innovation management" e "diagnostic medicine" ou "laboratory medicine" o resultado também é de 0 artigos encontrados. Idem para a plataforma Scopus. Ao realizar a busca em português pelas palavras "gestão da inovação" e "medicina diagnóstica" ou "Medicina laboratorial" ou "SADT" o resultado é 0.

Como premissa também adotada nos estudos de Pedroso (2010), o presente trabalho considera que o conhecimento científico na saúde vem se desenvolvendo a uma velocidade superior ao desenvolvimento dos modelos de gestão na saúde. Isso gera uma lacuna entre os conhecimentos conforme Figura 1. 
Figura 1: Lacuna de conhecimento na saúde

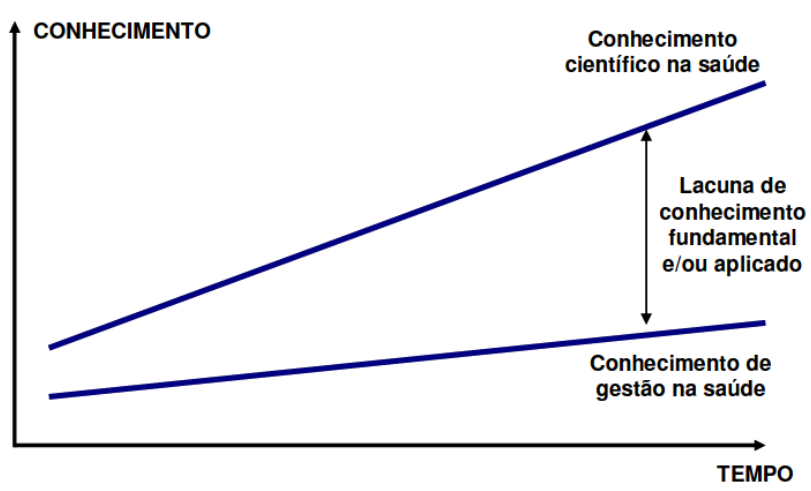

Fonte: Pedroso (2010)

É com o objetivo também de reduzir esta lacuna que se propõe este estudo. Por fim, o tema também é de interesse pessoal do pesquisador, dado que o mesmo faz parte do quadro de colaboradores de uma empresa de medicina diagnóstica reconhecida pelas práticas de gestão da inovação e por ter desempenhado funções administrativas nas áreas de gestão da inovação e desenvolvimento de novos produtos.

Portanto, dadas as justificativas acima, o estudo tem por objetivo colaborar para o entendimento do tema de gestão da inovação em medicina diagnóstica.

\subsection{Estrutura do Trabalho}

O trabalho é desenvolvido em quatro partes: Introdução, revisão da literatura, pesquisa de campo e conclusões. A parte I (introdução) consiste em um capítulo que trata dos objetivos, justificativas e estrutura do trabalho. A parte II (revisão da literatura) contempla três capítulos: o primeiro discorre sobre o setor de saúde, o segundo sobre medicina diagnóstica e o terceiro sobre gestão da inovação. A parte III (pesquisa de campo) discorre sobre a metodologia de pesquisa e a apresentação e discussão dos resultados do caso estudado. A parte IV finaliza com as considerações finais da pesquisa. A Figura 2 abaixo mostra a estrutura e a relação entre as partes do trabalho. 
Figura 2: Estrutura do Trabalho

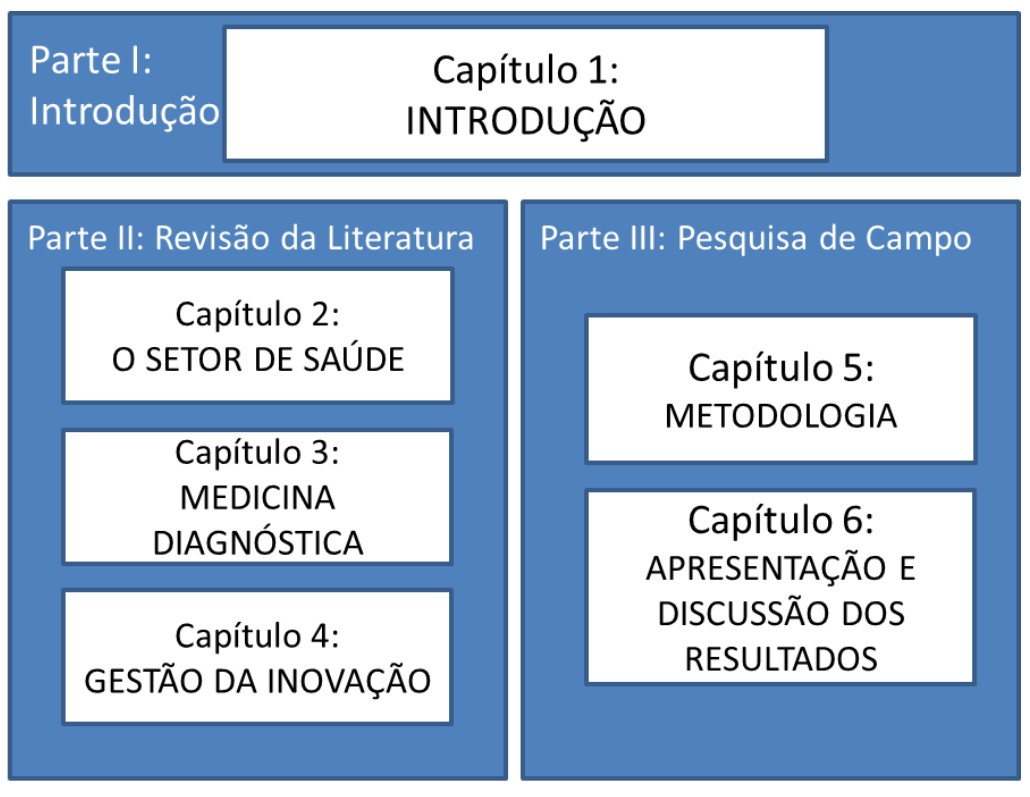

\footnotetext{
Parte IV:

Conclusões

Capítulo 7: CONSIDERAÇÕES FINAIS
} 


\section{O SETOR DE SAÚDE}

\subsection{As particularidades do setor de saúde}

A saúde é um setor com elevada complexidade de gestão e demanda estudos (CHRISTENSEN; GROSSMAN; HWANG, 2009; PORTER; TEISBERG, 2004; WINDRUM, GARCÍA-GOÑI, 2008). Essa complexidade se dá por uma série de particularidades. Dessa forma, é essencial conhecer as particularidades do setor de saúde, que são apresentadas por Pedroso e Malik (2011):

1) Escopo da saúde: Possui grande amplitude pois engloba distintos graus de saúde, desde a abordagem positiva de que saúde é o bem estar físico, mental e social, até a abordagem patológica da presença ou não de doença e sua severidade no indivíduo.

2) Consumo de saúde: Diferente de outros setores, o consumidor de saúde não deseja o produto ou serviço de saúde propriamente dito, mas sim a preservação ou melhoria da própria saúde. Desse modo, o consumo de saúde é tratado como investimento pois contribui para que o indivíduo tenha mais dias saudáveis de vida, gerando maior produtividade e consequentemente maior riqueza. Por outro lado, a falta de saúde ocasionada por doença grave ou acidentes por exemplo, pode levar o indivíduo à incapacidade de gerar riqueza, levando-o à ruína financeira quando não amparado pelo Estado ou um plano de saúde.

3) Impacto na vida: os produtos e serviços de saúde têm importante impacto na qualidade de vida, na morbidade e na mortalidade dos indivíduos. Além do risco associado ao uso destes produtos e serviços, há decisões que envolvem aspectos éticos, religiosos e culturais como aquelas relacionadas à vida (clonagem e fertilização) e à morte (aborto e eutanásia).

4) Relevância social: a saúde é um recurso essencial ao indivíduo. Alguns pesquisadores de economia da saúde consideram um bem social e dever do Estado provê-la à população. Já outros entendem como uma atividade econômica que deveria ser submetida às leis de mercado. Por vezes há aspectos ideológicos envolvidos nas discussões sobre gestão da saúde.

5) Relevância econômica: A saúde é um dos principais mercados nas economias dos países. Desse modo, as ineficiências têm grande impacto no sistema 
financeiro. A OMS estima que os desperdícios no setor de saúde correspondam algo entre $20 \%$ e $40 \%$ de todos os gastos com saúde.

6) Setor intensivo em conhecimento: Quando comparada com outros setores da economia, a saúde é uma área intensiva em conhecimento. Sendo um dos setores que mais investem em pesquisa e desenvolvimento, a saúde está em constante evolução de técnicas e novas descobertas. Cerca de 30 mil citações são inseridas todo mês no Medline, banco de dados on-line sobre periódicos médicos. No entanto, há lacunas de conhecimento além da não uniformidade da disponibilização deste conhecimento, o que gera assimetria de informação. Esta assimetria vem sendo reduzida por meio da imprensa leiga e da internet, o que gera uma nova relação médico paciente que outrora era bem hierárquica na detenção do conhecimento.

7) Cadeia de valor fragmentada: A cadeia de valor na saúde é bastante fragmentada, por vezes com decisões locais. Isto pode gerar a competição por soma zero, em que os atores lutam pela divisão do valor gerado e não por aumentar o valor na cadeia.

Apontada as particularidades do setor de saúde, podemos nos aprofundar sobre o tema, fornecendo uma visão geral sobre o setor no que tange o mercado e a cadeia de saúde.

\subsection{0 mercado de saúde}

O artigo 196 da constituição brasileira (BRASIL, 1988) afirma que "a saúde é direito de todos e dever do estado, garantido mediante políticas sociais e econômicas que visem a redução do risco de doença e de outros agravos e ao acesso universal e igualitário às ações e serviços para sua promoção, proteção e recuperação".

Esta condição de acesso universal gera uma despesa no sistema de saúde brasileiro que em 2014 atingiu o valor de $10,1 \%$ do produto interno bruto, ou $\mathrm{R} \$ 557$ bilhões (IESS, 2016). Conforme mostra a Gráfico 1, o gasto percentual em saúde no Brasil é comparado a países como França e Alemanha, e acima da média dos países da América do Sul. 
Gráfico 1: Despesas em saúde (\% PIB) ano 2014

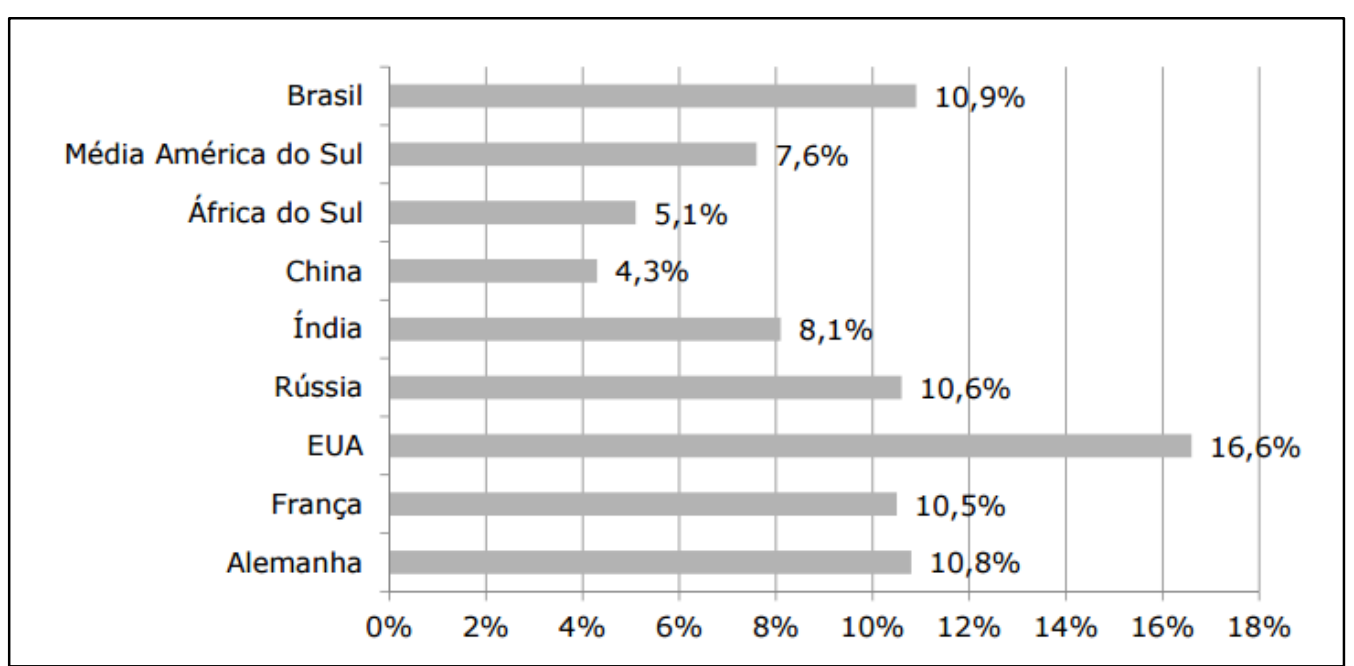

Fonte: Relatório IESS - A cadeia de saúde suplementar no Brasil, Avaliação de Falhas de Mercado e Propostas de Políticas, 2016

Sendo o acesso à saúde um dever do estado, a esfera pública está presente de forma determinante no sistema de saúde brasileiro. Neste contexto, o Sistema Único de Saúde (SUS) foi criado de maneira gradual a partir da Constituição Federal de 1988 para garantir este acesso. Primeiramente foi criado o Sistema Unificado Descentralizado de Saúde, em seguida, a incorporação do INAMPS - Instituto Nacional de Assistência Médica e Previdência Social - ao Ministério da Saúde (Decreto n 99.060, de 7 de março de 1990); e pôr fim a Lei Orgânica da Saúde (Lei no 8.080, de 19 de setembro de 1990) fundou o SUS. A Constituição previu, ainda, três fundamentos do sistema: a universalização do acesso às ações e aos serviços de atenção à saúde, a integralidade da cobertura dos serviços e a equidade na distribuição dos recursos públicos.

Sendo assim, o SUS busca cumprir o seu propósito por meio de recursos financiado pela União, Estados, Distrito Federal e Municípios, oferecendo atendimento de saúde à população.

No entanto, o estado desde 1988 não conseguiu cumprir integralmente o que previa a constituição no seu papel de prestação de serviço à população. Desse modo, o mercado passou a fornecer planos de saúde privados. O crescimento desses planos foi tamanho que foram necessárias medidas regulatórias visando defender os direitos dos consumidores desses serviços.

Desse modo foi criada a Agencia Nacional de Saúde Suplementar (ANS), o órgão regulador do Governo Federal que atua na normatização e fiscalização dos planos de saúde privados. O termo suplementar quer dizer que além do serviço 
público de saúde, o cidadão pode contratar serviços particulares de modo adicional, ou suplementar.

Atualmente, o Sistema de Saúde Suplementar é constituído primordialmente pelas Operadoras de Plano de Saúde (OPS). Segundo dados da ANS TABNET (2017), em dezembro de 2016 cerca de $25,4 \%$ da população brasileira tinha acesso à saúde suplementar, ou seja 47,8 milhões de beneficiários. Apesar de cobrir $25,4 \%$ da população, $50 \%$ dos gastos com saúde no Brasil eram provenientes do Sistema de Saúde Suplementar.

Conforme dados do Gráfico 2 a evolução do número de beneficiários de planos de saúde privados tem crescido ao longo dos anos, tendo leve queda nos dois últimos períodos.

Gráfico 2: Beneficiários de Plano de Saúde Privado no Brasil (Milhões)

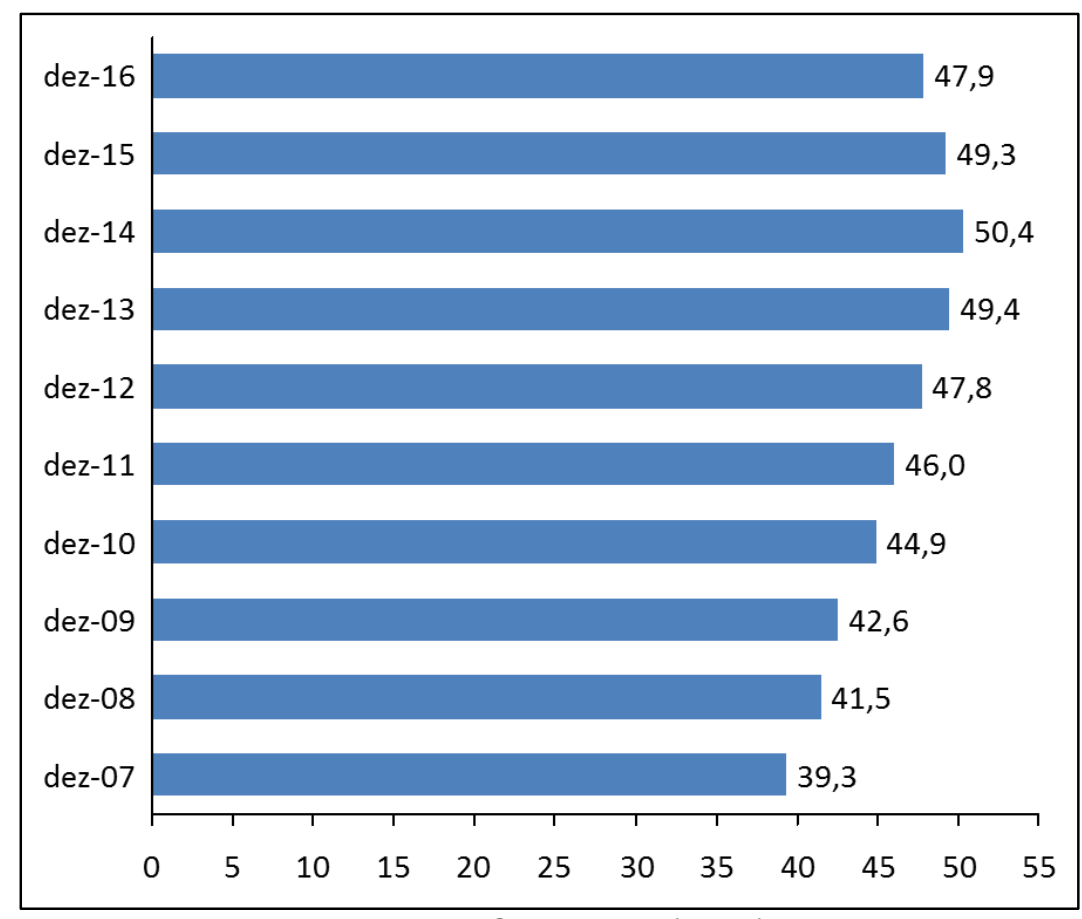

Fonte: ANS TABNET (2017)

Tal queda no número de beneficiários está relacionada ao aumento do desemprego, proveniente da crise política e econômica que o Brasil enfrenta desde 2015. Conforme podemos ver no Gráfico 3, cerca de 31,8 milhões de beneficiários (ou $66 \%$ do total) dos planos de saúde é do tipo coletivo empresarial, ou seja, um benefício que a empresa proporciona ao empregado. 
Gráfico 3: Beneficiários por modalidade de operadora em dezembro de 2016 (Milhões)

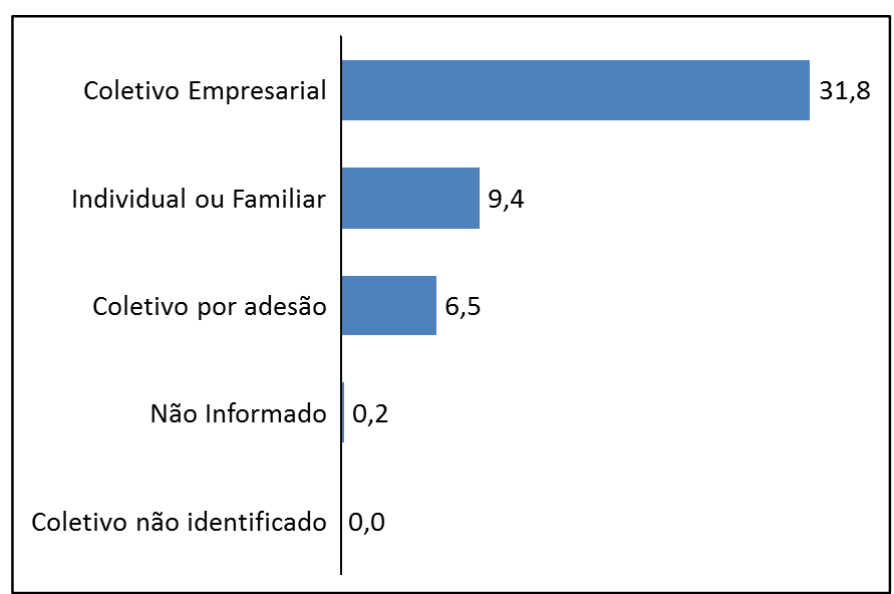

Fonte: ANS TABNET (2017)

Esta relação de empregos formais e número de beneficiários já é conhecida na literatura (ANDRADE; MAIA, 2006; MARTINS; AMORIM; LAS CASAS, 2012; IESS, 2016; CAMPANA; OPLUSTIL, GONZALEZ, 2011; MARTINS, 2014). E conforme podemos observar no Gráfico 4, o número de pessoas ocupadas (empregadas) e o número de beneficiários possuem uma relação direta. Nos últimos anos, podemos observar uma variação negativa nos dois indicadores.

Gráfico 4: Variação em 12 meses do número de pessoas ocupadas e de beneficiários de planos coletivos

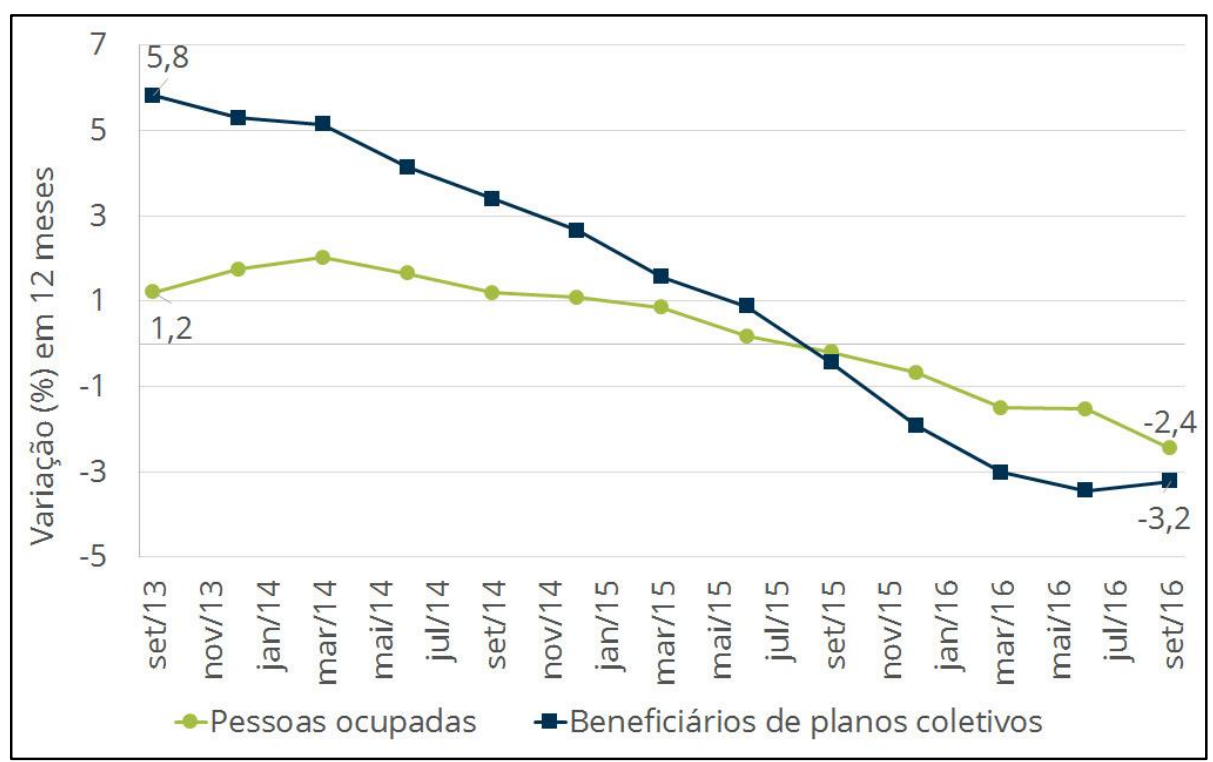

Fonte: Relatório IESS - Conjuntura da Saúde Suplementar, 2016

Ao olharmos o perfil do usuário pela demanda por serviços na Saúde Suplementar, observamos que as mulheres tendem a ter gasto médio superior aos 
homens, e famílias que possuem crianças, idosos e mulheres em idade reprodutiva possuem maior propensão a ter plano de saúde (ANDRADE; MAIA, 2006).

\subsection{A cadeia de valor da saúde}

Dada a visão sobre o mercado de saúde no Brasil, seja na esfera público ou privada, pode-se avançar na compreensão do setor considerando o sistema de saúde como uma cadeia de valor. Diversos autores apresentam trabalhos sobre a cadeia de valor da saúde (BURNS et al, 2002; PORTER; TEISBERG, 2007; PISANO, 2006; CHRISTENSEN; GROSSMAN; HWANG, 2009; GADELHA, 2003; CAMPOS et al, 2009). Uma abordagem mais recente é a de Pedroso e Malik (2012), que apresentam a cadeia de valor da saúde formado por nove elos, cada um deles contemplando um conjunto específico de atividades, conforme apresentado na Figura 3.

Figura 3: A cadeia de Valor da Saúde

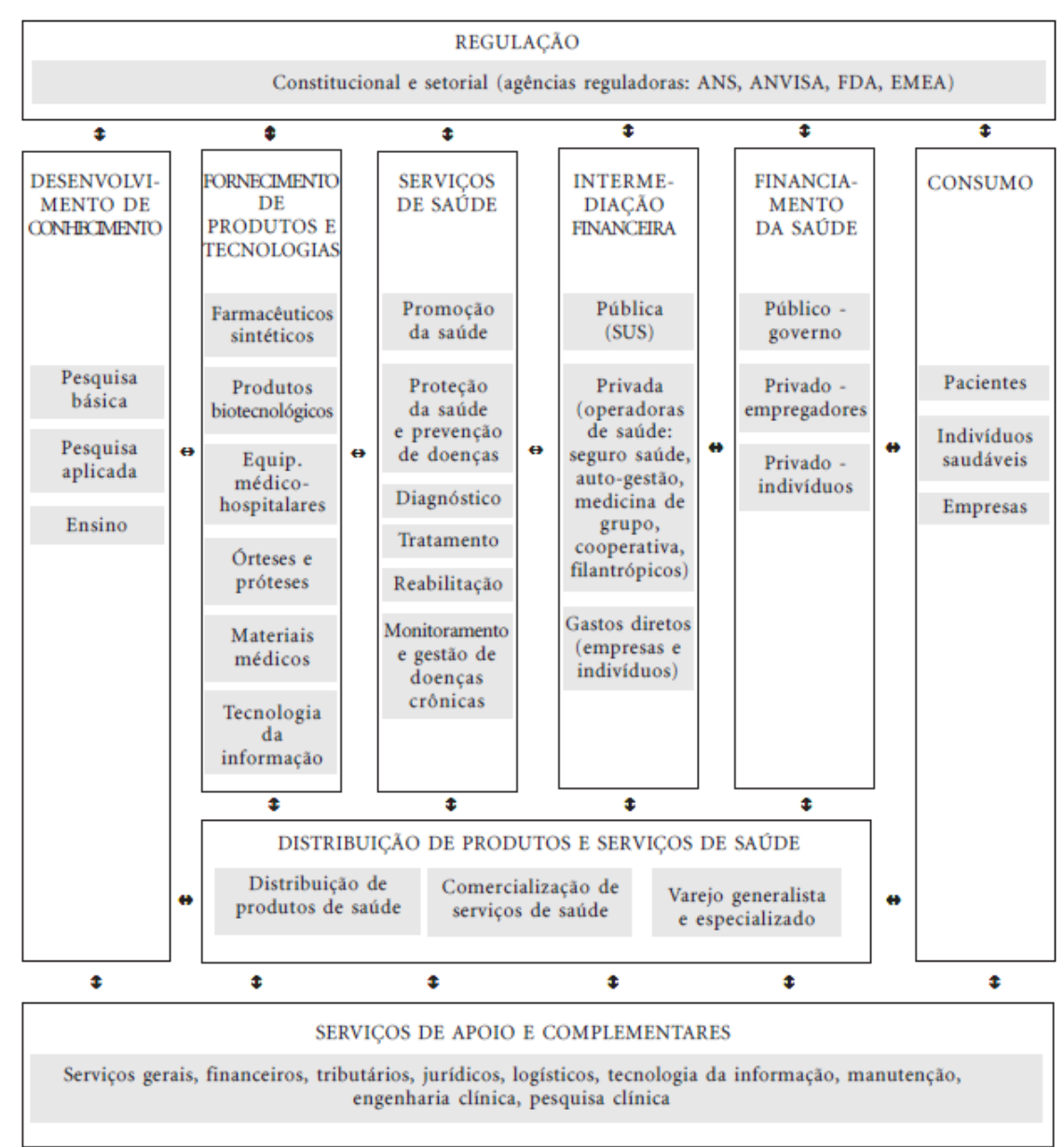

Fonte: Pedroso; Malik (2012) 
O primeiro elo vertical é onde ocorre o desenvolvimento do conhecimento na saúde por meio de atividades de ensino, pesquisa básica e aplicada. A missão deste elo é gerar e disseminar o conhecimento básico e aplicado em saúde. O segundo elo busca transformar esse conhecimento em produtos (ex: remédios, materiais médicos) e tecnologias (ex: equipamentos médicos, tecnologia da informação). O terceiro elo vertical é onde ocorre os serviços de saúde. Nele os recursos oferecidos pelos elos anteriores são consumidos com o objetivo de prestar o serviço de saúde aos consumidores finais. Neste elo estão as atividades de promoção de saúde e prevenção de doenças, diagnóstico, tratamento, reabilitação, monitoramento e gestão de doenças crônicas. O quarto elo vertical é onde ocorrem as intermediações financeiras, cuja missão é repassar todo financiamento da saúde aos elos anteriores, diluindo riscos e provendo o acesso universal. Aí estão representados os sistemas público (SUS) e o sistema privado (Saúde Suplementar), bem como os gastos de empresas e indivíduos ocorridos sem intermediação. O sistema privado incorpora todas as operadoras de saúde em diferentes modalidades como seguro saúde, autogestão, medicina de grupo e cooperativas médicas. O quarto elo interliga o terceiro elo com o quinto elo vertical, de onde provêm os recursos financeiros. O quinto elo tem por missão financiar o sistema de saúde, que pode ser público ou privado. A origem dos recursos financeiros pode ser pública, por meio do governo que arrecada impostos, ou privada, pago pelas empresas ou pelos próprios indivíduos. Por fim temos os consumidores, que podem ser pacientes, indivíduos saudáveis e empresas, e que tem por missão manter e melhorar a saúde e bem estar.

Neste modelo de Pedroso e Malik (2012) há também os elos horizontais. O primeiro elo horizontal, é representado pelas agências reguladoras como ANS e ANVISA, por exemplo, que têm por missão regular todo o sistema de saúde. O segundo elo representa a distribuição de produtos e serviços de saúde, e se relacionam às atividades de vendas e distribuição no varejo. Por último temos o elo de serviços de apoio e complementares como serviços financeiros, tributários, jurídicos, de manutenção e etc.

\subsection{Serviços de saúde}

Porter e Teisberg (2007) apresentam a cadeia de valor da prestação de serviços de saúde em uma unidade de prática integrada, conforme a figura 4. Esta 
proposta fornece uma estrutura para descrever os atuais processos de prestação de serviços de saúde e analisar como o processo de saúde pode ser melhorado. As atividades da prestação de serviço estão organizadas em torno da condição de saúde do paciente, e estão vinculadas, ou seja, o resultado de uma atividade pode afetar o resultado das outras atividades. Como exemplo, o resultado de uma fisioterapia realizada como atividade de reabilitação é diretamente impactado pelo resultado de uma cirurgia ocorrida na etapa anterior de intervenção.

Figura 4: A cadeia de valor da prestação de serviços de saúde em uma unidade de prática integrada

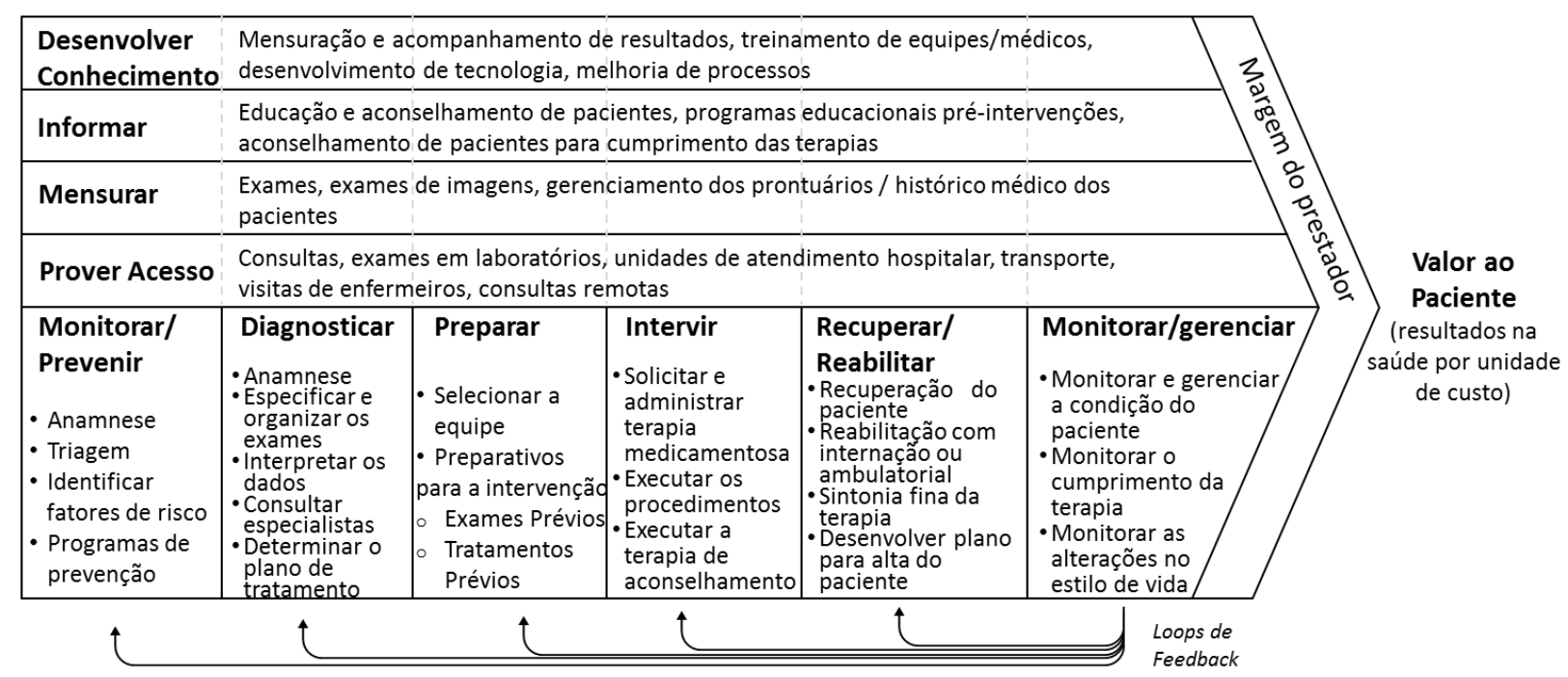

Fonte: Porter; Teisberg (2007)

A cadeia de valor de prestação de serviços de saúde se inicia com o monitoramento e prevenção. As atividades deste elo envolvem rastrear, avaliar os riscos e tomar os passos para prevenir ou reduzir a gravidade de uma doença ou lesão. Essas atividades podem ter grande valor, dado que é possível detectar precocemente alguma doença, sem a necessidade de um tratamento na etapa de intervenção. Esta etapa normalmente não é tão valorizada. Os médicos normalmente são remunerados por tratar doenças, e não por manter previamente os pacientes saudáveis.

Em seguida temos a etapa de Diagnosticar, que envolve um conjunto de atividades que incluem testes, exames, avaliações com especialistas, e um plano de intervenção ou tratamento. Um diagnóstico preciso têm um importante impacto na geração de valor da cadeia de serviços de saúde. 
Preparar é a terceira categoria de atividades, que envolve uma preparação cuidadosa antes da intervenção. Ela envolve a seleção da equipe que fará a intervenção, além de exames e tratamentos prévios.

Intervir é a quarta categoria de atividades, que visa reverter ou reduzir a condição de saúde do paciente. Ela envolve atividades como terapias e tratamentos medicamentosos, cirurgias, quimioterapias, entre outros. Pode haver vários tipos de intervenções para tratar uma condição de saúde.

Recuperar/reabilitar é a quinta categoria de atividades que por vezes não recebe atenção. Quando o paciente recebe alta e sai de uma unidade hospitalar por exemplo, a responsabilidade por sua recuperação não fica clara e muito menos é gerenciada de perto.

Gerenciar/monitorar é a última categoria de atividades e envolve o acompanhamento do paciente, sua condição de saúde, cumprimento da terapia e mudanças em seu estilo de vida. Caso haja uma alteração identificada, os loops de feedbacks o farão retornar às etapas anteriores. O monitoramento e gestão de doenças crônicas é um exemplo de atividades desta etapa. Com um bom monitoramento, é possível evitar que a condição de saúde do paciente piore.

Além dos grupos de atividades já descritas, há também as atividades cross em toda a cadeia. A primeira delas é prover acesso a cada uma das atividades. Ter acesso por exemplo a consultas médicas e programas de prevenção, exames em laboratórios de diagnóstico, tratamentos em hospitais, visita de fisioterapeutas e enfermeiros na habilitação, monitoramento a distância.

Mensuração envolve um conjunto de atividades transversais, necessárias para a avaliação das circunstâncias de saúde de um paciente. São as medidas das condições do paciente, coletadas ao longo de toda cadeia. Pode ser os resultados encontrados nos exames e testes, por exemplo.

Informar é notificar, educar e orientar o paciente. Todas as atividades, desde a explicação do diagnóstico até o aconselhamento sobre melhores práticas de saúde, dietas e tratamentos, são envolvidas nesta etapa. Um paciente bem informado pode ter importante influência nos resultados ao longo de toda cadeia.

Por fim, é necessário desenvolver o conhecimento em todos os elos da cadeia, por meio de treinamentos de equipes e médicos, novas tecnologias e melhorias nos processos. 


\section{MEDICINA DIAGNÓSTICA}

\subsection{0 mercado de medicina diagnóstica}

Dada a visão geral do setor de saúde, podemos nos aprofundar no elo de serviços de saúde, onde a medicina diagnóstica se encontra.

De modo semelhante, é importante ter a visão geral sobre o setor de Medicina Diagnóstica no Brasil, em especial sua gestão (pública ou privada) e concentração nas regiões do país.

Tais informações são disponibilizadas no Cadastro Nacional de Estabelecimentos de Saúde (CNES). Conforme mostra a Tabela 1, em outubro de 2015, o banco de dados do CNES registrava 284.651 estabelecimentos de saúde, sendo que $72 \%$ desse total correspondiam a instituições privadas. Pode-se observar a grande concentração na região Sudeste, com $46 \%$ do total de estabelecimentos.

Tabela 1: Estabelecimentos por Região e Esfera Administrativa em outubro de 2015

\begin{tabular}{|l|l|l|l|l|}
\hline Região & Público & Privada & Total & \% Por Região \\
\hline 1 Região Norte & 7097 & 7124 & $\mathbf{1 4 2 2 1}$ & $\mathbf{5 \%}$ \\
\hline 2 Região Nordeste & 28381 & 29556 & $\mathbf{5 7 9 3 7}$ & $\mathbf{2 0 \%}$ \\
\hline 3 Região Sudeste & 24789 & 105532 & $\mathbf{1 3 0 3 2 1}$ & $\mathbf{4 6 \%}$ \\
\hline 4 Região Sul & 11814 & 46835 & $\mathbf{5 8 6 4 9}$ & $\mathbf{2 1 \%}$ \\
\hline 5 Região Centro-Oeste & 6116 & 17407 & $\mathbf{2 3 5 2 3}$ & $\mathbf{8 \%}$ \\
\hline Total & 78197 & 206454 & $\mathbf{2 8 4 6 5 1}$ & $\mathbf{1 0 0 \%}$ \\
\hline
\end{tabular}

Fonte: CNES, 2017

O IBGE realizou no ano de 2009 a pesquisa AMS (Assistência MédicoSanitária), que tem por objetivo descrever o perfil da capacidade instalada em saúde no Brasil. Nesta pesquisa, foram considerados 19.294 estabelecimentos exclusivos de SADT, que representava $20,5 \%$ do total de estabelecimentos de saúde do país naquele período. Já em relação ao acesso, ficou evidente a forte concentração de particulares, que representavam $90,8 \%$ do total de estabelecimentos exclusivos de SADT. A alta concentração pode ser explicada pelo fato de que é mais raro ter estabelecimentos exclusivos de SADT no setor público. Normalmente o serviço está incluído em outros estabelecimentos centralizados de maior complexidade, como hospitais. De todo modo, a relevância dos estabelecimentos particulares fica evidente 
até mesmo na esfera pública. Conforme observamos na Tabela 2, quase $40 \%$ dos estabelecimentos que atendem o SUS são privados.

Tabela 2: Estabelecimentos com Tipo de Atendimento Prestado - SADT em outubro 2015

\begin{tabular}{|l|r|r|r|r|}
\hline \multicolumn{1}{|c|}{ Esfera Administrativa } & Público & \multicolumn{1}{|c|}{ Privada } & \multicolumn{1}{c|}{ Total } & $\begin{array}{r}\text { T Tipo de Atendimento } \\
\text { Privado }\end{array}$ \\
\hline SUS & 14100 & 9253 & $\mathbf{2 3 3 5 3}$ & $\mathbf{3 9 , 6 \%}$ \\
\hline Particular & 54 & 32508 & $\mathbf{3 2 5 6 2}$ & $\mathbf{9 9 , 8 \%}$ \\
\hline Plano de Saúde Público & 54 & 2482 & $\mathbf{2 5 3 6}$ & $\mathbf{9 7 , 9 \%}$ \\
\hline Plano de Saúde Privado & 38 & 18391 & $\mathbf{1 8 4 2 9}$ & $\mathbf{9 9 , 8 \%}$ \\
\hline
\end{tabular}

Ou seja, tanto na esfera pública quanto na esfera privada, os estabelecimentos SADT privados são relevantes.

Quando avaliamos os gastos com saúde, fica evidente também a relevância dos serviços SADT. Na tabela 3 pode-se observar os gastos ocorridos no ano de 2015, referentes à despesa assistencial. Os gastos com exames complementares totalizaram mais de 25 bilhões de reais e representam $21 \%$ do total de despesa assistencial. É o segundo maior gasto em Saúde Suplementar.

Tabela 3: Gastos com despesa assistencial em 2015 na Saúde Suplementar

\begin{tabular}{|l|c|c|}
\hline Tipo & Despesa Assistencial & $\%$ \\
\hline Internações & 51.973 .049 .555 & $43 \%$ \\
\hline Exames complementares & 25.163 .748 .788 & $21 \%$ \\
\hline Consultas médicas & 19.435 .580 .682 & $16 \%$ \\
\hline Outros atendimentos ambulatoriais & 8.234 .537 .693 & $7 \%$ \\
\hline Terapias & 6.865 .482 .083 & $6 \%$ \\
\hline Demais despesas médico-hospitalares & 5.573 .465 .709 & $5 \%$ \\
\hline Procedimentos Odontológicos & 2.984 .153 .465 & $2 \%$ \\
\hline TOTAL & $\mathbf{1 2 0 . 2 3 0 . 0 1 7 . 9 7 5}$ & $\mathbf{1 0 0 \%}$ \\
\hline
\end{tabular}

Fonte: ANS, 2015

Olhando para o futuro, os números devem crescer. Campana, Oplustil e Gonzalez (2011) apontam que o envelhecimento da população brasileira levará a um 
maior consumo pelos serviços de medicina diagnóstica. De fato, há maior prevalência de doenças crônicas em idades mais elevadas, aumentando a necessidade por exames nesta população. A maior utilização dos serviços de saúde pela população idosa projeta um aumento nos gastos das operadoras de saúde e consequentemente, maior pressão por redução de custos sob os prestadores de serviços.

Portanto, o setor de Medicina Diagnóstica no Brasil possui relevante abrangência, e em especial os estabelecimentos particulares concentram boa parte dos atendimentos, tanto na esfera pública como na privada, sendo esta última onde ocorre a segunda maior despesa em saúde, com tendência ao crescimento.

\subsection{A cadeia de valor de medicina diagnóstica}

Após a visão geral de mercado, podemos avançar no entendimento da cadeia de valor de medicina diagnóstica no Brasil. A Figura 5 representa de maneira simplificada esta cadeia, composta por seis elos que unem as atividades, desde 0 fornecimento de equipamentos, tecnologias e insumos, passando pelos serviços de medicina diagnóstica, atendimento, intermediação financeira, financiamento, até a chegada ao consumo final.

Figura 5: Cadeia de valor do setor de medicina diagnóstica no Brasil: atividades centrais

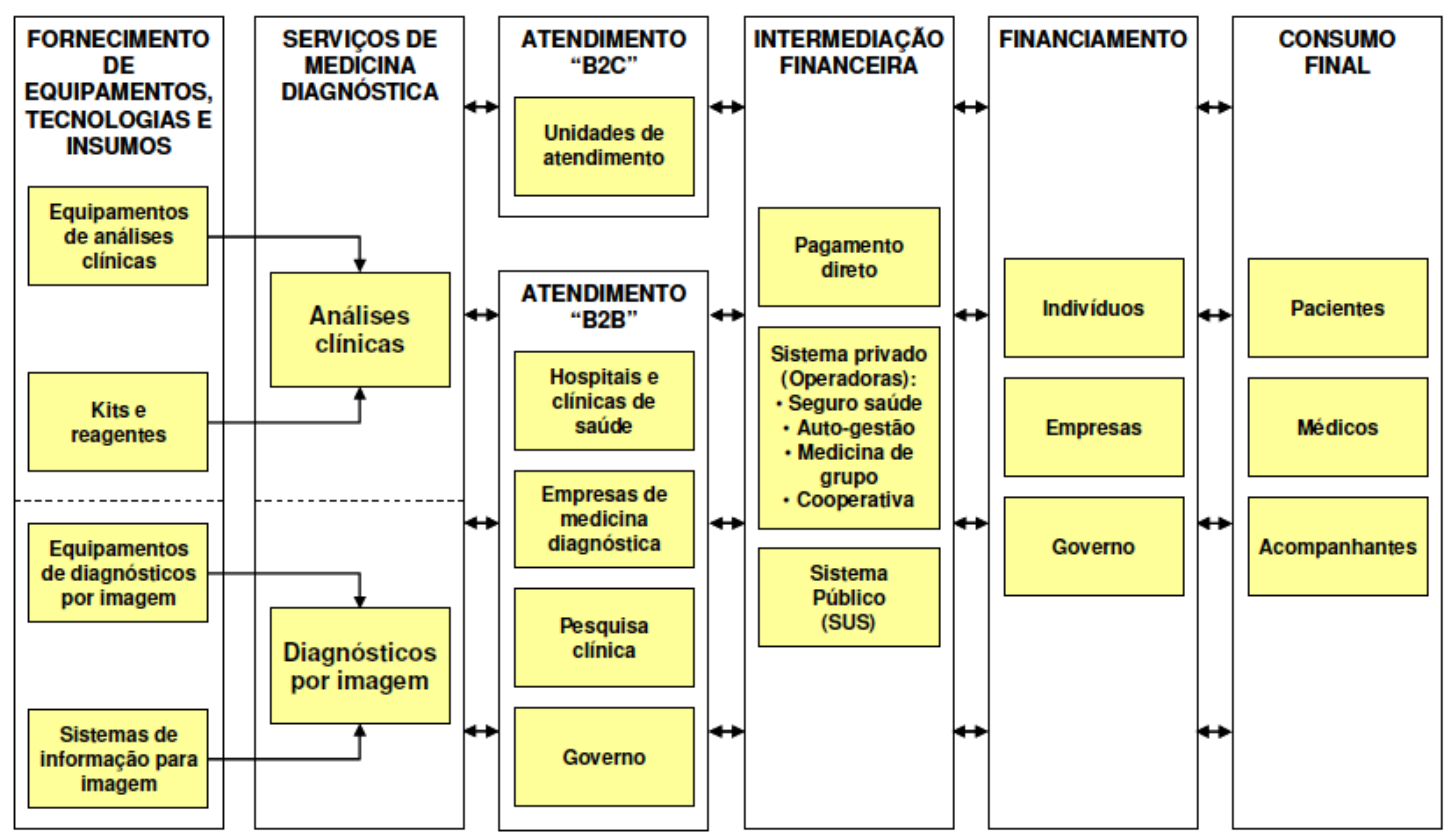

Fonte: Pedroso (2016) 
Em resumo, no primeiro elo temos o fornecimento de equipamentos, tecnologias e insumos tanto de análises clínicas (equipamentos, kits e reagentes) quanto para diagnóstico por imagem (equipamentos e sistemas de informação para imagem). Este elo fornece então todos os insumos para o segundo elo de serviços de medicina diagnóstica, segmentado em análises clínicas e diagnóstico por imagem. Estes serviços são oferecidos no terceiro elo (atendimento), tanto para o mercado $\mathrm{B} 2 \mathrm{C}$, que atende os consumidores em unidades de atendimento, quanto no elo B2B, representado pelos hospitais e clínicas de saúde, outras empresas de medicina diagnóstica, pesquisa clínica e governo. O quarto elo representa aqueles que fazem intermediação financeira, assumindo o risco (como seguro de saúde por exemplo) de repassar os gastos ocorridos nos elos anteriores. Neste elo, pode ocorrer o pagamento direto pelo cliente, o pagamento pelo sistema privado, composto por operadoras ou convênios de saúde, ou o pagamento pelo SUS. O quinto elo representa o financiamento da cadeia, que pode ocorrer pelo próprio indivíduo (pelo pagamento particular, de seguro ou de impostos), pelas empresas que concedem benefícios aos funcionários, como plano de saúde, ou pelo próprio Governo que arrecada os impostos. Por fim, temos o sexto elo, representado pelos clientes que realizam os exames, pelo médico que solicita os exames e pelos acompanhantes dos pacientes, quando necessário.

\subsection{Produtos e serviços em medicina diagnóstica}

Segundo Pedroso e Malik (2012), os serviços de medicina diagnóstica estão contemplados dentro do elo de serviços de saúde.

$\mathrm{Na}$ última década, o termo medicina diagnóstica vem sendo adotado pelo mercado em substituição ao termo "serviços auxiliares de diagnóstico e terapêutica" (SADT) utilizado por órgãos reguladores como a Agencia Nacional de Saúde (ANS) para categorizar os estabelecimentos de serviços de medicina diagnóstica.

O serviço de medicina diagnóstica engloba as atividades de laboratório clínico, também chamado de medicina laboratorial e medicina por imagem, que engloba a radiologia, ultrassonografia, tomografia, ressonância magnética, medicina nuclear, endoscopia, cardiologia, e outras especialidades médicas (AURIEMO; ROSENFELD, 2006). 
Conforme Knottnerus, Van Weels e Muris (2002) o objetivo da medicina diagnóstica é detectar ou excluir a existência de doenças, bem como avaliar prognóstico, monitorar um tratamento médico adotado e fornecer subsídios que possibilitem uma avaliação do estado geral de saúde de um paciente.

O produto de um serviço de medicina diagnóstica é a informação materializada no laudo do exame (BECKER, 2004; Campana, Faro e Gonzalez (2009)

Forsman, (1996), Auriemo, Rosenfeld (2006) e Campana, Oplustil e Gonzalez (2011) relatam que mais de $70 \%$ das decisões médicas estão apoiadas em informações provenientes da medicina diagnóstica. Estas decisões são sempre baseadas na somatória de evidências clínicas, epidemiológicas e laboratoriais, e conduzem o médico nos seus diagnósticos, nas decisões terapêuticas, no controle da evolução dos pacientes e nas avaliações e orientações de medicina preventiva.

Campana, Faro e Gonzalez (2009) definem medicina diagnóstica como sendo um grupo de especialidades médicas direcionadas à realização de exames complementares no auxílio do diagnóstico com impacto nos diferentes estágios da cadeia de saúde: prevenção, diagnóstico, prognóstico e acompanhamento terapêutico. De fato, medicina diagnóstica não se restringe somente ao diagnóstico. Pedroso (2016) exemplifica além do auxílio diagnóstico (ex: doenças oncológicas, doenças cardiológicas), o monitoramento de doenças (ex: doenças crônicas como diabetes), detecção precoce (ex: screening de câncer de mama e próstata) e atuação preditiva de doenças (ex: mapeamento de doenças genéticas).

Em relação aos produtos e serviços prestados, a medicina diagnóstica se segmenta basicamente em análises clínicas, anatomia patológica, e radiologia ou exame de imagem (AURIEMO; ROSENFELD, 2006; CAMPANA; FARO; GONZALEZ, 2009; PEDROSO, 2016) 
Figura 6: Tipos de serviços de medicina diagnóstica

\begin{tabular}{|c|c|c|c|}
\hline Tipo & Subespecialidades & Descrição & Exemplos \\
\hline \multirow{10}{*}{$\begin{array}{l}\text { Análises } \\
\text { Clínicas }\end{array}$} & Hematologia & Analisa os componentes celulares do sangue & Hemograma completo \\
\hline & Hemostasia & Analisa os mecanismos de coagulação do sangue & Coagulograma \\
\hline & Bioquímica clínica & Analisa os componentes químicos do sangue, urina e outros fluidos orgânicos & Glicemia, colesterol total e frações \\
\hline & $\begin{array}{l}\text { Endocrinologia } \\
\text { Laboratorial }\end{array}$ & Analisa os hormônios & Dosagem de cortisol livre \\
\hline & Uranálise & $\begin{array}{l}\text { Analisa as características gerais da urina (cor, aspecto, odor, ph, densidade, presença } \\
\text { de proteínas, glicose, corpos cetônicos, etc) }\end{array}$ & Urina Tipo I \\
\hline & Imunologia & $\begin{array}{l}\text { Analisa as interações imunológicas (ou seja, as reações antígeno-anticorpo) do } \\
\text { sangue e outros fluidos orgânicos }\end{array}$ & FAN ou fator anti-núcleo \\
\hline & Microbiologia & $\begin{array}{l}\text { Analisa a flora microbiológica humana (e animal) e os microorganismos presentes } \\
\text { no ambiente e em objetos, detectando a presença de bactérias (bacteriologia), vírus } \\
\text { (virologia), fungos e micotoxinas (micologia) }\end{array}$ & Antibiograma \\
\hline & Parasitologia & $\begin{array}{l}\text { Analisa as característiacs dos parasitas externos (ectoparasitas) e internos } \\
\text { (endoparasitas) }\end{array}$ & Exame parasitológico de fezes \\
\hline & Biologia Molecular & Analisa as biomoléculas (ex: DNA e RNA) & Exame de paternidade \\
\hline & Genética & Analisa a genética humana e suas anomalias & $\begin{array}{l}\text { Exames relacionados a erros inatos } \\
\text { do metabolismo }\end{array}$ \\
\hline \multirow{2}{*}{$\begin{array}{l}\text { Anatomia } \\
\text { Patológica }\end{array}$} & Análise Macroscópia & Analisa peças cirurgicas (patologia cirúrgica) & Exames de pólipos intestinais \\
\hline & Análise Microscópia & Analisa tecidos (histopatologia) e células (citopatologia) & $\begin{array}{l}\text { Exames associados a biópias, } \\
\text { Papanicolau }\end{array}$ \\
\hline \multirow{8}{*}{ Radiologia } & Raio - X & $\begin{array}{l}\text { Analisa imagens geradas por meio de emissões eletromagnéticas de natureza } \\
\text { semelhante à luz visível (raio-x) }\end{array}$ & Raio-x de tórax \\
\hline & Ultra-sonografia & $\begin{array}{l}\text { Analisa imagens geradas por emissões de ondas sonoras acima dos limites audíveis } \\
\text { do ser humano (aproximadamente } 20.000 \mathrm{~Hz} \text { ) }\end{array}$ & Ultra-som de abdomen total \\
\hline & $\begin{array}{l}\text { Tomografia } \\
\text { Computadorizada }\end{array}$ & $\begin{array}{l}\text { Analisa imagens que representam uma secção (ou fatia) do corpo, obtidas por meio } \\
\text { de processamento por computador de informação recolhida após exposição do } \\
\text { corpo a uma sucessão de raios-x }\end{array}$ & $\begin{array}{l}\text { Tomografia computadorizada de } \\
\text { pelve }\end{array}$ \\
\hline & \begin{tabular}{|l|} 
Ressonância \\
Magnética \\
\end{tabular} & $\begin{array}{l}\text { Analisa imagens que representam uma seção (ou fatia) do corpo, obtidas por meio } \\
\text { de emissão de campo magnético }\end{array}$ & $\begin{array}{l}\text { RM de articulação têmporo- } \\
\text { mandibular }\end{array}$ \\
\hline & Endoscopia & $\begin{array}{l}\text { Analisa imagens geradas por endoscópios permitindo a visibilização da mucosa } \\
\text { interna (ex: dos aparelhos digestivos e respiratórios) }\end{array}$ & Colonoscopia \\
\hline & Medicina Nuclear & $\begin{array}{l}\text { Analisa imagens geradas por meio da emissão de radiação (utilizando para tanto os } \\
\text { radiofármacos) }\end{array}$ & Cintilografia \\
\hline & Métodos Gráficos & $\begin{array}{l}\text { Analisa os registros gráficos obtidos por meio da captação da atividade bioelétrica } \\
\text { (ex: cerebral e cardíaca) }\end{array}$ & $\begin{array}{l}\text { Eletroencefalograma (EEG), } \\
\text { eletrocardiograma (ECG) }\end{array}$ \\
\hline & $\begin{array}{l}\text { Radiologia } \\
\text { intervencionista } \\
\text { (hemodinâmica) }\end{array}$ & $\begin{array}{l}\text { Contempla intervenções guiadas por acesso percutâneo ou outros (ex: introdução } \\
\text { de cateteres), que utilizam imagem fluoroscópica para diagnostica e tratar doenças } \\
\text { internas }\end{array}$ & $\begin{array}{l}\text { Angiografia, embolização arterial } \\
\text { de hemorragia digestiva }\end{array}$ \\
\hline
\end{tabular}

Fonte: Pedroso (2016)

Conforme mostra a Figura 6, de Pedroso (2016), as análises clínicas contemplam os exames realizados em material biológico como sangue, urina e fezes. Tais exames são classificados em subespecialidades que incluem a hematologia, hemostasia, bioquímica, endocrinologia, uranálise, imunologia, microbiologia, parasitologia, bioquímica clínica, biologia molecular e genética. A maior parte desses exames é realizada de maneira automatizada e processada em grande escala. Exames mais específicos e de menor volume são processados de maneira semi automatizada ou de forma totalmente manual. Os exames de anatomia patológica analisam peças cirúrgicas, tecidos e células humanas. Tanto os exames de análises clínicas como os de anatomia patológica são denominados in vitro, pelo fato dos processos de análise ocorrerem fora dos sistemas vivos em ambiente controlado de um laboratório. 
Já os exames de radiologia, ainda conforme Pedroso (2016), utilizam diferentes equipamentos como raio-x, tomografia computadorizada, ressonância magnética, endoscopia entre outros, para capturar e analisar imagens internas e registros gráficos do corpo humano. Estes exames são denominados in vivo, pelo fato dos processos ocorrerem no próprio organismo vivo.

\subsection{A experiência dos clientes de medicina diagnóstica}

A Figura 7 de Pedroso (2016) representa o ciclo de experiência dos clientes em serviços de medicina diagnóstica no setor privado. Conforme o autor, há ciclos de experiência para três clientes que consomem os serviços de medicina diagnóstica: (i) O primeiro deles é o cliente final, chamado habitualmente de paciente, que de fato será investigado por meio dos exames. (ii) O segundo cliente é o médico, que demanda conforme a necessidade do paciente, pois em boa parte dos casos depende de um resultado de qualidade para tomar as decisões sobre o diagnóstico e tratamento. (iii) $O$ terceiro cliente é a fonte pagadora, que credencia os prestadores de serviços e desse modo limita o acesso do paciente aos credenciados.

Deste modo, cada um dos três clientes possuem ciclos de experiência, onde basicamente as fontes pagadoras farão o repasse financeiro à prestadora de serviço de medicina diagnóstica pelo serviço solicitado pelo médico e efetivamente realizado pelo paciente. 
Figura 7: Experiência dos clientes em serviços de medicina diagnóstica

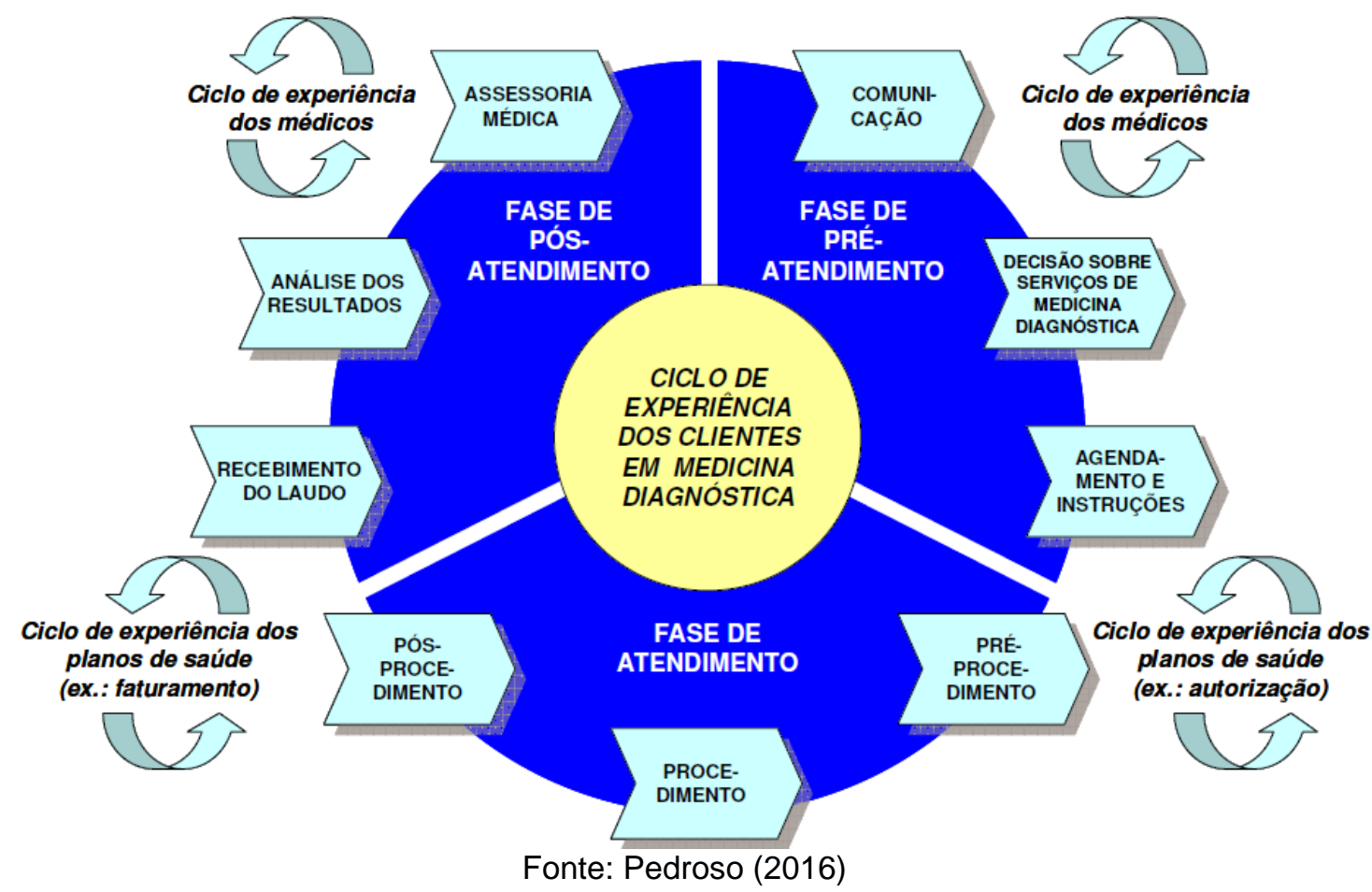

Pedroso (2016) explica que cada cliente possui um ciclo de experiência a depender da etapa em que o serviço ocorre. Essas etapas são segmentadas em fase de pré atendimento, de atendimento e pós atendimento.

O autor descreve que a fase de pré atendimento envolve as atividades entre 0 primeiro contato com o prestador de serviço até antes do cliente ser efetivamente atendido. Nesta fase estão as atividades de comunicação (propaganda, programa de relacionamento, site da empresa e boca a boca), decisão sobre o serviço de medicina diagnóstica (inclui a prescrição e recomendação médica), o agendamento e instruções de preparo, bem como em alguns casos as autorizações por parte das fontes pagadoras para a realização dos procedimentos.

A fase do atendimento envolve as atividades antes do procedimento, como a chegada no estacionamento, recepção, triagem, abertura de ficha e espera, passando pelo procedimento em si (coleta do material ou realização do exame de imagem), até as atividades após o procedimento, como o repouso pós exame, lanche e saída do estabelecimento.

A fase de pós atendimento engloba o recebimento do laudo (ex: via internet ou via portador), análise dos resultados (realizado pelo médico normalmente), e 
assessoria médica, que pode ser realizada entre o médico do paciente e o assessor especializado do prestador de serviço.

SEKI et al (2003) relatam que alguns anos atrás os laboratórios se orientavam pela perspectiva de dentro da empresa para fora do mercado. Ou seja, para se diferenciar, os prestadores de serviços concentravam seus esforços na oferta de exames com melhores condições técnicas. Com a evolução do mercado e a profissionalização do setor, a disseminação de kits diagnósticos industrializados tornou acessíveis determinadas técnicas. Como consequência, a maior parte dos exames começou a se comportar como commodities, não sendo mais o diferencial. Paralelamente, os clientes começaram a prevalecer seu direito de escolha pelo prestador de saúde, exigindo um serviço de atendimento diferenciado. Ainda segundo os autores, a percepção de qualidade por parte dos clientes está cada vez mais relacionada ao local de atendimento, como a conservação das instalações, reformas de ambientes como recepção e salas de espera, serviço de copa/cafeteria, serviços de coletas especializadas, estacionamento e espaços para divulgação de artistas regionais. 


\section{GESTÃO DA INOVAÇÃO}

\subsection{Conceitos de inovação}

Os primeiros trabalhos sobre a temática de inovação surgiram com Schumpeter (1982) em sua obra clássica "Teoria do desenvolvimento econômico". Neste trabalho, Schumpeter preconiza que as empresas utilizam a inovação para obter vantagem estratégica. Nesta visão, as empresas que detêm uma inovação passam a explorá-la com o objetivo de obter altos lucros, chamado de "lucros de monopólio". No entanto, outras empresas tentarão copiar a inovação, e à medida que a inovação for imitada pelos concorrentes, perde-se a vantagem competitiva e os lucros diminuem de forma a entrar em equilíbrio e assim permanecem até que surja outra inovação que desencadeará novamente o ciclo. Este processo é chamado de "destruição criativa", onde há uma constante busca pelo novo, que por sua vez, "destroem" os antigos paradigmas. Desse modo, Schumpeter afirma que a busca pelo novo, é o que mantém o movimento do sistema econômico.

Schumpeter ainda deixa claro que inovação não é sinônimo de invenção. Enquanto que inovação provém de uma invenção, para Schumpeter (1982), há três fases básicas no processo de inovação: i) a invenção relacionando-se à descoberta, novas técnicas e com potencial comercial ainda a ser realizado; ii) a inovação como o desenvolvimento da invenção comercialmente; iii) e a difusão como a expansão de uma inovação em uso comercial, novos produtos e processos.

Esta distinção entre invenção e inovação é conhecida na literatura. Enquanto a invenção se relaciona somente com a descoberta, a inovação é o resultado de pôr em prática a descoberta e capturar valor por meio dela (DRUCKER, 2003; TIDD; BESSANT, 2015; UTTERBACK, 1996).

Os autores Varkey, Horne e Bennet (2008) definem a inovação como a implementação bem-sucedida de uma ideia nova, de forma a criar valor convincente para alguns ou todos os stakeholders.

Já no Manual de Oslo (OCDE, 2004) a inovação é definida como a implementação de um produto (bem ou serviço) novo ou significativamente melhorado, ou um processo, ou um novo método de marketing, ou um novo método organizacional nas práticas de negócios, na organização do local de trabalho ou nas relações externas. 
Nesta definição do Manual de Oslo (OCDE, 2004) pode-se observar uma classificação dos tipos de inovação:

Inovação de Produto é a introdução de um bem ou serviço novo ou significativamente melhorado no que concerne às suas características ou usos previstos. Incluem-se melhoramentos significativos em especificações técnicas, componentes e materiais, softwares incorporados, facilidade de uso ou outras características funcionais.

Inovação de Processo é a implantação de um método de produção ou distribuição novo ou significativamente melhorado. Incluem-se mudanças significativas em técnicas, equipamentos e/ou softwares.

Inovação de Marketing é a implantação de um novo método de markerting, envolvendo mudanças significativas na concepção do produto ou em sua embalagem, no posicionamento do produto, em sua promoção ou fixação de preços.

Inovação Organizacional é a implantação de um novo método organizacional nas práticas de negócios da empresa, na organização de seu local de trabalho ou em suas relações externas.

Tidd e Bessant (2015) reconhecem, além dos tipos de inovação de produto e processo, a inovação de posição e paradigma. A inovação de posição é quando há mudança no contexto no qual o produto e serviço são introduzidos, e a inovação de paradigma envolve mudanças nos modelos mentais que moldam o que a organização faz. Para os autores, a linha divisória entre os tipos é muito tênue, sendo permeáveis entre si.

Outra forma de classificação da inovação é quanto ao grau ou intensidade da mudança de inovação, que pode ser incremental (ou não disruptiva) ou radical (de ruptura, disruptiva) (FREEMAN; PEREZ, 1988; CHRISTENSEN; BOHMER; KENAGY, 2000; SCHUMPETER, 1982, TIDD; BESSANT, 2015; UTTERBACK, 1996):

- Radical - É fazer algo totalmente novo. Representa uma grande mudança em produtos, serviços e processos existentes. É uma quebra de paradigma. Inovações radic'ais tendem a provocar grande mudanças inclusive na forma que o produto ou serviço é consumido, criando por vezes novos modelos de negócio.

- Incremental - É melhorar algo que já existe. Representa uma pequena mudança em produtos, serviços e processo existentes. Inovações incrementais promovem continuamente o processo de mudança. 
Segundo Davila, Epstein e Shelton (2007), uma inovação radical só ocorre quando há a introdução de uma nova tecnologia, simultaneamente com a implantação de um novo modelo de negócio.

Sob o aspecto de como acontece a inovação, na visão de Dosi (1982), as mudanças tecnológicas podem ocorrer de maneira "puxada" pelas necessidades do consumidor e do mercado, como também podem ocorrer de maneira "empurrada" por meio das atividades de pesquisa e desenvolvimento da empresa.

A inovação tem papel muito importante nas empresas. Para que a empresa tenha forças de competir e se inserir em novos mercados, alavancando a sua competitividade e promovendo o desenvolvimento econômico, a inovação se posiciona como a principal solução estratégica (DRUCKER, 2003; PROENÇA et al, 2015; TIDD; BESSANT, 2015).

Davila, Epstein e Shelton (2007) destacam que no longo prazo, o único fator realmente capaz de garantir o futuro de qualquer empresa é sua capacidade de inovar melhor, de forma mais contínua, e por mais tempo que as concorrentes.

De modo geral, as diferentes visões apresentadas sobre a inovação possuem em comum o conceito de que inovação é a introdução de uma nova ideia, implantada que gera valor. A inovação também pode ter diferentes tipos (produtos e serviços, processos, marketing etc) e graus ou intensidade (radical ou incremental). O objetivo final daquele que inova é obter vantagens competitivas e explorá-las junto ao mercado.

\subsection{Gestão de operações de serviços}

Conforme já citado, os primeiros trabalhos de inovação surgiram com Schumpeter, na época que o desempenho da economia era centralizado nas indústrias. O olhar sobre serviços era pobre, tratando-o de forma residual na economia, com papel marginal (COSTA, 2016). Hoje a situação econômica é diferente e a atividade de serviços já representa 73,3\% do PIB Brasileiro (IBGE, 2016).

Mesmo com tamanha importância na economia, a definição de serviços ainda é uma tarefa complexa.

Zeithaml, Parasuraman e Berry (1985) trazem uma abordagem de serviços vinda do marketing, onde elencam as principais características que diferem serviços e produtos sendo: 
- Perecibilidade - Serviços não podem ser estocados, e se depreciam instantaneamente após a produção. Desse modo, há dificuldade em sincronizar a demanda com produção.

- Intangibilidade - os serviços não possuem forma física, eles são experiências, e portanto não é possível tocar ou saborear um serviço.

- Heterogeneidade - O mesmo serviço nunca é igual ao outro. Há variação tanto em relação ao produtor, ao cliente, ao dia, e ao local em que o serviço é prestado.

- Inseparabilidade - A produção e o consumo do serviço ocorrem simultaneamente, sendo estes inseparáveis. O consumidor deve estar presente no ato da produção em grande parte dos serviços.

Salerno (2001) rebate a ideia de inseparabilidade entre o consumo e a produção na mesma hora, com a presença do cliente. Os serviços de telefonia não necessitam da presença física do cliente, e no caso dos serviços de manutenção de algum equipamento, nem mesmo necessitam do contato com o cliente. Também rebate a ideia de que a hora da verdade gera a percepção da qualidade do serviço. Ele apresenta como exemplo o caso de um paciente que foi muito bem atendido em um hospital, mas que dois dias depois, já em casa, contraiu infecção hospitalar. O autor questiona se este paciente julgará o serviço apenas pelos momentos que teve contato direto com os médicos, enfermeiras, atendentes do hospital, ou também pelo momentos após o consumo.

Fugindo da dualidade indústria-serviço, Salerno (2001) apresenta o conceito de "relação de serviço", em que trata não o setor de serviço em si, mas a intensidade das relações e interações entre os atores da oferta e da demanda. Desse modo, relações de serviço são modalidades de interconexão entre os prestadores de serviço e os clientes a propósito da resolução do problema pelo qual o cliente se dirige ao prestador. Assim, a relação de serviço pode haver em qualquer setor.

Corrêa e Caon (2006) e Shostack (1977) também fogem desta classificação dicotômica em relação à intangibilidade, entre empresas de produtos (tangíveis) e empresas de serviços (intangíveis), o qual julgam ser simplória e ultrapassada. Afinal, com raríssimas exceções, o pacote de valor que as empresas entregam ao cliente em troca de pagamento considera aspectos tangíveis e intangíveis. Não é fácil determinar a diferença entre produto e serviço. Normalmente, a compra de um produto vem acompanhada de um serviço e apoio, e a compra de um serviço muitas vezes inclui 
alguns bens (FITZSIMMONS; FITZSIMMONS, 2011; ZEITHAML; BITNER, 2003). Há poucos serviços puros ou bens puros (FITZSIMMONS; FITZSIMMONS, 2011; CORREAA; CAON, 2006; ZEITHAML; BITNER, 2003; SHOSTACK, 1977).

Corrêa e Caon (2006) ressaltam que em um ambiente competitivo as empresas ofertam aos clientes "pacotes de valor" que por sua vez são compostos em parte de produtos e outra parte de serviços. Desse modo, definem dois principais elementos componentes do pacote de valor entregue ao cliente: (i) elementos não estocáveis; (ii) e elementos estocáveis, que podem ter sua propriedade transferida durante a prestação de serviço ou não.

Desde 1977, Peter Hill propôs a definição de serviços como "uma mudança na condição de uma pessoa ou de um bem pertencente a um agente econômico, que vem à baila como resultado da atividade de outro agente econômico, por acordo prévio, ou seja, solicitação da pessoa ou agente econômico anteriores". (HILL, 1977).

Esta definição está distante daquela que caracteriza os serviços à sua armazenabilidade ou perecibilidade. Esta definição, ainda hoje muito utilizada, envolve dois tipos de relações sociais: a de uma demanda de intervenção, que inicia a relação de serviço; e outra de propriedade. Sendo assim, o serviço é uma operação de mudança, desejada ou pedida por um agente econômico (consumidor, cliente ou usuário), detentor da realidade a ser transformada (sua própria pessoa, seus bens, etc), e que para tal, recorre a outro agente econômico (prestador de serviço, produtor).

Nesta definição, o produto (do serviço) é a mudança de estado da realidade submetida à intervenção.

Assim, Gadrey (2001) tenta precisar esta definição incluindo o fato de que o resultado do serviço não pode circular economicamente independente do estado de realidade. Ele define a atividade de serviço como "uma operação que visa uma transformação do estado de uma realidade $C$, possuída ou utilizada por um consumidor $B$ (cliente ou usuário), realizada por um prestador de serviços $A$, a pedido de $B$, e com frequência relacionada a ele, não chegando porém à produção de um bem que possa circular economicamente independentemente do suporte de C".

Outra definição de serviço relacionada aos recursos e as consequências é a de Philippe Zarifian (2011b) que define serviço como sendo uma organização e uma mobilização, o mais eficiente possível, de recursos para interpretar, compreender e gerar a mudança perseguida nas condições de atividade do cliente-usuário. 
Johnston e Clark (2012) apontam duas perspectivas ao pensar em serviço: perspectiva cliente, que inclui a experiência e o resultado, e a perspectiva da operação, ou seja, a maneira como o serviço é prestado.

Sob a perspectiva do cliente, o resultado do serviço é aquilo que o cliente espera. Nesta visão os autores definem serviço como a combinação dos resultados e experiências proporcionadas ao cliente e recebidos por ele. Desse modo, a qualidade segundo o cliente envolve tanto a experiência quanto o resultado.

Já a perspectiva da operação é a configuração dos recursos e processos que entregam o serviço ao cliente. Neste sentido, Corrêa e Caon (2006), ressaltam o fato de os serviços terem normalmente algum nível de contato do cliente com o recurso produtivo, não significa que este contato ocorra em todos os aspectos do processo produtivo. Os autores apontam dois tipos de atividades:

- Atividades de contato, também chamadas de "linha de frente" ou de "front office", é a relação direta entre o cliente e a organização.

- Atividades sem o contato do cliente, também chamadas de atividades de "retaguarda" ou de "back office", contêm os processos executados longe do cliente.

Para Zarifian (2001b), produzir o serviço é o processo que transforma as condições de existência de um indivíduo ou de um grupo de indivíduos. Portanto, o serviço deve atuar nas condições de uso ou sobre as condições de vida do destinatário (cliente ou usuário), de modo a atender as expectativas deste último. No caso, serviços de saúde é o processo de transformação das condições de saúde da população (ZARIFIAN, 2001b).

Conforme mostra a Figura 8, a produção do serviço é composta por três grandes universos: a) o universo da concepção das novas tecnologias e dos novos produtos ou serviços, chamado de conceptores; b) o universo dos grandes sistemas técnicos que asseguram a produção material desses produtos ou serviços, chamado de produtores ( as fábricas na indústria, as unidades técnicas nos serviços); c) 0 universo da relação direta com os clientes ou usuários, que permite estruturar 0 contato com estes últimos, chamado de comerciais (as agências comerciais e redes comerciais) (ZARIFIAN, 2001a). 
Figura 8: As três atividades de Produção de Serviços

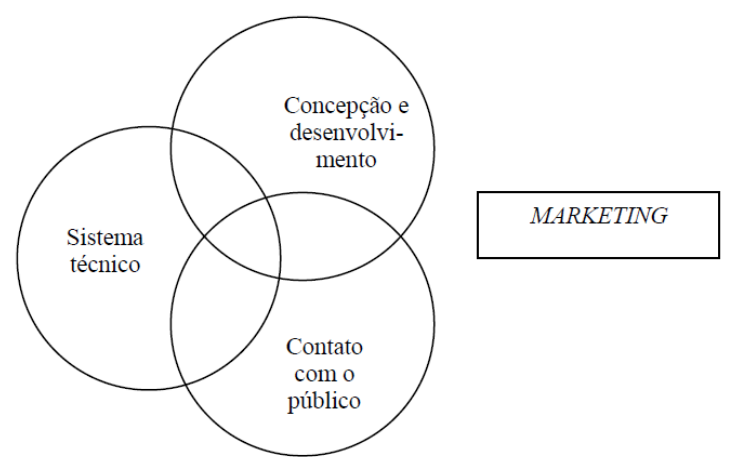

Fonte: Zarifian (2001a)

O modelo de produção industrial de serviço busca utilizar a lógica fordista de operar economias de escala por meio da concentração da produção, e a lógica de serviço, cuja ideia principal é que o serviço não é somente o ponto de chegada da produção, mas também o ponto de partida. No entanto, estas lógicas não se combinam facilmente num mesmo modelo produtivo. Por exemplo, enquanto que o universo do sistema técnico e o universo de concepção aplicam a lógica fordista de concentrar suas unidades produtivas, objetivando economias de escala, o universo do contato do cliente visa a desconcentração e a maior proximidade, aumentando assim o conhecimento do usos locais dos produtos e serviços e permitindo desenvolver estratégias locais e adaptadas. (ZARIFIAN, 2001a).

As lógicas que envolvem os universos são por vezes conflitantes. Para reduzir os efeitos deste conflito, algumas micro inovações organizacionais ajudam a criar um tecido relacional denso entre a unidade técnica e as agências comerciais. Como exemplo, o aumento da comunicação entre as unidades técnicas e as agências comerciais, por meio de sistemas e aproximação de profissionais dos dois universos.

\subsection{Inovação em serviços}

A inovação tem sido assunto de pesquisa desde 0 início do século $X X$. $A$ literatura de inovação até os anos 80 focou a maior parte dos estudos em inovações de produtos (bens tangíveis), tendo então os primeiros estudos de inovação de serviços surgido, em especial nos anos 90 . Os primeiros trabalhos de inovação de serviços se iniciaram com Shostack (1982) com seu estudo de como projetar um serviço. Gadrey, Gallouj e Weinstein (1995) apontaram que a inovação de serviços é 
diferente da inovação industrial. No entanto, isto não significava que as experiências oriundas na indústria não poderiam ser aproveitadas e adaptadas aos serviços.

Para Sundbo e Gallouj (1998) as inovações de serviços podem ser categorizadas em quatro tipos: inovação de produtos, inovação de processo, inovação organizacional e inovação de mercado.

- Inovações de produto (serviço final): relacionadas a oferta de um novo serviço, uma nova solução ao cliente.

- Inovações de processos: são inovações nos procedimentos de produção e entrega do serviço. A inovação do processo pode ser dividida em duas categorias: inovações em processos de produção (back office) ou em processos de entrega (front office).

- Inovações organizacionais: são novas práticas de organização ou gerenciamento, como a introdução de TQM, grupos auto-orientadores, etc.

- Inovações de mercado: são novos comportamentos no mercado. Encontrando um novo segmento de mercado, entrando em outra indústria e seu mercado (como, por exemplo, varejo começando a vender contas de depósito bancário).

- Inovações ad hoc: são soluções para problemas específicos dos clientes, criadas a partir de uma construção interativa. Este tipo de inovação é coproduzida pelo cliente e o fornecedor do serviço, não sendo diretamente reprodutível, mas sim indiretamente por meio da codificação e formalização de parte da experiência e competência.

Ainda segundo, Sundbo e Gallouj (1998), a inovação de serviços pode ser tecnológica ou não, podendo gerar a criação de um novo conhecimento ou informação, ou novas formas de lidar com coisas e pessoas. As inovações de serviço podem ser puxadas pelas necessidades dos clientes ou empurradas pelas áreas internas da empresa. Normalmente as inovações de serviços são incrementais e o processo de inovação normalmente é prático. Na visão dos autores, o serviço não pode ser totalmente separado do produto, ou seja, é difícil mudar um produto sem mudar seus processos.

Sundbo e Gallouj (2000) apontam forças que dirigem o processo inovação em serviços. Estas forças podem ser internas ou externas conforme a figura 9. 
Figura 9: Driving Forces Behind Service Innovations

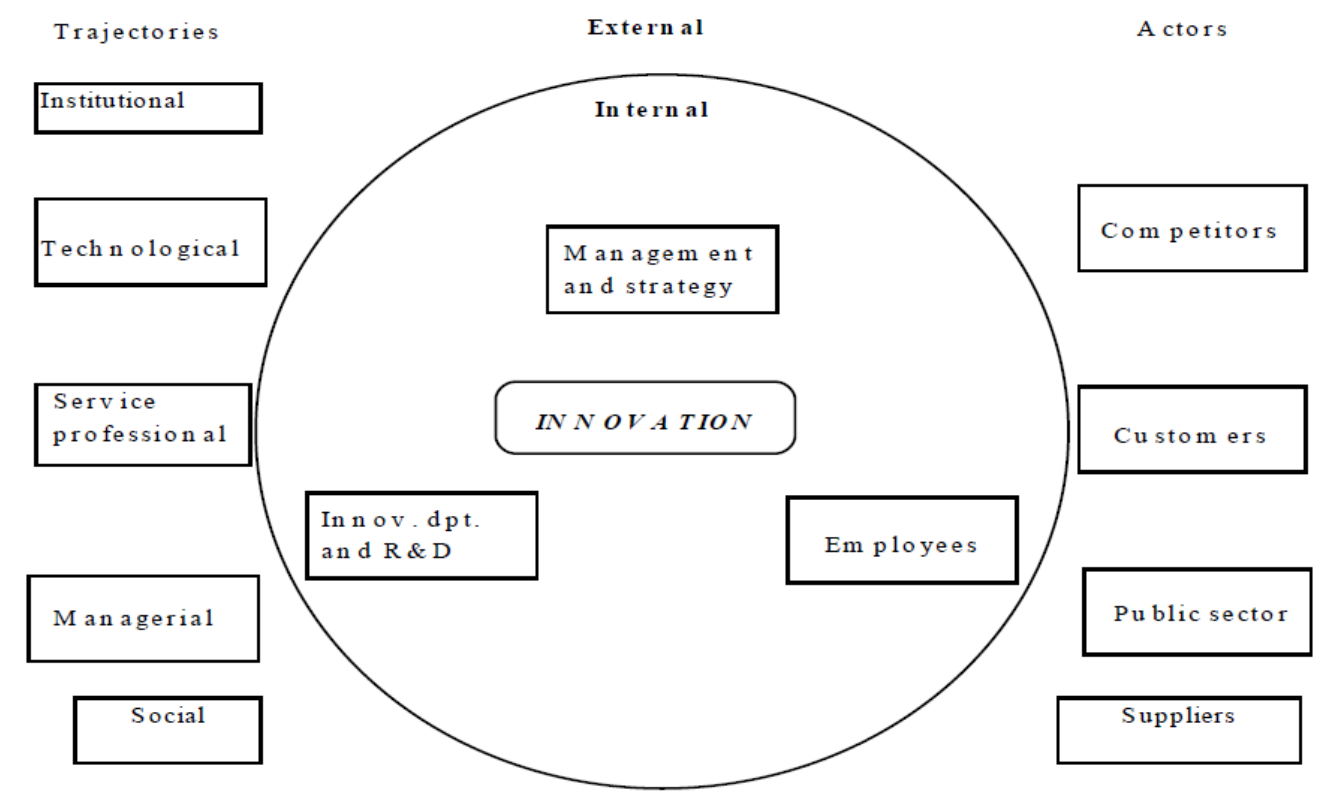

Fonte: Sundbo e Gallouj (2000)

As forças internas estão relacionadas à existência ou não de estruturas dedicadas à inovação como P\&D, ao envolvimento dos colaboradores no processo de inovação, à integração do processo de inovação, e à gestão e estratégia. As forças externas são separadas em trajetórias e atores. As trajetórias são ideias e lógicas que são difundidas no sistema social, e correspondem ao ambiente e sua dinâmica. As trajetórias podem ser institucionais, tecnológicas, de profissionais de serviços, gerencias, e sociais. Os atores, são pessoas, firmas ou organizações que acabam influenciando o processo de inovação de serviços. São considerados atores os competidores, consumidores, o setor público e os fornecedores.

Ao estudar inovação de serviços, Gallouj (1998) aponta três abordagens: tecnicista, orientada a serviços e integradora.

$\mathrm{Na}$ abordagem tecnicista, a inovação de serviços é reduzida à utilização de tecnologia (como tecnologia de informação e comunicação, ou TICs). Relaciona-se com a introdução de sistemas técnicos nas organizações como equipamentos, materiais e comunicação.

A abordagem orientada a serviço, busca considerar possibilidades de inovações, ampliando para aquelas de cunho não tecnológico. A ideia central desta abordagem é levar em conta também a relação usuário produtor, e toda a parte relacional como uma fonte das fontes de inovação, não necessariamente envolvendo 
tecnologia. Neste sentido, Gallouj (1998) classifica a inovação em serviços em três tipos: inovações ad hoc (processos de construção de soluções para um problema específico), inovações de novas especialidades (novo campo de conhecimento ou expertise a ser explorado) e inovações de formalização (que buscam tornar as saídas dos processos menos difusas por meio de metodologias e ferramentas).

A abordagem integradora propõe uma visão de produtos e serviços sob uma mesma teoria da inovação. Esta abordagem considera que o produto (bem ou serviço) pode ser representado por um conjunto de vetores de características e competências interconectadas. A inovação pode ser definida de acordo com mudanças que afetam um ou mais vetores de características ou de competências.

Esta visão integradora teve início com Saviotti e Metcalfe (1984) que entendem o fornecimento de um produto, seja ele um bem manufaturado ou um serviço, como resultado de um conjunto de características técnicas e de processos (Figura 10). Sendo assim as características finais do bem ou serviço (S) são conforme o ponto de vista do usuário, como por exemplo em um carro seria o seu tamanho, performance, elementos de segurança etc. As características internas do produto, chamadas de características técnicas $(\mathrm{T})$, descrevem as características tecnológicas internas ao produto, como por exemplo, no motor do carro seriam os mecanismos técnicos do motor, transmissão, suspensão dentre outros. Por fim, as características de processo (P) se relacionam ao método em que os produtos são produzidos, e as tecnologias e modos envolvidos na organização (o material usado, a forma com que é processado). Na produção de um carro, a linha de montagem é um exemplo das características de processo. 
Figura 10: Relationship between process, technical characteristics and service characteristics in the Saviotti-Metcalfe framework

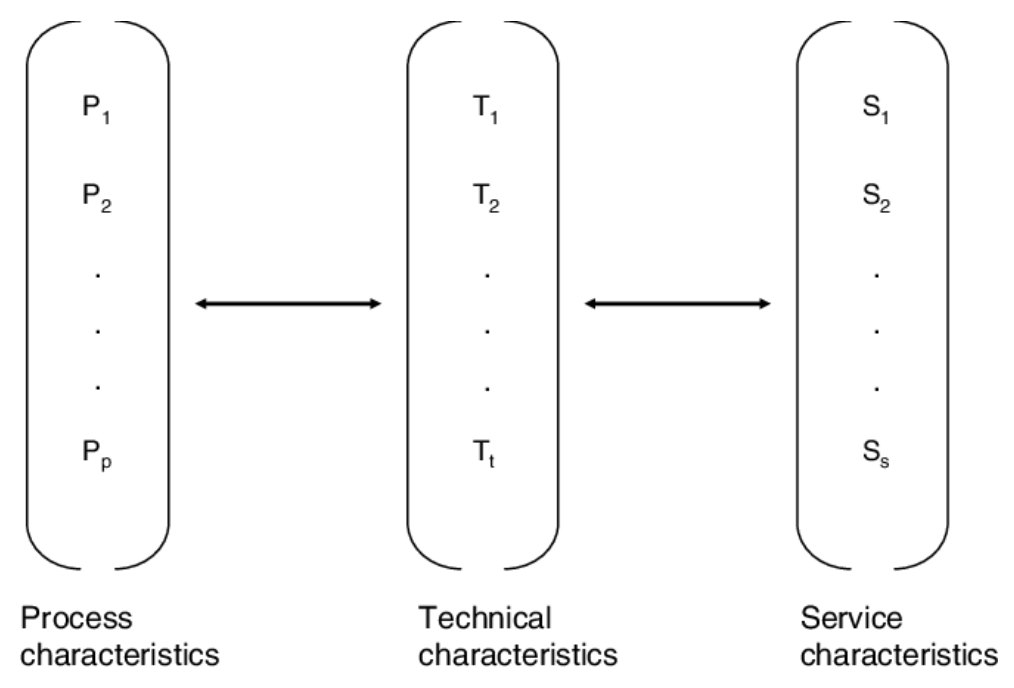

Fonte: Saviotti e Metcalfe (1984)

Esta abordagem de serviço como resultado de uma combinação de características também é seguida por Gallouj e Weinstein (1997), que adicionam ao framework de Saviotti e Metcalfe (1984) um vetor que representa as competências mobilizadas $(\mathrm{C})$ do prestador de serviço. Em relação às características de processo e características técnicas, os autores unificam em um conjunto só, chamado características técnicas $(X)$, isto porque para os autores é difícil distinguir processo de produtos, em serviços. Desse modo, os autores definem produto (bem ou serviço) como um conjunto de características, e a inovação é a mudança que afeta um ou mais termos de um ou mais vetores de características.

Tomando como base os trabalhos anteriores, Windrum e García-Goñi (2008) elaboraram um framework voltado para o setor de saúde conforme a Figura 11: 
Figura 11: Operationalized model with user-facing competences and back office competences

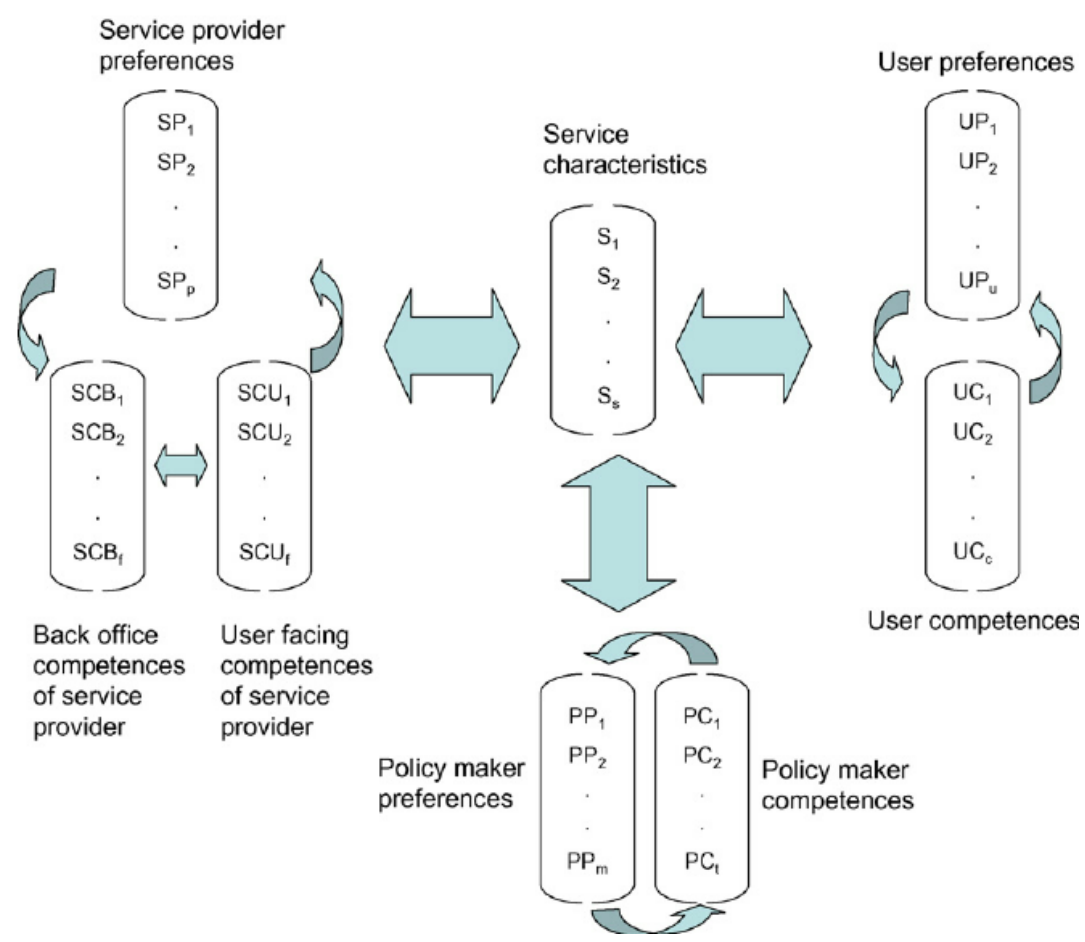

Fonte: Windrum e García-Goñi (2008)

Neste framework os autores apontam os vetores relacionados ao provedor do serviço, ao usuário e aos órgãos regulatórios.

Os autores separam em preferências e competências. Por exemplo, a qualidade de um diagnóstico estará relacionada à competência do cliente em relatar seus sintomas, fornecendo informações mais ou menos precisas. Eventualmente o cliente pode esconder alguma informação relevante, o que impacta no serviço prestado. O cliente também pode seguir o tratamento corretamente ou não, o que pode influenciar o resultado. Em relação às suas preferências, por questões religiosas ou morais, um cliente pode preferir determinados procedimentos ou tratamentos

Em relação aos aspectos regulatórios (policy markers), os autores destacam a forte influência na inovação de serviços de saúde, em especial em serviços públicos.

Em relação ao provedor de serviços, todas as características técnicas e de serviço estão contidas nas competências do provedor. Os autores destacam que em serviços intensivos em conhecimento, como é o caso de serviços de saúde, as competências do profissional e a interação com as competências do usuário são mais relevantes do que a própria tecnologia. Como exemplo, ele cita uma cirurgia, que em condições iguais de tecnologia, o diferencial é basicamente a competência do médico que a realiza. Obviamente, o médico possui preferências sobre o procedimento, 
material entre outros fatores a utilizar que influencia o serviço ao final. Também se desdobra em competências de front office e back office.

\subsection{Inovação em serviços de saúde}

A definição de inovação em saúde é a introdução e a aplicação intencional de ideias, processos, produtos ou procedimentos que simultaneamente sejam relevantes para a unidade que as adota e que beneficiem o indivíduo, grupo ou sociedade em geral (COSTA, 2016). Para Thakur, Hsu e Fontenot (2012) a inovação em serviços de saúde é definida como a adoção das melhores práticas que garantem a segurança e os melhores resultados para o paciente, além de afetar positivamente a performance da organização. Estas inovações são focadas em melhores resultados para o paciente e ajudam os profissionais de saúde a trabalhar de maneira mais inteligente, rápida, e mais eficiente em custos.

Diferentemente do que se verifica na maioria dos mercados, no setor de saúde as novas tecnologias representam uma fonte de aumento de gasto, e não de redução de custos, conforme os trabalhos de Barbash e Glied (2010), e Goyen e Debatin (2008). O grupo de estudiosos do Instituto de Estudos de Saúde Suplementar (IESS, 2016) apontam os principais motivos para esta situação:

- Avanços tecnológicos podem implicar aumento de custos simplesmente porque o novo tratamento é mais complexo e mais custoso;

- $\quad$ Permitem que um número mais amplo de pacientes possa ser tratado;

- Inovações podem permitir tratamento de doenças antes incuráveis;

- Permitem descobertas e/ou tratamento de doenças secundárias e efeitos colaterais das enfermidades que antes não eram assistidas;

- $\quad$ Amplia o tempo de tratamento das doenças justamente por permitir maior longevidade do paciente.

- $\quad$ Avanços clínicos, com tratamentos que antes extrapolavam as fronteiras médicas e passam a ser incorporados na rotina de tratamento do paciente (doenças mentais, por exemplo).

Goyen e Debatin (2008) afirmam que a simples presença de um mercado de planos de saúde já pode estimular os avanços tecnológicos pois haveria alguma demanda. 
Por outro lado, Christensen, Grossman e Hwang (2009) mostram como a inovação pode reduzir custos e melhorar a qualidade e acessibilidade à saúde. Seus estudos são focados principalmente no sistema de saúde americano, e são baseados na teoria da inovação de ruptura, que por sua vez tem como princípios centrais: (i) Como produtos e serviços se tornam mais baratos e acessíveis ao longo do tempo e (ii) as dificuldades das organizações terem sucesso na inovação de ruptura.

Esta visão também é corroborada por Porter e Teisberg (2007), que argumentam que o problema não é a inovação em si, mas pelo contrário, há diversos casos em que a inovação trouxe redução nos custos. Como exemplo ele relata que nos últimos 20 anos as inovações em quatro áreas (infarto, diabetes tipo 2, derrame cerebral e câncer de mama) tiveram um retorno de US $\$ 2,40$ a US $\$ 3,00$ por dólar investido. Além disso as inovações reduziram a duração de períodos de internação em UTIs e hospitais, e consequentemente o custo total do paciente. Os autores rebatem também a ideia de que curar doenças às vezes causa mais custos pois o paciente pode vir a padecer de algo mais dispendioso no futuro. Esta visão não considera as contribuições positivas de se ter um indivíduo mais saudável, com menor necessidade de tratamentos, e inclusive injetando receita para o sistema de segurosaúde.

Em resumo, Porter e Teisberg (2007) entendem que o que deve ser feito é buscar estrategicamente inovações que aumentem o valor para o paciente (resultado obtido por capital investido) ao longo da cadeia de prestação de serviços, olhando de maneira holística. Estas inovações devem ser altamente recompensadas e há imensas oportunidades de obtê-las avançando nos campos de conhecimento de estratégias, estruturas organizacionais, instalações, processos e parcerias (PORTER; TEISBERG, 2007).

Segundo Varkey, Horne e Bennet (2008), as inovações em saúde podem ser do tipo produto, processo ou estrutura. Inovação de produto é o bem ou serviço novo que o consumidor está efetivamente pagando. Inovação de processos implica na inovação do método de produção ou de entrega do produto. E por fim inovação de estrutura é tudo aquilo que afeta a estrutura interna ou externa da compania, e cria um novo modelo de negócios.

Assim como o setor de saúde é considerado complexo (CHRISTENSEN; GROSSMAN; HWANG, 2009; PORTER; TEISBERG, 2007; WINDRUM, GARCÍAGOÑI, 2008), o processo de inovação na saúde também apresenta complexidades 
(COSTA, 2016; OMACHONU; EINSPRUCH, 2010; HERZLINGER, 2006). Herzlinger (2006) aponta algumas complexidades no processo de inovação na saúde como objetivos conflitantes entre atores, particularidades de financiamento, regulamentação do setor, taxa de incorporação médica, aumento do poder dos pacientes nas decisões sobre saúde e a necessidade de prestação de contas e redução de custos.

Um fator que merece destaque em serviços de saúde é a forte interação entre os stakeholders do setor, como pacientes, fontes pagadoras, fornecedores e médicos (THAKUR; HSU; FONTENOT, 2012). Esta interação é muito importante no surgimento de inovações no setor. Goes e Park (1997) estudaram 400 hospitais da Califórnia, EUA, e chegaram à conclusão que há uma significante relação entre o surgimento de inovações com o grau de relação que os hospitais no estudo tinham com outros hospitais.

A participação dos stakeholders do setor de saúde é bastante marcante no processo de inovação, envolvendo diversos agentes, como universidades, institutos de pesquisa, instituições financeiras, profissionais de saúde, grupos de classe etc. Estas interações entre os diversos atores da cadeia que influenciam a inovação são bastante evidenciadas em hospitais (GOES; PARK, 1997; BOHRER; VARGAS, 2009; SILVA, 2011), em especial se destaca a forte influência dos médicos no processo de inovação devido ao seu forte envolvimento na gestão (GARCíA-GOÑI; MAROTO; RUBALCABA, 2007). Este fato é identificado principalmente na fase de ideação, onde Bohrer e Vargas (2009) apontam que 52\% dos 44 casos de inovação analisados em seus estudos foram idealizados por médicos. O médico atua como prescritor, ou seja, é um elemento essencial no direcionamento da demanda. Portanto, seu papel de influenciador entre o paciente e o prestador de serviço dá ao médico poder de exigir certos investimentos por parte do prestador de serviço (Vargas, 2006).

Além dos médicos influenciando o processo de inovação, Pisano (2006) e Chaves e Albuquerque (2006) destacam que o setor de saúde é fortemente baseado em ciência, tendo boa parte da inovação deste setor sendo desenvolvida nas universidades e institutos de pesquisa. Albuquerque e Cassiolato (2002) também destacam a importância das universidades e institutos de pesquisa neste no processo de inovação e a relação com o setor de saúde. Além das universidades e institutos de pesquisa, os autores destacam o papel dos reguladores legais, associações profissionais e escolas médicas, que possuem um importante papel de avaliar e filtrar as inovações que surgem nos institutos de pesquisa. 
Vargas (2006) e Windrum e Garcĺa-Goñi (2008) também apontam os órgãos reguladores como influenciadores no processo de inovação, dado que podem incluir ou retirar procedimentos do acesso de cobertura das operadoras. Os autores também destacam que hospitais e centros médicos têm um papel importante no que se refere à implantação, difusão e melhoria destas inovações, e a produção de inovações no setor de saúde requer uma formação universitária sofisticada.

Os fornecedores, em especial a indústrias de equipamentos médico hospitalares, a indústria farmacêutica e indústria biotecnológica também participam intensamente da inovação no setor de saúde, interagindo fortemente com as universidades, dado que fornecem insumos para o setor (CHAVES E ALBUQUERQUE, 2006). Gadelha (2003) destaca a indústria de equipamentos mecânicos, eletrônicos, próteses e órteses, bem como materiais de consumo, presente no complexo industrial da saúde, como uma importante fonte de inovações nas práticas de assistência à saúde.

Conforme Vargas (2006) observou em hospitais, as operadoras de planos de saúde exercem influência no processo de inovação visto que as operadoras exercem forte pressão para a redução dos custos.

Para estudos de inovação em serviços de saúde, é importante mapear os diferentes stakeholders envolvidos (COSTA, 2016). Omachonu e Einspruch (2010), citam cinco atores-chave no processo de inovação em saúde e as suas necessidades específicas, desejos e expectativas, conforme a Tabela 4:

Tabela 4: Atores Chave do Processo de Inovação em Saúde

\begin{tabular}{|c|c|}
\hline $\begin{array}{l}\text { Partes Interessadas / Atores- } \\
\text { Chave }\end{array}$ & Necessidades, vontades e expectativas \\
\hline $\begin{array}{l}\text { Médicos e prestadores de } \\
\text { serviços }\end{array}$ & $\begin{array}{l}\text { Melhoria nos resultados clínicos, melhoria no diagnóstico e no } \\
\text { tratamento. }\end{array}$ \\
\hline Pacientes & $\begin{array}{l}\text { Melhoria na experiência dos pacientes, melhoria no bem-estar } \\
\text { psicológico, redução do tempo de espera, redução dos } \\
\text { atrasos. }\end{array}$ \\
\hline Organizações & $\begin{array}{l}\text { Maior eficiência em operações internas, contenção de custos, } \\
\text { maior produtividade e melhoria nos resultados de qualidade. }\end{array}$ \\
\hline Empresas de Inovação & Rentabilidade, melhoria de resultados. \\
\hline Agências de Regulação & Redução de riscos e melhoria na segurança do paciente. \\
\hline
\end{tabular}

Os médicos e prestadores de serviço buscam melhorias nos resultados clínicos, no diagnóstico e no tratamento. Diversos estudiosos afirmam que é difícil 
mudar o comportamento médico (GRECO; EISBERG, 1993). Também vale ressaltar que o uso de inovações em saúde muitas vezes é regulada por leis, o que torna mais difícil a incorporação das mudanças (FAULKNER; KENT, 2001).

Figura 12: A Conceptual Framework for Innovation in Healthcare

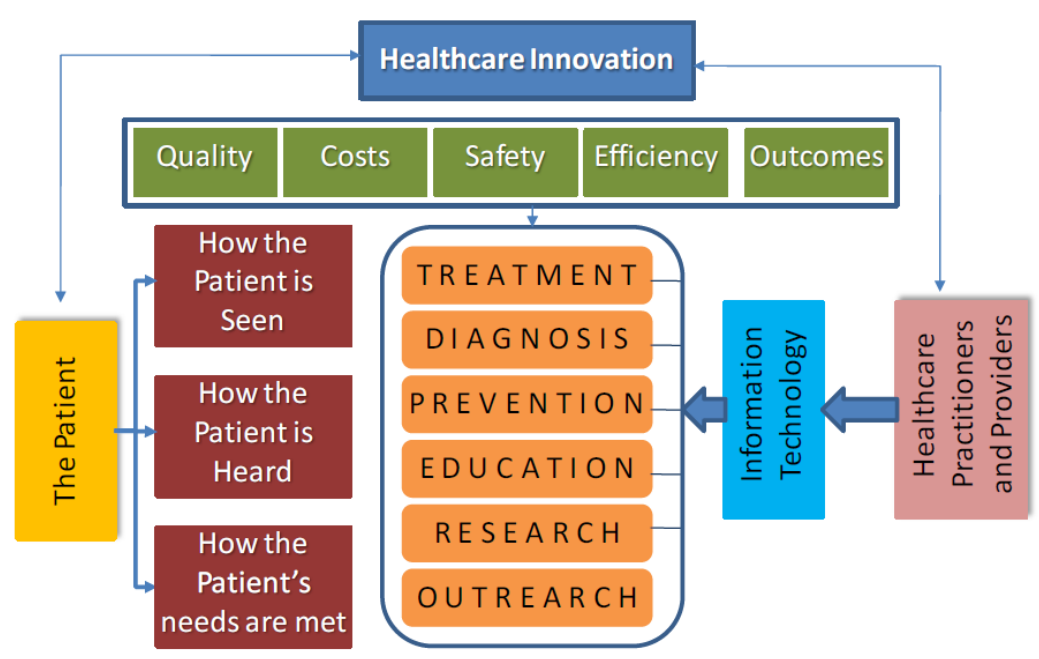

Fonte: Omachonu e Einspruch (2010)

Conforme a Figura 12, as organizações de saúde buscam seis diferentes propósitos - tratamento, diagnóstico, prevenção, educação, pesquisa e acesso. Para atingir esses propósitos as organizações devem gerenciar a qualidade, custos, segurança, eficiência e resultados. No centro da inovação da saúde estão as necessidades dos pacientes e profissionais de saúde, bem como os prestadores. Muito frequentemente as organizações de saúde chegam à inovação baseando-se em tecnologia da informação nova ou existente. Quando bem sucedida, a inovação em saúde se concentra em três áreas: a) como o paciente é visto; b) como o paciente é ouvido; e c) como as necessidades do paciente são atendidas.

Os mesmos autores abordam o processo de inovação de maneira mais ampla conforme a Figura 13: 
Figura 13: O processo de inovação em saúde

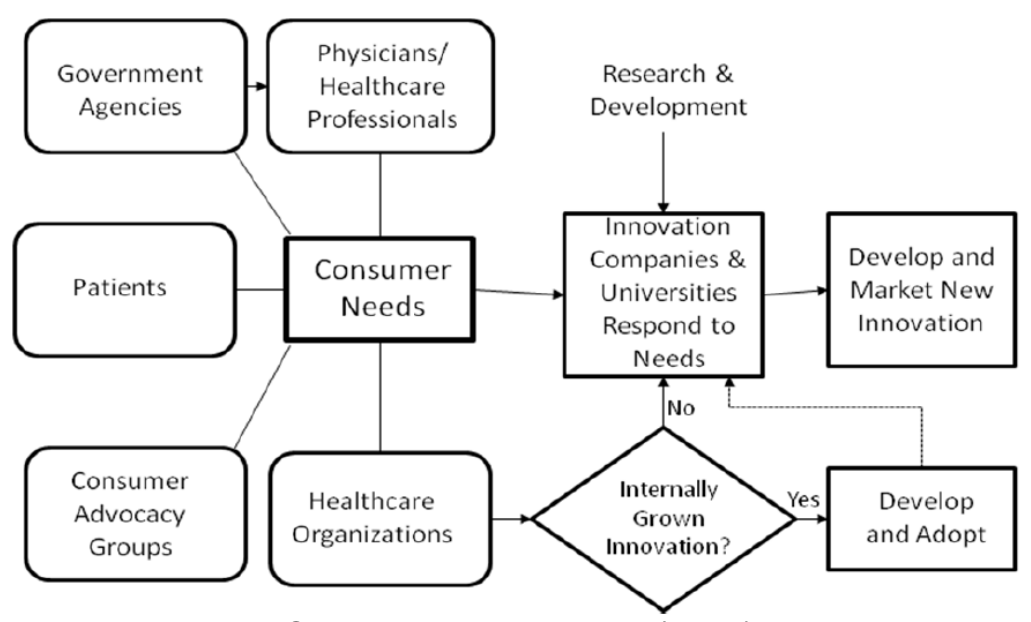

Fonte: Omachonu e Einspruch (2010)

Muitas inovações são iniciadas por atores chave da saúde, como pacientes, agências do governo, médicos e profissionais de saúde, consumidores e organizações de saúde. Em alguns casos estas necessidades são forçadas pelo governo a serem atendidas pelas organizações de saúde, que podem desenvolver internamente uma solução ou contratar uma universidade ou empresa de inovação para desenvolver a solução. Também pode ocorrer da organização de saúde desenvolver a solução imperfeita e a universidade ou empresa de inovação refinar a solução e retornar para a organização de saúde. Curtis e Schulman (2006) apontam que a regulamentação quando se torna rígida, inibe a inovação de ruptura.

\subsection{Modelos de gestão da inovação}

No início do século XX, Joseph Schumpeter propôs a inovação como sendo o diferencial competitivo entre empresas e o motor do crescimento econômico. Desde então, cresceu-se a necessidade de estudar como as empresas organizam suas práticas de inovação com o objetivo de alavancar a sua competitividade.

Baregheh, Rowley e Sambrook (2009), com base na análise de definições da literatura, afirmam que a inovação é um processo de várias etapas através das quais as organizações transformam ideias em produtos novos/melhorados, serviços ou processos, a fim de avançar, competir e se diferenciar com sucesso em seu mercado. 
Montanha Junior et al (2008) entendem que apesar da inovação poder acontecer informalmente, ela deva ocorrer prioritariamente por meio de um processo formal.

Neste sentido, Davila, Epstein e Shelton (2007) também entendem a inovação como um processo que deve ser gerido e definem o processo de inovação como novas ideias que são desenvolvidas e implantadas para atingir resultados desejados, por pessoas que se empenham em transações com outros, para mudar contextos institucionais e organizacionais.

Tidd e Bessant (2015) também entendem a inovação como resultado de um processo, sendo essencial entender suas partes para poder gerenciá-las e influenciar o resultado final.

Desse modo, o conceito de gestão da inovação refere-se a adoção de métodos de gestão robustos e adequados para levar adiante, de forma eficaz e metodológica, os processos de inovação (PANTALEÃO; ANTUNES JÚNIOR; PELLEGRIN; 2007).

Desde os primeiros trabalhos em inovação com Schumpeter até os dias atuais, diversos estudos focaram na representação deste processo de gestão da inovação por meio de modelos. Utterback (1971) foi um dos primeiros autores a tentar representar o processo de inovação. No caso ele abordou as inovações tecnológicas e separou o processo em três etapas: (i) geração de ideias, (ii) solução de problemas e (iii) implantação e difusão.

Roy Rothwell (1994) apresenta uma perspectiva histórica da evolução dos modelos de gestão da inovação em cinco diferentes gerações. A primeira geração se estabeleceu nos anos 50 a 60, sendo caracterizada por modelos de processos lineares, voltados ao P\&D, com pesquisa básica e conhecimento aplicado ao desenvolvimento tecnológico de dentro para fora das empresas, sendo conhecida assim pela abordagem technology-push.

A segunda geração vai entre os anos 60 e 70, e também é caracterizada por modelos lineares, porém o P\&D apresenta uma abordagem direcionada às necessidades do mercado, resultando no modelo chamado demand pull.

A terceira geração foi chamada de modelo acoplado ou em inglês coupling model, presente nos anos 70 a 80 , e reconheciam a integração dos dois modelos anteriores, ou seja, o modelo de terceira geração é um acoplamento que apresenta tanto a influência de capacidades tecnológicas como também as necessidades do mercado. Ainda neste modelo, começa a surgir interfaces entre as áreas internas da 
empresa com agentes externos, como por exemplo a comunidade científica, reconhecendo a interação entre eles e os constantes feedbacks entre os elos.

A quarta geração foi dos anos 80 a 90, quando as empresas começam a dar ênfase nos seus relacionamentos externos, por meio de alianças estratégicas, e envolvimento de fornecedores no processo de inovação, sendo este mais complexo, não linear e interativo. A indústria japonesa competia forte no mercado global e trazia consigo as características de integração e paralelismo, marcantes nesta geração. Por fim, os modelos de quinta geração tiveram início na década de 90 e são caracterizados pela integração de sistemas e networking amplo, preocupação com tempo de lançamento rápido de produtos, integração de produto e produção, maior regulamentação dos governos e alianças internacionais.

Silva, Bagno e Salerno (2014) em seu trabalho de revisão da literatura sobre modelos de gestão da inovação agrupam os modelos conforme suas características e contribuições dominantes em:

1) Modelos processuais, focados no desenvolvimento de produtos;

2) Modelos construídos sob a lógica do funil;

3) Modelos voltados ao processo total de gestão da inovação;

4) Modelos focados na integração entre elementos organizacionais;

5) Modelos híbridos;

De modo geral, apesar das particularidades de cada modelo, Silva, Bagno e Salerno (2015) afirmam ser possível identificar uma estrutura geral do processo baseada na sequência: geração de ideias, seleção, desenvolvimento e difusão. Este processo básico pode apresentar variação no nome de cada etapa, e na consolidação ou separação entre elas. Por exemplo, Hansen e Birkinshaw (2007) resumem esta estrutura básica em ideação (geração de ideias), conversão (seleção e desenvolvimento) e difusão.

Tidd e Bessant (2015) enfatizam que este modelo básico é aplicável também em serviços. O que é desenvolvido pode ser menos tangível do que um produto manufaturado, mas a estrutura fundamental do processo é a mesma.

Neste sentido, Silva, Bagno e Salerno (2014) em seu trabalho de revisão bibliográfica relatam um ponto relevante: apesar da predominância de modelos voltados ao desenvolvimento de inovações tecnológicas e de produtos, há vários modelos aderentes à serviços como os modelos de Wheelwright e Clark (1992), Goffin e Mitchell (2005), e Hansen e Birkinshaw (2007) entre outros. 
O modelo do funil da inovação Wheelwright e Clark (1992), foi o primeiro na lógica de relacionar um funil com o processo de inovação. Iniciando com uma gama de ideias (entradas) e gradualmente filtrando e selecionando, de modo que de diversas ideias de produtos e processos, somente uma pequena parte realmente entra em desenvolvimento. Desse modo, os autores oferecem um modelo visual para o processo de desenvolvimento de novos produtos e processos, conforme a Figura 6, desde a geração de ideias até a introdução no mercado.

Este modelo de inovação é representado na figura 14 pelas atividades: Avaliação e Previsão da Tecnologia, Avaliação e Previsão do Mercado Desenvolvimento de Objetivos e Metas, Plano Agregado de Projetos, Gestão de Projetos e Execução. Este modelo também considera as estratégias tecnológicas e de produto/mercado como direcionadores ao longo de todo o processo, devendo ser considerado em cada fase de avaliação.

Figura 14: Modelo do Funil da Inovação de Wheelwright e Clark

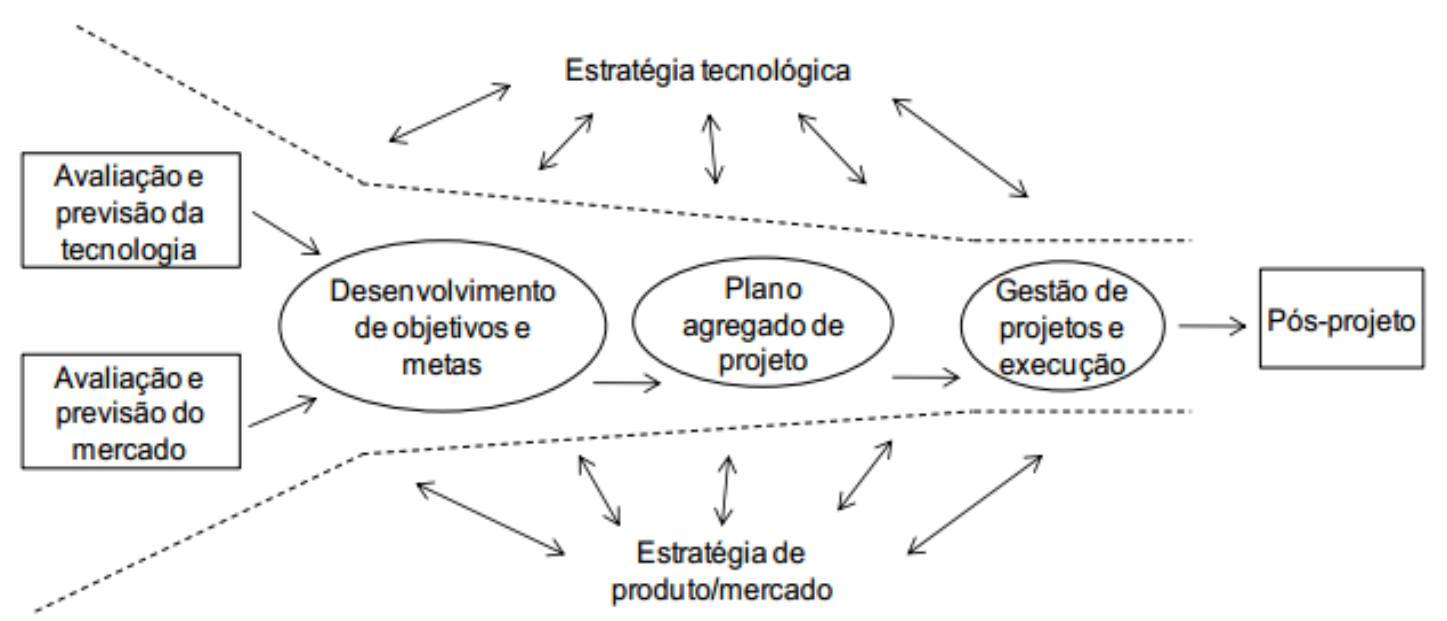

Fonte: Wheelwright e Clark (1992)

Os autores não detalham as características das duas primeiras fases iniciais pois relatam que estas duas primeiras fases ocorrem em paralelo e são comuns à maioria dos modelos. Logo justificam que o maior trabalho está nas duas fases seguintes.

A fase de "desenvolvimento de objetivos e metas", tem por objetivo alinhar as estratégias de tecnologias e produto/mercado com os objetivos estratégicos do negócio. Este alinhamento passa pela definição inicial de metas e objetivos que devem ser alcançados no desenvolvimento. A avaliação do market share, retorno financeiro esperado, e do timing de novas tecnologias aplicadas e plataformas, 
direcionam para o alcance destes objetivos e metas. Podemos citar como exemplos de dimensões de desempenho o time-to-market, a produtividade e a qualidade.

Já na etapa do "plano agregado de projeto", deve-se garantir que o portfólio de projetos irá entregar os objetivos e metas apontados na fase anterior, além de avaliar e garantir as competências organizacionais necessárias para obter o sucesso no desenvolvimento dos projetos. Cabe a esta fase classificar os tipos de projetos; avaliar os recursos críticos e o tempo para cada tipo de projeto; avaliar os recursos disponíveis e os necessários; priorizar os novos projetos em função do tipo e dos objetivos futuros; avaliar a capacidade de desenvolvimento dos novos projetos priorizados; determinar mudanças de escopo nos projetos selecionados para aumentar a probabilidade de sucesso; e determinar e integrar no plano de projeto as mudanças requeridas para melhorias no desempenho do desenvolvimento ao longo do tempo.

Por fim temos a gestão de projetos em execução, que nada mais é do que pôr as melhores práticas na condução destes projetos.

Uma proposta baseada no funil da inovação Wheelwright e Clark (1992) foi feita por Docherty (2006), onde o autor apresenta o modelo tradicional do funil com o conceito de open innovation, popularizado por Chesbrough (2003). Deste modo, o processo de inovação não tem uma entrada nem uma saída definida, mas múltiplas entradas e saídas ao longo do funil. Essas entradas podem ocorrer por meio de licenciamentos, patentes, escalonamento de produtos, desenvolvimento externo entre outros. Neste modelo, o processo não se comporta de maneira contínua e restritiva, gerando oportunidades de entrada e saída em cada estágio.

O modelo stage gates de Cooper (1990) é um modelo conceitual e operacional para projetos desde a ideia até o lançamento. Apesar de ter surgido na indústria de manufatura, o modelo sofreu evoluções e detalhamentos que, segundo o autor, está sendo amplamente utilizado em organizações prestadoras de serviços. Neste sentido, Cooper e Edgett (1999) publicaram um livro sobre o modelo stage gates focado apenas em serviços.

Conforme apresentado na Figura 15, o modelo apresenta uma sequência de estágios e momentos de avaliação ou aprovação. 
Figura 15: Modelo stage gates de Cooper

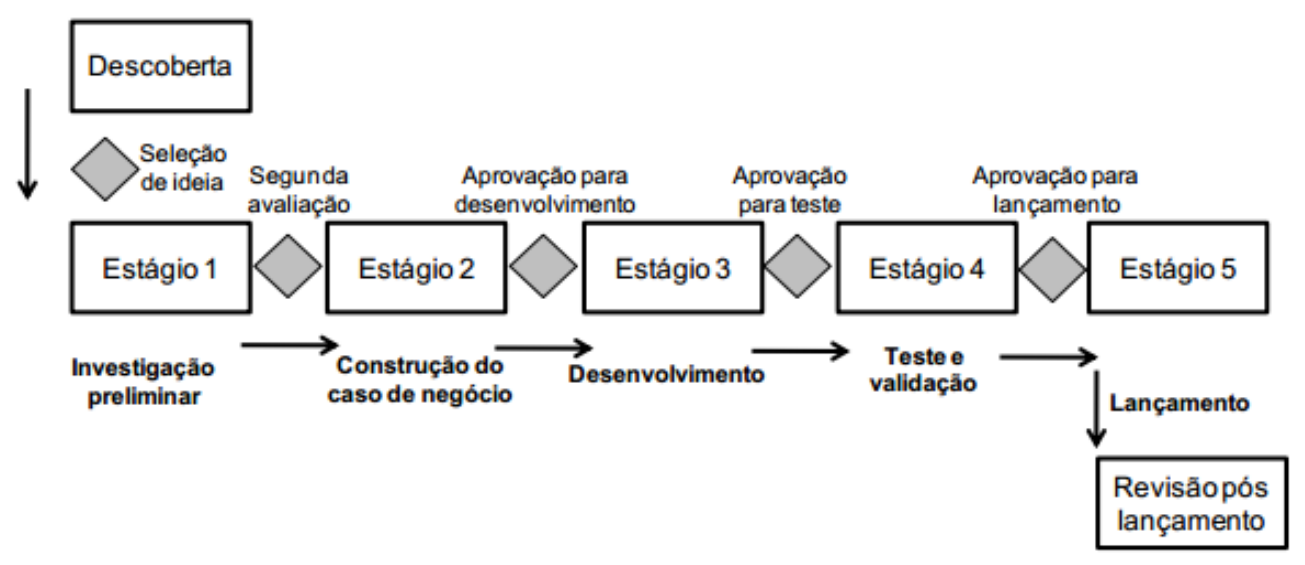

Fonte: Cooper (1990)

No modelo de Cooper (1990), encontramos cinco estágios: Investigação Preliminar; Construção do caso de Negócio; Desenvolvimento; Teste e Validação; e Lançamento. Para cada estágio há um gate de avaliação. Se por um lado os estágios definem as melhores práticas, os gates auxiliam a tomada de decisão.

Há também o Estágio de Descoberta, para auxiliar o processo de geração de ideias. Nesta fase temos o processo de captura de novas ideias. Lá estão envolvidas as atividades de pesquisas técnicas, novas tecnologias, análise de necessidades dos clientes, pesquisas de mercado, entre outras, tudo com o objetivo final de gerar novas oportunidades. Diversas técnicas podem ser utilizadas, desde brainstorming, visita a fornecedores, pesquisa focus group com clientes, observar clientes, realizar workshops com as áreas técnicas, aplicar surveys entre outras. Tendo a ideia, o próximo passo é submetê-la para um banco de ideias, por meio de formulários eletrônicos ou mesmo de papel, por exemplo. Este processo de submissão deve ser simples e fácil.

No primeiro gate temos a seleção da ideia, por meio de uma avaliação macro, se esta atinge um mínimo de critérios. Esta etapa não deve dispender muito tempo e recurso. Os critérios aplicados nesse primeiro gate incluem o alinhamento com a estratégia de negócio, e a visão inicial sobre a viabilidade técnica. O objetivo é eliminar as ideias que claramente não apresentam um potencial mínimo. Nesta etapa um ranking com critérios e notas resultando em um escore pode ser feito para priorizar os projetos.

Em seguida temos o primeiro estágio de "investigação preliminar" que objetiva identificar as características de mercado e técnicas do projeto de uma maneira macro, 
rápida e simples. A ideia é definir fatores básicos como tamanho de mercado, aceitação do público alvo, potencial comercial, e investigação técnica. Desse modo, podem ser feitas pesquisas e entrevistas com clientes, por meio de focus group e testes de conceito. Já a avaliação técnica, visa levantar os possíveis custos operacionais e as competências técnicas. Também busca identificar os riscos técnicos, legais e regulatórios. Essas informações facilitam a próxima etapa onde são realizadas as avaliações financeiras e de negócios. O segundo gate ocorre semelhante ao primeiro mas com maior rigor, pois já se tem informações relevantes sobre a viabilidade do projeto. Um diferencial desse gate é a utilização de análise financeira e de riscos do projeto como critérios.

No segundo estágio de "construção do caso de negócio", é realizada uma investigação detalhada sobre a aceitação do serviço. Informações como mercado alvo, visão do conceito (requisitos e especificações iniciais do serviço) e posicionamento estratégico. Detalhes de custos, volume, receita, recursos necessários além do tempo de desenvolvimento, são aprofundados com precisão em torno de $90 \%$ da realidade. Estudos financeiros são realizados. Então ocorre o terceiro gate, onde o foco são os resultados financeiros, e normalmente a aprovação ocorre no nível sênior da organização. Ao final do gate, é proposto um plano de ação e recursos são alocados ao projeto.

No terceiro estágio de desenvolvimento, com o plano previamente aprovado inicia-se o desenvolvimento do serviço, toda a parte operacional, sem deixar de monitorar a situação externa de mercado e aceitação positiva. É então desenvolvido o plano de testes a ser aplicado na próxima etapa. Ações do plano de marketing, treinamentos, vendas, operações e qualidade são refinados. Dados financeiros são atualizados, e a entrega final é um serviço internamente testado, financeiramente revisado e todos os estágios subsequentes planejados. Ocorre o quarto gate que aprova os resultados do desenvolvimento e marca as atividades comerciais, iniciando seu teste com consumidores.

Em seguida inicia-se o quarto estágio com o teste de conceito para avaliar a aceitação do novo serviço. Testes na produção são realizados, bem como testes de preço e aceitação. Dados financeiros são atualizados.

Ocorre o quinto gate, sendo crítico, pois é a decisão do lançamento. Portanto, se avaliará os resultados dos testes. 
A quinta etapa é o "lançamento" com os planos de marketing, operações e qualidade finalizados. Planos de vendas, riscos, treinamentos são implantados. O monitoramento e preparo do pós lançamento são feitos.

O último check point é a revisão pós lançamento. Esta fase ocorre após a implementação do lançamento estar completa e rodando naturalmente. O foco desta etapa é levantar as lições aprendidas e os resultados alcançados. Comparações com as projeções são feitas, como custos, receitas, margens, tempos.

Partindo de uma analogia de que a gestão da inovação é como uma corrida de maratona, que precisa de atenção constante e visão de longo prazo, Goffin e Mitchell (2005) fazem uma comparação da gestão da inovação com um pentathlon, onde se deve buscar a alta performance em cada etapa que o compõem. Desse modo, os autores apresentam o Pentathlon da Inovação conforme mostrado na figura 16. Como o nome sugere, o modelo identifica cinco áreas ou elementos da gestão da inovação, e ter boa performance em cada uma dessas cinco áreas é essencial.

Figura 16: Modelo Pentathlon da Inovação de Goffin e Mitchell

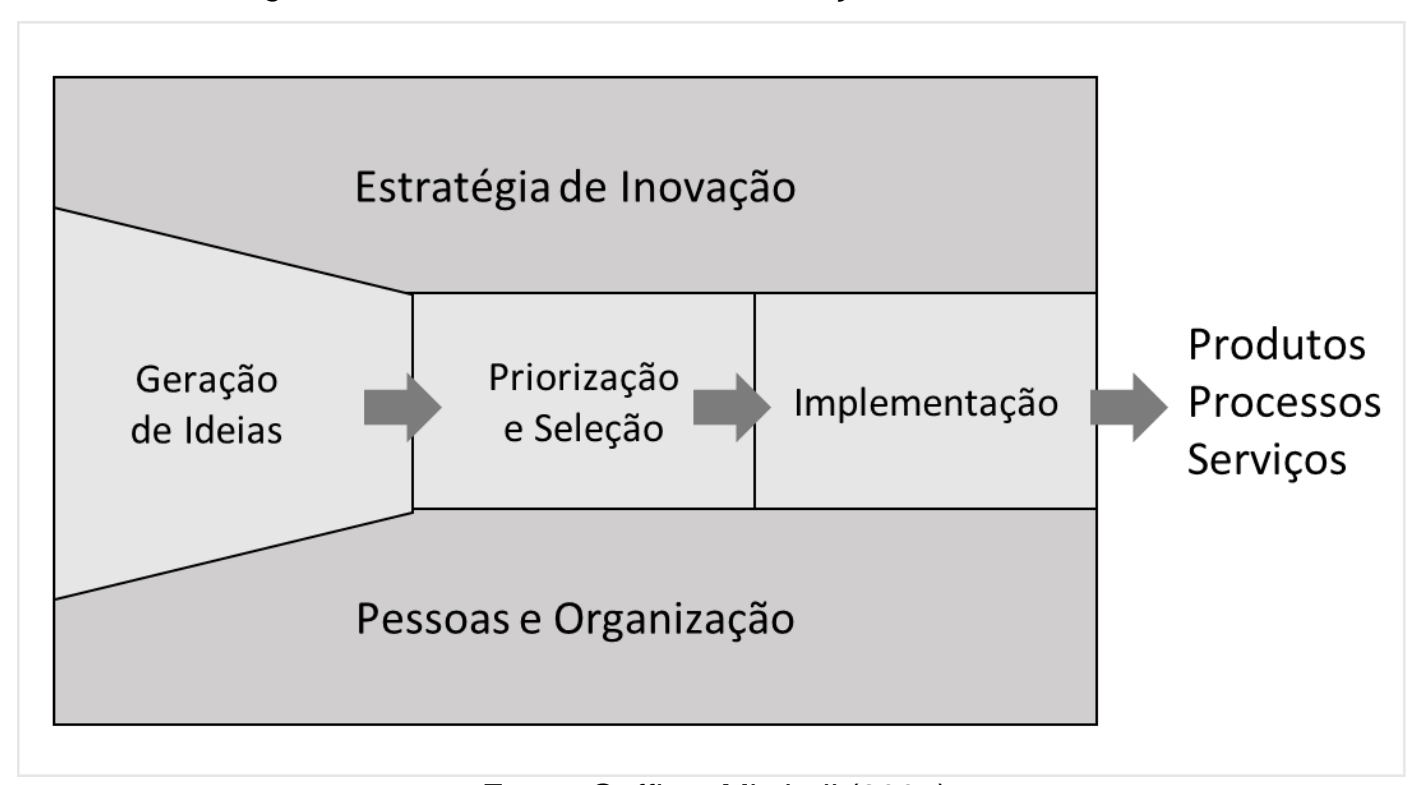

Fonte: Goffin e Mitchell (2005)

De modo geral, os autores incluem no funil da inovação de Clark e Wheelwright (1992) dois elementos extras considerados chave para o processo de inovação - a estratégia de inovação e pessoas e organização. Essas inclusões são necessárias dado que os autores perceberam em pesquisas realizadas, a importância da interação dos projetos com a estratégia como um todo, bem como o suporte dos diferentes níveis de inovação por meio da gestão de pessoas. 
A estratégia de inovação deve permear todo o processo. Ela aponta para onde a companhia deve ir em termos de inovação. Questões como mapeamento de tendências, oportunidades, tecnologias e como obtém expertise para inovar são consideradas nesta etapa. Tidd e Bessant (2015) apontam técnicas uteis para explorar o futuro que a companhia deve seguir: pesquisa de consumidor e mercado; geração de ideias (brainstorm); método delphi ou opinião de especialistas; e desenvolvimento de cenários. O direcionamento é dado a todas as outras etapas, garantindo que os processos estejam alinhados com a estratégia de inovação. É preciso haver alinhamento da estratégia de inovação com a estratégia da empresa (DAVILA; EPSTEIN; SHELTON, 2007)

Análise estratégica de fatores externos como o mercado, movimento de competidores, mudanças das tendências tecnológicas, mudanças nos hábitos e necessidades dos clientes, mudanças no ambiente de negócios, bem como os fatores internos como as marcas e linhas de negócio que a empresa quer crescer, influenciam na definição da estratégia de inovação (DAVILA; EPSTEIN; SHELTON, 2007; GOFFIN; MITCHEL, 2005; TIDD; BESSANT, 2015).

A geração de ideias é onde surgem as ideias em um ambiente organizacional que suporta a criatividade individual e em equipe, tanto dentro como fora da organização com atores internos e externos. Para gerar ideias, diversas técnicas podem ser utilizadas, como brainstorming, $5 \mathrm{~W} 2 \mathrm{H}$, surveys, focus group, observação, entrevistas, patentes entre outras.

A priorização e seleção é a busca em garantir que as melhores ideias são escolhidas para serem desenvolvidas e implementadas. Requer o uso de ferramentas de análise de risco e retornos financeiros por exemplo. Neste momento também se avalia todo o portfólio de ideias, checando se as ideias que estão sendo selecionadas estão alinhadas com a estratégia de inovação. Diferentes métodos de avaliação podem ser utilizados, desde métodos de avaliação mais simples como dar pesos e notas a determinadas variáveis e chegar a uma pontuação, até métodos mais complexos como simulação de Monte-Carlo. Avaliações técnicas e comerciais também são podem ser consideradas nesta etapa.

A implementação deve focar em desenvolver de forma rápida e eficiente novos, serviços e processos ou a combinação destes. Nesta etapa estão os times cross funcionais, os testes e pilotos. Comercialização é a última etapa da implementação e é acompanhada com o lançamento no mercado. 
Pessoas e organização estão relacionadas a como a companhia gerencia seus recursos humanos, e isso inclui as políticas de contratação e treinamento, estruturas organizacionais que facilitam a inovação. Além disso a cultura dos colaboradores também faz parte desta etapa. A cultura corresponde a regras não escritas, crenças compartilhadas e modelos mentais das pessoas que afetam a inovação. Uma cultura que motiva a inovação é fundamental. Programas de reconhecimento e premiação fazem parte de um processo de inovação. Seki et al (2003) apontam que a cultura de inovação dos valores deve concentrar-se nos recursos humanos, incluindo processos de seleção e recrutamento, treinamentos periódicos da equipe e métodos adequados de avaliação. Davila, Epstein e Shelton (2007) destacam que a inovação não inclui apenas processos e ferramentas de stage gate. Apesar de reconhecerem a importância dos processos, eles devem funcionar em conjunto com um sistema de incentivo de modo a transformar planos em realidade.

Para incentivar a inovação, a organização precisa atrair e contratar pessoas que sejam inovadoras. Algumas pessoas podem ser naturalmente mais inovadoras que outras, mas mesmo assim, deve-se as inserir em um ambiente inovador, com uma cultura de inovação, para então extrair sua total capacidade de inovação. (DAVILA, EPSTEIN, SHELTON, 2007). Goffin e Mitchel (2005) ainda citam além dos benefícios financeiros diretos, como aumentos salariais, pagamentos etc, mas também treinamentos e cursos educacionais. Os autores também citam o reconhecimento também como um importante aspecto motivacional no processo de inovação, como por exemplo o reconhecimento em público do funcionário, a elaboração de certificados, placas de agradecimento etc.

A performance da inovação também é influenciada pelo recrutamento, manutenção e desenvolvimento do colaborador. É essencial trazer pessoas que possam trazer mais inovação para a empresa, e para isso os critérios de seleção devem levar em consideração as competências ou valores de inovação que aquela pessoa carrega. Testes psicométricos devem ser aplicados com o objetivo de identificar se o candidato é ou não um inovador. Não somente habilidades técnicas, e conhecimento do mercado devem ser testados, mas também sua capacidade de se sociabilizar em times cross funcionais. É importante o candidato ter um bom relacionamento com pares e gestores.

A cultura equivale aos padrões de valores, crenças e normas aceitas que orienta os comportamentos de determinado grupo (TIDD, BESSANT 2015). Portanto 
quando se fala em cultura da inovação, são os valores arraigados nas pessoas que direcionam seu comportamento para praticar a inovação. A formação da cultura passa por símbolos, histórias, rituais, entre outros fatores (GOFFIN; MITCHELL, 2005). Faz parte da cultura as histórias que circulam ao longo da organização, ilustrando manifestações extremas dos valores da organização. Os protagonistas são transformados em heróis e são exemplos a serem seguidos. (DAVILA, EPSTEIN, SHELTON, 2007)

\section{O Modelo da Cadeia de Valor da Inovação de Hansen e Birkinshaw (2007)} considera que a inovação deve ser um processo integrado, compreendendo três fases principais: geração de ideias, conversão e difusão. O modelo conforme mostra a figura 17 proporciona uma visão de onde os esforços de inovação estão sendo empregados, fortalecendo cada fase ou elo da cadeia. A capacidade de inovar será tão boa quanto o elo mais fraco da cadeia.

Figura 17: O modelo da Cadeia de Inovação de Hansen e Birkinshaw

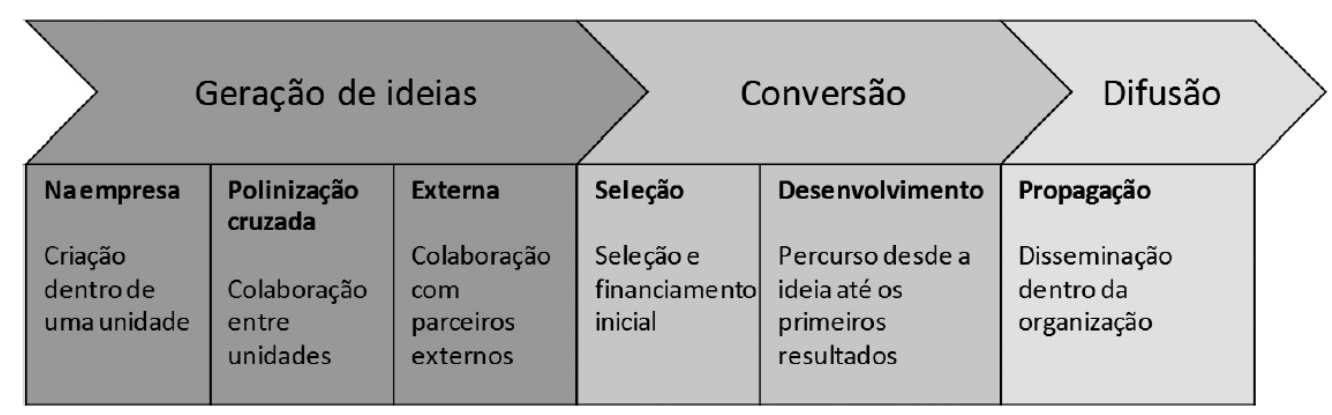

Fonte: Hansen e Birkinshaw (2007)

A primeira etapa é a fase de ideação, onde o foco é a geração de ideias que podem surgir internamente, dentro da unidade de negócio ou entre as unidades, e externamente com universidade, fornecedores, clientes etc.

A segunda etapa é a fase de conversão, e envolve a seleção e o desenvolvimento da ideia. A seleção se refere aos processos de avaliação e escolha, bem como os mecanismos de financiamento das ideias. $O$ desenvolvimento é 0 percurso desde a ideia até os primeiros resultados. São todos os processos envolvidos na concretização da ideia em realidade, gerando valor para a companhia.

Por fim, temos a última etapa que é a difusão do produto. A companhia deve difundir suas inovações não somente no mercado mas também internamente. A velocidade de difusão no meio externo e interno também deve ser considerada. 
Competidores podem copiar rapidamente uma inovação e difundi-la a uma velocidade mais rápida no mercado, caso o elo da difusão seja fraco.

De modo geral, o modelo ressalta que a empresa pode apresentar elos mais fortes e outros mais fracos. Pode ser uma excelente geradora de ideias e não ser tão boa assim na etapa de difusão. Neste sentido, Hansen e Birkinshaw (2007) propõem a partir de uma visão expandida da cadeia, uma avaliação sobre suas forças e fraquezas, gerando aprendizado contínuo e conhecimento, e melhorando seu processo de inovação.

Muito tem sido escrito sobre modelos e processos de inovação. No entanto, há pouca informação sobre o processo de inovação no setor de saúde. (OMACHONU; EINSPRUCH, 2010; VARKEY; HORNE; BENNET, 2008).

No entanto, Varkey, Horne, Bennet (2008) apresentam um modelo de gestão da inovação para serviços de saúde com 8 elementos conforme a Figura 18.

Figura 18: O modelo de processo de inovação de Varkey, Horne, Bennet

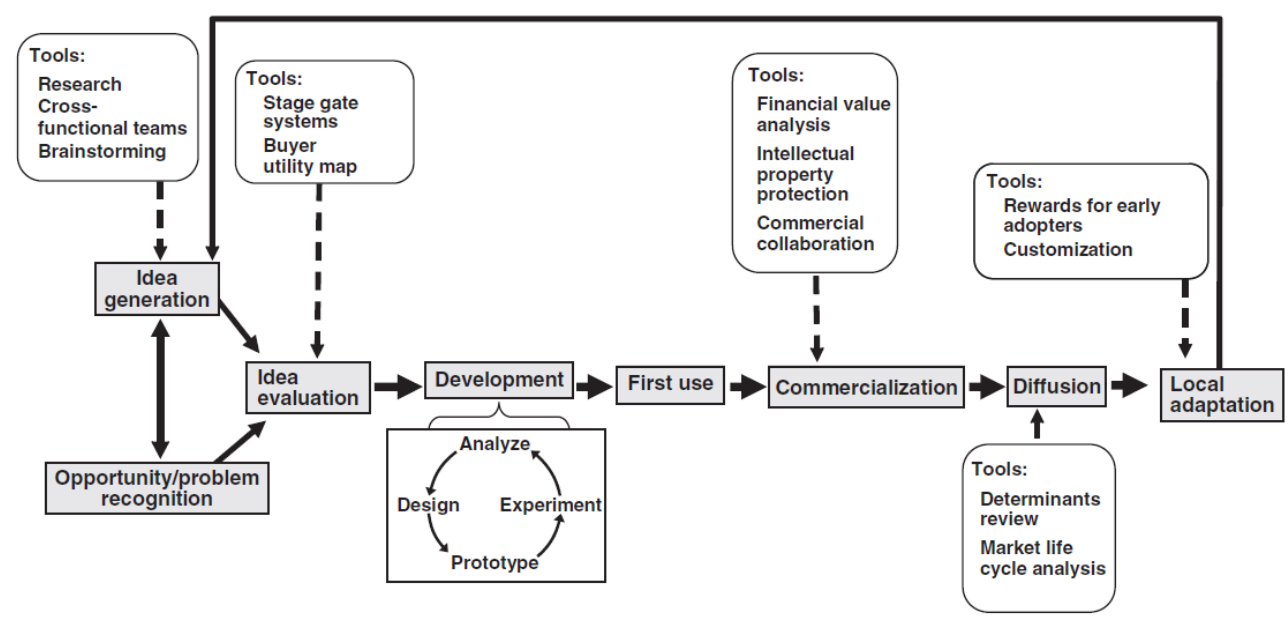

Fonte: Varkey, Horne, Bennet (2008)

A primeira etapa é a de geração de ideias, identificação de problemas e reconhecimento de oportunidades.

A geração de ideias inclui pesquisas acadêmicas (não limitadas ao setor de saúde), pesquisas ou entrevistas com stakeholders, e seções de brainstorming. Também é possível que oportunidades e problemas identificados sejam reconhecidos e que soluções podem iniciar o processo diretamente, sem uma etapa formal de geração de ideias. O objetivo do reconhecimento de oportunidades é identificar ideias que tenham um bom potencial de negócios e valor para o cliente. Uma variedade de empresas usam estruturas organizacionais como ferramentas para melhorar a 
geração de ideias. Estas incluem a criação de equipes multifuncionais (por exemplo, redes de inovação, centros de ideias, oficina de ideias etc) separados das pressões do dia dia.

Em seguida temos a etapa de Avaliação de ideias. As organizações podem ter mais ideias inovadoras do que recursos, e precisarão avaliar suas ideias. O sistema de stage gate, outro instrumento de avaliação, também pode ser muito eficaz na avaliação das ideias.

Logo após se inicia a fase de desenvolvimento. O processo de desenvolvimento leva as poucas ideias que foram criadas e controladas pelos participantes de brainstorming e passa através dos estágios de projeto, prototipagem, experimentação e análise em um processo iterativo. Em última análise, o processo culmina com a entrega de um produto, sistema ou dispositivo que cumpra a visão dos usuários e atenda aos requisitos do projeto. Protótipos são usados para comunicar parâmetros de design com a ideia inicial. O protótipo permite que os riscos sejam tomados, porque o tempo e os recursos consumidos são muitas ordens de magnitude menor do que será necessário para criar uma solução de qualidade comercial.

$\mathrm{Na}$ sequência, ocorre o primeiro uso que difere da prototipagem pois é a implementação inicial da ideia de uma forma padronizado, repetível e projetado para capturar o valor previsto para a inovação. Em saúde, o primeiro usuário pode ser um dos colaboradores da inovação. Deve-se esperar a primeira utilização para então propor modificações.

Continuando o processo, entramos na etapa de comercialização, que envolve a incorporação da inovação ao mercado. A inovação também pode ser patenteada ou protegida, e a empresa pode obter ganhos ao licenciar ou comercializar a inovação para outras empresas.

Por fim, chegamos na etapa de difusão, que é como a inovação se espalha por toda a cadeia. Antes da comercialização, um inovador deve avaliar a inovação para garantir que a oportunidade para a difusão bem-sucedida é maximizada.

\subsection{Considerações sobre o material pesquisado}

A revisão da literatura iniciou no capítulo 2, e mostrou que o setor de saúde é um setor com elevada complexidade de gestão e demanda estudos (CHRISTENSEN; GROSSMAN; HWANG, 2009; PORTER; TEISBERG, 2007; WINDRUM, GARCÍA- 
GOÑI, 2008). Essa complexidade se dá por uma série de particularidades apontadas por Pedroso (2016), como 1) o escopo amplo da saúde, 2) a visão do consumo na saúde como investimento, 3) o alto impacto que os produtos e serviços de saúde têm na vida das pessoas, 4) a relevância social da saúde, 5) a relevância econômica, 6) a cadeia de valor fragmentada.

Ao entrarmos nos dados de mercado, em 2014 o sistema de saúde brasileiro teve uma despesa equivalente a $10,1 \%$ do produto interno bruto, ou $R \$ 557$ bilhões (IESS, 2016), sendo comparado aos percentuais gastos em países desenvolvidos como França e Alemanha.

Cerca de $50 \%$ deste gasto é proveniente do Sistema de Saúde Suplementar, ou sistema privado, que cobre $25,4 \%$ da população (ANS, 2015).

A cadeia de valor da Saúde (PEDROSO; MALIK, 2012) envolve diversos elos que vão desde o desenvolvimento de conhecimentos em saúde, em universidades e centros de pesquisa por exemplo, passando por toda a cadeia, e chegando ao consumidor final. Nesta cadeia o fluxo de inovação e conhecimento é crítico para o desempenho da cadeia e a inovação tecnológica é considerada um dos principais fatores responsáveis pelo incremento de custos médicos. Os investimentos de inovação neste setor são considerados elevados e propagam de maneira lenta e deficiente (PEDROSO; MALIK, 2012). Burns et al (2002) também apontam o fluxo de inovação como crítico no sistema, destacando os médicos e hospitais como elementos determinantes na utilização das inovações.

A revisão bibliográfica no capítulo 3 também mostrou a relevância do setor de Medicina Diagnóstica, onde apesar de $72 \%$ dos estabelecimentos de medicina diagnóstica serem particulares, $40 \%$ destes realizam atendimento SUS.

Ao olharmos os custos com a saúde suplementar, o segundo maior gasto é com os exames complementares, representando $21 \%$ das despesas totais, ou 25 bilhões de reais em 2015 (ANS, 2015), com tendência de crescimento conforme Campana, Oplustil e Faro (2011).

Conforme Pedroso (2016), a cadeia de valor de medicina diagnóstica é composta por seis elos que unem as atividades desde o fornecimento de equipamentos, tecnologias e insumos, passando pelos serviços de medicina diagnóstica, atendimento, intermediação financeira, financiamento, até a chegada ao consumo final. 
O serviço de medicina diagnóstica engloba as atividades de laboratório clínico, também chamado de medicina laboratorial; medicina por imagem, que engloba a radiologia, ultrassonografia, tomografia, ressonância magnética, medicina nuclear, endoscopia, cardiologia, e outras especialidades médicas.

Conforme Knottnerus, Van Weels e Muris (2002) o objetivo da medicina diagnóstica é detectar ou excluir doenças, bem como avaliar prognóstico, monitorar um tratamento médico adotado e fornecer subsídios que possibilitem uma avaliação do estado geral de saúde de um paciente.

Os produtos ou serviços de medicina diagnóstica se segmentam em análises clínicas, anatomia patológica, e radiologia ou exame de imagem (AURIEMO; ROSENFELD, 2006; CAMPANA; FARO; GOZALEZ, 2009; PEDROSO, 2016). No final, o output do produto de um serviço de medicina diagnóstica é a informação materializada no laudo do exame (BECKER, 2004; CAMPANA; FARO; GONZALEZ, 2009). Esta informação do laudo do exame é de extrema importância dado que mais de $70 \%$ das decisões médicas estão apoiadas em informações provenientes da medicina diagnóstica (FORSMAN, 1996; AURIEMO; ROSENFELD, 2006; CAMPANA; OPLUSTIL; GONZALEZ, 2011).

Nos serviços de medicina diagnóstica há a parte relacional refletida nos processos de atendimento, que resultam em uma experiência ao cliente de medicina diagnóstica (PEDROSO, 2016). Estas etapas ocorrem mesmo antes do atendimento nas unidades, quando o cliente liga para agendar um exame, e seguem mesmo depois do atendimento, quando o cliente recebe os laudos. Além do cliente final, médicos e operadoras também participam da experiência, e são os principais clientes em medicina diagnóstica (PEDROSO, 2016). A percepção de qualidade por parte dos clientes está cada vez mais atenta ao local de atendimento (SEKI et al, 2003)

No capítulo 4, abordou-se os temas de gestão da inovação.

O conceito de inovação adotado nesta pesquisa parte da definição de Varkey, Horne e Bennet (2008) na qual inovação é a implementação bem-sucedida de uma ideia nova, de forma que cria valor convincente para alguns ou todos os stakeholders. Essa definição foi considerada simples e clara além de tornar ampla as possibilidades de inovação. Esta visão de pôr em prática (implantar) a descoberta (nova ideia) e capturar valor por meio dela também é mencionada por Drucker (2003), Tidd e Bessant (2015) e Utterback (1996). Portanto, esta definição também reflete a visão destes autores. 
A importância da inovação considerada neste estudo parte da proposta de Schumpeter (1982) ao afirmar que a busca pelo novo é o que mantém o movimento do sistema econômico. Davila, Epstein e Shelton (2007) destacam que a longo prazo, o único fator realmente capaz de garantir o futuro de qualquer empresa é sua capacidade de inovar melhor e de forma mais contínua por mais tempo que as concorrentes. Neste sentido, a inovação se posiciona como a principal solução estratégica para que as empresas tenham forças em competir nos mercados atuais e avançar em novos mercados (DRUCKER, 2003; PROENÇA et al, 2015; TIDD; BESSANT, 2015).

Quanto às classificações do tipo de inovação, foram apresentadas as classificações do Manual de Oslo (OCDE, 2004), de Tidd e Bessant (2015) e de Varkey, Horne e Bennet (2008). Optou-se por adotar a classificação de Varkey, Horne e Bennet (2008) que é voltada aos serviços de saúde. Nesta definição as inovações em saúde podem ser do tipo produto ou serviço, processo ou estrutura. Inovação de produto é o bem ou serviço novo que o consumidor está efetivamente pagando. Inovação de processos implica na inovação do método de produção ou de entrega do produto. E por fim, inovação de estrutura é tudo aquilo que afeta a estrutura interna ou externa da companhia, e cria um novo modelo de negócios. Em relação ao grau ou intensidade da mudança de inovação, adotou-se a classificação de inovação incremental (ou não disruptiva) e inovação radical (de ruptura, disruptiva) (FREEMAN; PEREZ, 1988; CHRISTENSEN; BOHMER; KENAGY, 2000; SCHUMPETER, 1982, TIDD; BESSANT, 2015; UTTERBACK, 1996).

Sob o aspecto de como acontece a inovação, na visão de Dosi (1982), as mudanças tecnológicas podem ocorrer de maneira "puxada" pelas necessidades do consumidor e do mercado, como também podem ocorrer de maneira "empurrada" por meio das atividades de pesquisa e desenvolvimento da empresa.

O conceito adotado de gestão da inovação é a adoção de métodos de gestão robustos e adequados para levar adiante, de forma eficaz e metodológica, os processos de inovação (PANTALEÃO; ANTUNES JÚNIOR; PELLEGRIN; 2007). Esta visão também vai ao encontro com a de Tidd e Bessant (2015) que entendem a inovação como resultado de um processo, sendo essencial entender suas partes e poder gerenciá-las e influenciar o resultado final.

Dentre os diversos modelos de gestão da inovação encontrados na literatura, focou-se naqueles que apresentam em sua composição a estrutura geral do processo 
(ideação, conversão, difusão), sendo esta também aplicada a serviços (TIDD; BESSANT, 2015), e aqueles modelos voltados ao processo total de gestão da inovação (maior nível de abstração e não centrados em P\&D). Silva, Bagno e Salerno (2015), apontam que os modelos de Clark e Wheelwright (1992), Goffin e Mitchell (2005) e Hansen e Birkinshaw (2007) são considerados pelos autores aderentes a serviços. O modelo de Cooper (1990) também foi considerado aderente a serviços conforme Cooper e Edgett (1999).

a) Stage-Gate, proposto por Cooper (1990) e aplicado a serviços por Cooper e Edgett (1999) - Apesar da boa estrutura e detalhe de cada etapa, o modelo não contempla outros elementos externos ao processo, como estratégia, pessoas, organização, cultura etc. Também não contempla a fase de difusão interna das inovações.

b) Funil de Desenvolvimento de Produtos, proposto por Wheelwright e Clark (1992) - focado nas atividades de desenvolvimento de produtos, não contempla etapas de pré e pós desenvolvimento, nem considera a interação com outros atores no processo de inovação. No entanto a orientação estratégica presente no processo é um fator relevante.

c) Penthatlon Framework, proposto por Goffin e Mitchell (2005) - Considera o processo tradicional como central e inclui elementos organizacionais como a orientação estratégica ao longo do processo e pessoas e organização como base do processo.

d) Cadeia de Valor da Inovação, proposta por Hansen e Birkinshaw (2007) Modelo simplificado que considera um processo integrado de três grandes etapas. Este modelo é mais simplificado e considera interação entre os atores internos e externos na fase de ideação e as interações entre eles, e também considera a difusão não somente de maneira externa mas também internamente.

e) Processo de Inovação, proposto por Varkey, Horne, Bennet (2008) - Modelo focado no setor de saúde, apresenta maiores detalhes das etapas envolvidas, mas ainda não traduz as interações com outros atores da cadeia, nem mesmo como a estratégia de inovação se insere no processo.

O modelo de Hansen e Birkinshaw (2007) foi considerado para este estudo devido as características mais amplas do modelo, que considera a interação da organização com outros atores internos e externos, prevendo a difusão não apenas 
no ambiente externo mas também dentro da organização e apresenta uma estrutura simplificada. Desse modo, o modelo de Hansen e Birkinshaw (2007) foi definido como a base de gestão da inovação conforme os três elos apontados: ideação; conversão e difusão.

A ideação é o processo de geração de ideias que podem surgir internamente, dentro da unidade de negócio ou entre as unidades, e externamente com universidade, fornecedores, clientes, médicos etc. Ela pode surgir por meio de técnicas de brainstorming, $5 \mathrm{~W} 2 \mathrm{H}$, focus group de clientes, observação do comportamento do consumidor, surveys, pesquisa de satisfação e reclamações, entrevistas com stakeholders, visita a conferências e feiras, visita a fornecedores, workshops com equipe técnica, pesquisa acadêmicas, publicações científicas ou comerciais, patentes dentre outras, e são submetidas por meio manual ou eletrônico, de preferência o mais simples possível. A conversão compreende todos os processos necessários para transformar a ideia em realidade, e envolve a seleção e avaliação, onde diferentes critérios e priorização podem ser utilizados como o alinhamento estratégico, viabilidade técnica, mercado potencial, diferenciação, retornos financeiros, riscos, método de pesos e notas, simulação de Monte-Carlo, avaliações técnicas e comerciais, e o desenvolvimento e implantação. O desenvolvimento e implantação, envolvem etapas de prototipagem, testes, experimentação e análise em um processo iterativo. Engloba também o desenvolvimento da parte operacional do serviço, monitorando a aceitação ou não do cliente. Nesta etapa também é desenvolvido o plano de marketing, treinamentos, vendas, operações e qualidade, para em seguida serem implantados. Por fim, a difusão deve ocorrer tanto internamente, entre seus colaboradores, como também externamente, divulgando e capturando valor da inovação por toda a cadeia. (HANSEN; BIRKINSHAW, 2007; VARKEY; HORNE; BENNET, 2008; GOFFIN; MITCHELL, 2005; TIDD; BESSANT, 2015; COOPER; EDGETT 1999)

Tomando como base o modelo de Goffin e Mitchell (2005) foram adicionados os elementos: (i) estratégia da inovação e (ii) pessoas e organização.

A estratégia de inovação é a base para as tomadas de decisão ao longo do processo de inovação bem como deve estar alinhada à estratégia corporativa (DAVILA; EPSTEIN; SHELTON, 2007; WHEELWRIGHT; CLARK, 1992; TIDD; BESSANT, 2015; GOFFIN; MITCHELL, 2005). Análise estratégica de fatores externos como o mercado, movimento de competidores, mudanças das tendências 
tecnológicas, mudanças nos hábitos e necessidades dos clientes, mudanças no ambiente de negócios, bem como os fatores internos como as marcas e linhas de negócio que a empresa quer crescer, influenciam na definição da estratégia de inovação (DAVILA; EPSTEIN; SHELTON, 2007; GOFFIN; MITCHEL, 2005; TIDD; BESSANT, 2015).

Pessoas e organização são a pedra fundamental da inovação. Aspectos motivacionais (sistemas de incentivos), contratação e desenvolvimento profissional, e a cultura organizacional são elementos chave para o processo de inovação. (SEKI et al, 2003; DAVILA; EPSTEIN; SHELTON, 2007; GOFFIN; MITCHELL, 2005; TIDD; BESSANT, 2015).

Foram apresentados os conceitos de serviço, desde a abordagem proveniente em marketing, até o conceito de "relação de serviço" de Salerno (2015), em que trata não o setor de serviço em si, mas a intensidade das relações e interações entre os atores da oferta e da demanda. Conforme Corrêa e Caon (2006), o fato de os serviços terem normalmente algum nível de contato do cliente e com o recurso produtivo, não significa que este contato ocorre em todos os aspectos do processo produtivo. Os autores apontam dois tipos de atividades:

- $\quad$ Atividades de contato, também chamadas de "linha de frente" ou de "front office" - é a relação direta entre o cliente e a organização.

- Atividades sem o contato do cliente, também chamadas de atividades de "retaguarda" ou de "back office"- contém os processos executados longe do cliente

Algumas definições sobre serviços foram apresentadas (HILL, 1977; GADREY; 2001; ZARIFIAN, 2001b). Para este trabalho, seguiremos com a definição de Zarifian (2011b) em que define serviço como sendo uma organização e uma mobilização, o mais eficiente possível, de recursos para interpretar, compreender e gerar a mudança perseguida nas condições de atividade do cliente-usuário.

Foram apresentados os tipos de inovação de serviços conforme, podendo ser tecnológica ou não, puxadas pelas necessidades dos clientes ou empurradas pelas áreas internas da empresa, sendo normalmente inovações incrementais Sundbo e Gallouj (1998).

Também foram apresentados, conforme visão de Sundbo e Gallouj (2000), as apontam forças que dirigem o processo inovação em serviços, sendo elas internas ou externas (trajetórias e atores). 
Foram apresentadas as três abordagens de inovação em serviços: tecnicista, orientada a serviços e integradora (Gallouj, 1998). Para este trabalho optou-se por trabalhar com a visão integradora que considera o produto como resultado de vetores de características ou de competências. Neste sentido foram apresentadas as visões de Saviotti e Metcalfe (1984), Gallouj e Weinstein (1997) e Windrum e García-Goñi (2008).

Por fim, identificou-se que a inovação em serviços de saúde apresenta algumas particularidades. Apesar de pesquisadores atribuírem o aumento nos custos de saúde ao processo de inovação como Barbash e Glied (2010) e Goyen e Debatin (2008), Christensen, Grossman e Hwang (2009) reforçam que a inovação, pode reduzir custos e melhorar a qualidade e acessibilidade à saúde. Porter e Teisberg (2007) entendem que o que deve ser feito é buscar estrategicamente inovações que aumentem o valor para o paciente (resultado obtido por capital investido) ao longo da cadeia de prestação de serviços, olhando de maneira holística. Estas inovações devem ser altamente recompensadas e há imensas oportunidades de obtê-las avançando nos campos de conhecimento de estratégias, estruturas organizacionais, instalações, processos e parcerias (PORTER; TEISBERG, 2007).

Um fator que merece destaque em serviços de saúde é a forte interação entre os stakeholders do setor, como pacientes, fontes pagadoras, fornecedores, e médicos (THAKUR; HSU; FONTENOT, 2012). Estas interações entre os diversos atores da cadeia que influenciam a inovação são bastante evidenciadas, especialmente em hospitais (GOES; PARK, 1997; BOHRER; VARGAS, 2009; SILVA, 2011),

Alguns atores são relevantes e influenciam no processo de inovação em saúde: (i) órgãos reguladores, devido ao seu papel de criar e alterar leis ou regulamentos que afetam o setor de saúde (ALBUQUERQUE; CASSIOLATO, 2002; OMACHONU; EINSPRUCH, 2010; VARGAS, 2006; WINDRUM; GARCÍA-GOÑI, 2008); (ii) médicos que definem a inovação a ser utilizada (BURNS et al, 2002; GARCÍA-GOÑl; MAROTO; RUBALCABA, 2007; BOHRER; VARGAS 2009); (iii) pacientes que possuem preferências e necessidade (GARCÍA-GOÑI; MAROTO; RUBALCABA, 2007; OMACHONU; EINSPRUCH, 2010); (iv) fornecedores que transformam o conhecimento em materiais, em especial a indústria farmacêutica e de equipamentos eletrônicos, próteses e órteses, e materiais de consumo. (PEDROSO, 2010; CHAVES; ALBUQUERQUE, 2006; GADELHA, 2003); (v) universidades pelo setor de saúde ser fortemente embasado em ciência (PISANO, 2006; CHAVES; 
ALBUQUERQUE, 2006; ALBUQUERQUE; CASSIOLATO, 2002); (vi) operadoras de saúde que buscam o menor custo (VARGAS, 2006).

Dado a revisão teórica, chegou-se à estrutura do modelo de gestão da inovação considerado nesta pesquisa, conforme mostra a figura 19:

Figura 19: Estrutura conceitual considerado na pesquisa

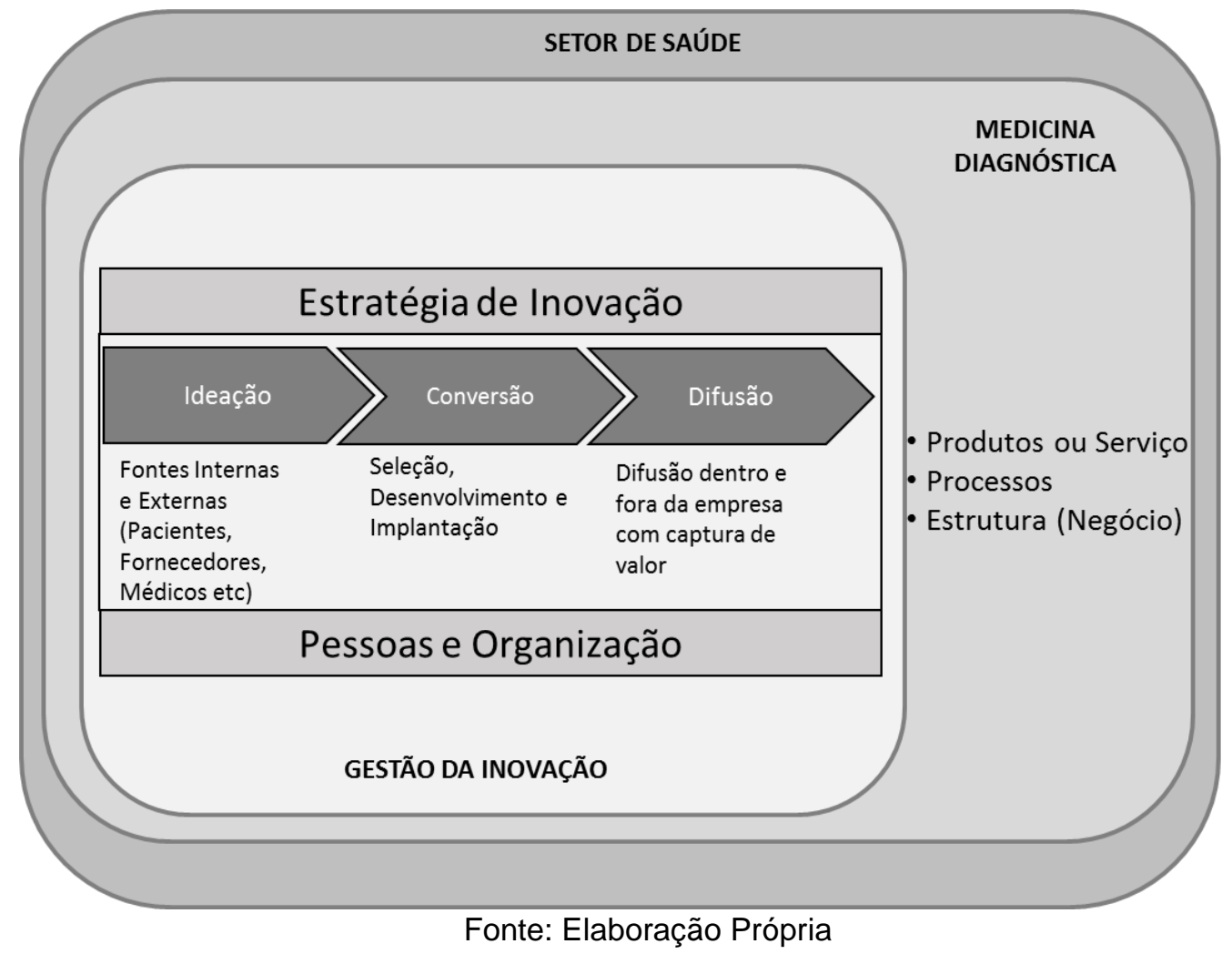

Por fim, o quadro conceitual relacionado com as perguntas que nortearam as entrevistas são apresentadas no Apêndice 2. 


\section{METODOLOGIA}

Seguindo as classificações de Marconi e Lakatos (2007), esta pesquisa tem natureza teórico-prática de enfoque qualitativo e objetivos de caráter exploratório, pois visa proporcionar maior familiaridade com o problema, tornando-o explícito. As pesquisas exploratórias acontecem quando o conhecimento existente é deficiente e a literatura não fornece estruturas ou hipóteses relevantes (YIN, 2010).

Nas pesquisas qualitativas, é frequente que o pesquisador procure entender os fenômenos, segundo a perspectiva daquele que vivencia a situação estudada e a partir daí situe sua interpretação dos fenômenos estudados. (NEVES, 1996)

Segundo GIL (2008), as pesquisas exploratórias podem ser realizadas por meio de levantamento bibliográfico, entrevistas com pessoas que tiveram experiências práticas com o problema pesquisado, análise de exemplos, e em especial, para este projeto, estudo de caso.

Yin (2010) ressalta que as questões do tipo "como" e "por que" são mais exploratórias e possibilitam a aplicação do estudo de caso.

Neste sentido, o estudo de caso consiste no estudo profundo e exaustivo de um objeto, de maneira que permite seu amplo e detalhado conhecimento, tarefa praticamente impossível mediante outros delineamentos já considerados (GIL, 2008). O autor ainda define um conjunto de etapas para estudo de caso que em parte serão seguidas neste projeto:

- $\quad$ Formulação do Problema

O problema desta pesquisa consiste em responder a seguinte questão principal: Como ocorre a gestão da inovação em uma empresa de Medicina Diagnóstica? Dada esta pergunta, temos que o objetivo deste trabalho é aprofundar a compreensão sobre a gestão da inovação em uma empresa de medicina diagnóstica, buscando avançar no conhecimento de cada etapa do processo de gestão da inovação. Neste sentido, partindo de uma abordagem processual, tomando como base as etapas do processo de gestão da inovação encontrados na literatura, a questão de pesquisa principal pode ser derivada em questões complementares: 1) Como é o processo de ideação, conversão e difusão da inovação em Medicina Diagnóstica? 2) Como a estratégia de inovação se insere no processo de gestão da 
inovação em Medicina Diagnóstica? 3) Como pessoas e organização se inserem no processo de inovação em Medicina Diagnóstica?

\section{- Definição da unidade-caso}

A escolha da unidade de estudo é uma decisão de grande relevância em estudos qualitativos (EINSENHARDT, 1989; YIN, 2010). De fato, a unidade de estudo deve ser capaz de contribuir para os objetivos da pesquisa, possibilitando 0 entendimento dos elementos em investigação.

YIN (2010) aponta que a utilização de um único caso é apropriada em algumas situações: quando o caso representa um caso crítico do teste de uma teoria; quando é um estudo raro ou extremo, ou seja, não existem muitas situações semelhantes para que sejam feitos estudos comparativos; quando é típico ou representativo; quando o caso é revelador, por permitir o acesso a informações não facilmente disponíveis, e quando se pretende reunir, numa interpretação unificada, inúmeros aspectos de um objeto pesquisado. A pesquisa se enquadra ao estudo de caso único, dado que são poucas as empresas de medicina diagnóstica que possuem uma gestão da inovação, então aquela que possui, acaba por ser típica e representativa. Além disso, o fato do pesquisador ter acesso a informações mais facilmente por ser colaborador torna 0 caso revelador.

Neste sentido, alguns critérios foram utilizados como forma de selecionar a unidade conforme segue:

1) Ser um centro de Medicina Diagnóstica de grande porte, de preferência com presença e impacto nacional;

2) Ser um centro de Medicina Diagnóstica reconhecido por práticas de inovação, bem como o desenvolvimento de pesquisa, de maneira independente ou em associação com outras instituições de ensino;

3) Ser um centro de Medicina Diagnóstica reconhecido por práticas de gestão;

O pesquisador é colaborador do Centro de Medicina Diagnóstica Grupo Fleury e em contato prévio identificou a abertura por parte dos gestores em desenvolver a pesquisa. Além disso, outras pesquisas desenvolvidas pela Faculdade de Administração e Economia da USP já tiveram o apoio do Grupo Fleury como unidade de estudo. Ainda que está pré-seleção tenha sido realizada intencionalmente, dada a conveniência gerada pelas relações anteriores da Universidade e do pesquisador, 
todos os critérios de seleção foram atendidos pelo Fleury, conforme informações obtidas no Site do Grupo Fleury (2017a), e relatadas abaixo:

Ser um centro de Medicina Diagnóstica de grande porte, de preferência com presença e impacto nacional.

Com 90 anos, o Grupo Fleury é em uma das maiores e mais respeitadas empresas de medicina e saúde do País, referenciada pela comunidade médica e pela opinião pública por sua excelência em serviços ao cliente, inovação e qualidade técnica. Realiza por ano cerca de 55 milhões de exames de análises clínicas, 4 milhões de imagem, 8,2 mil colaboradores e 1,8 mil médicos. Possui 138 unidades de atendimento, 17 unidades de processamento em hospitais, presentes em 6 estados brasileiros e distrito federal.

Ser um centro de Medicina Diagnóstica reconhecido por práticas de inovação, bem como o desenvolvimento de pesquisa, de maneira independente ou em associação com outras instituições de ensino.

A inovação é um dos principais pilares competitivos da companhia. Em 2016, a companhia implantou mais de 40 novos produtos no mercado, além de inovações em processos e modelos de negócio como o IBM Watson Saúde, iniciativa de utilizar a inteligência artificial para ajudar oncologistas na etapa de tratamento de pacientes. $O$ Grupo Fleury possui financiamento da FINEP (Financiadora de Estudos e Projetos), para inovações tecnológicas e uma plataforma open innovation para submissão de projetos em parceria com outras instituições e pesquisadores. O Grupo Fleury reconhece a pesquisa nacional com foco na área da saúde por meio do Prêmio de Inovação do Grupo Fleury (PIF). Por outro lado, o Grupo Fleury também é premiado como uma instituição inovadora. É líder no ranking anual da Strategy\& e Valor Econômico na categoria Serviços e está entre as 30 empresas mais inovadoras do País. Também está em 19º entre 100 empresas mais inovadoras do Brasil, segundo ranking da AT Kearney e Época Negócios.

$\checkmark \quad$ Ser um centro de Medicina Diagnóstica reconhecido por práticas de gestão e qualidade.

A marca Fleury ganhou o Prêmio Consumidor Moderno. Eleita pela $15^{\circ}$ vez, sendo a sétima consecutiva, a melhor no setor de Medicina Diagnóstica. O prêmio reconhece a qualidade do relacionamento com clientes. 
O Grupo Fleury foi eleito a empresa mais hospitaleira do Brasil pelo sétimo ano consecutivo pela pesquisa conduzida pelo Instituto Brasileiro de Hospitalidade Empresarial (IBHE).

Certificado em 1999 pela norma ISO 9001, em 2002 pela norma ISO 14001 e em 2010 pelo PALC da SBPC, o Grupo Fleury ainda participa ativamente de rigorosos programas de controle de qualidade de nível nacional e mundial, entre os quais se destacam o Surveys and Anatomic Pathology Education Programs, do College of American Pathologists (CAP) e a Proficiência em Ensaios Laboratoriais, da Sociedade Brasileira de Patologia Clínica/Medicina Laboratorial (SBPC/ML).

Desse modo, o Grupo Fleury foi selecionado como caso de estudo, fornecendo subsídios para a análise de gestão da inovação em medicina diagnóstica.

\section{- Técnicas Utilizadas}

Yin (2010) aponta seis técnicas de levantamento utilizadas em estudos de casos.

- Documentos: Cartas memorandos, agendas, anúncios, documentos administrativos, relatórios etc.

- Registro em arquivos: arquivos de uso público, como censos ou outros dados do governo, registro de serviços, registros organizacionais, mapas e gráficos das características geográficas.

- Entrevistas: Guiadas, que podem seguir protocolos estruturados ou semi-estruturados, podem ser abertas, em grupo ou individuais.

- Observações diretas: no local, constatação visual de um fato em visitas de campo, e de determinado comportamento durante alguns períodos de tempo.

- Observações participante: nesta modalidade o entrevistador não é passivo, mas sim participa nos eventos estudados. Por exemplo em estudos de interações sociais. Muito utilizado em estudos antropológicos.

- Artefatos físicos: evidencia de um artefato físico ou cultural como um dispositivo tecnológico, uma ferramenta ou instrumento, uma obra de arte ou alguma outra evidência física. 
Do ponto de vista dos procedimentos técnicos, foram utilizadas as técnicas de entrevistas semiestruturadas, observação direta na empresa, e análise de documentos, fornecidos pela organização e provenientes de fontes indiretas (sites, jornais etc).

\section{- Elaboração do Protocolo}

Para a etapa de pesquisa foi elaborado um protocolo semiestruturado com questões orientadoras tomando como base a pesquisa bibliográfica a respeito de gestão da inovação e o setor de saúde e medicina diagnóstica. O protocolo foi validado por meio de uma primeira pesquisa piloto com um dos entrevistados, onde os primeiros resultado foram discutidos com o orientador e o feedback do entrevistado sobre a condução da entrevista foi coletado. O conteúdo não foi alterado, e apenas foram feitas alterações na forma de questionar.

\section{- $\quad$ Coleta de dados}

Inicialmente foi contatado pessoalmente o gerente de estratégia e inovação para apresentar a pesquisa e solicitado sugestões para os entrevistados, respeitando o fato de que estes deveriam estar diretamente envolvidos com o tema de gestão da inovação, em especial com processos, estratégia da inovação, e pessoas e organização. Em seguida os entrevistados sugeridos foram contatados por telefone, e-mail ou pessoalmente e informados sobre o objetivo dessa pesquisa, e receberam oficialmente um e-mail convite conforme consta no apêndice. Agendou-se então uma data com os gestores e a entrevista foi conduzida com auxílio do questionário semiestruturado. Foi solicitada a permissão de se gravar as entrevistas para posterior transcrição e análise. Também foi solicitado ao participante a disponibilização dos dados por meio do termo de consentimento exigido pela empresa, conforme consta no apêndice.

Durante os meses de fevereiro e março de 2017, foram realizadas 12 entrevistas. Para cada um dos entrevistados, focou-se em determinados elementos da pesquisa, dado o cargo que ocupam e escopo de atuação.

As entrevistas duraram em média 62 minutos, sendo a mais longa de 140 minutos e a mais curta de 23 minutos. 
Com o objetivo de garantir o sigilo da identidade dos entrevistados, os mesmos serão nominados com a letra "P" seguido de um número de 1 a 12 , conforme apontado no quadro 1 :

Quadro 1: Entrevistados da Pesquisa

\begin{tabular}{|lllc|}
\hline Identificação & Foco & Cargo & Duração (min) \\
\hline P1 & Estratégia & Presidente & 35 \\
P2 & Estratégia & Diretor Executivo de Estratégia e Inovação & 23 \\
P3 & Estratégia/Pessoas/ Processo & Diretora Executiva Médica e de P\&D & 60 \\
P4 & Pessoas & Diretor de Cultura & 118 \\
P5 & Pessoas & Gerente de Desenvolvimento Educacional & 50 \\
P6 & Estratégia e Processo & Gerente de Estratégia e Inovação & 140 \\
P7 & Processo & Gerente de P\&D & 50 \\
P8 & Processo & Gerente de Processos de Atendimento & 30 \\
P9 & Processo & Gerente de Processos de Enfermagem & 57 \\
P10 & Processo & Gerente de Processos Médicos & 42 \\
P11 & Processo & Coordenadora de P\&D & 112 \\
P12 & Processo & Coordenadora de Estratégia e Inovação & 35 \\
\hline
\end{tabular}

Fonte: Elaboração Própria

Para reforçar a análise, alguns trechos das entrevistas foram citados na apresentação e discussão do caso. De todo modo, mesmo que não citado de forma direta, o conteúdo de todas as entrevistas foi considerado na análise.

\section{- Avaliação e análise dos dados}

A avaliação e análise dos dados coletados em campo foram divididos em (i) análises de conteúdo das entrevistas; (ii) triangulação de dados.

Desse modo, o áudio das gravações das entrevistas foram transcritos. No total foram 752 minutos de gravações que totalizaram 250 páginas transcritas. As transcrições foram analisadas de forma a buscar partes relevantes dos dados para análise e posterior comparação com os outros entrevistados. Esta busca foi direcionada pelo protocolo de pesquisa e itens discutidos na literatura. Os trechos foram categorizados conforme as perguntas do protocolo.

Documentos fornecidos pela empresa foram analisados e a triangulação das entrevistas, documentos e observação direta foi realizada. 


\section{APRESENTAÇÃO E DISCUSSÃO DOS RESULTADOS}

\subsection{Contextualização do caso}

As informações obtidas para esta contextualização foram obtidas do site, da apresentação institucional e do relatório anual de sustentabilidade; todos disponíveis em Grupo Fleury (2017a; 2017b; 2017c).

Fundado em 1926 pelo médico Gastão Fleury Silveira, o Grupo Fleury constituiu-se ao longo dos seus mais de 90 anos, em uma das mais tradicionais organizações de medicina diagnóstica do país, sendo referenciada pela comunidade médica e pela opinião pública por sua excelência em serviços ao cliente, inovação e qualidade técnica.

Com faturamento em 2016 de mais de $\mathrm{R} \$ 2,3$ bilhões de reais e geração de caixa operacional superior a $R \$ 520$ milhões, o Grupo Fleury é sediado na cidade de São Paulo e conta com um portfólio de aproximadamente 3,5 mil testes em 37 diferentes áreas diagnósticas.

O tipos de serviço diagnóstico que o Grupo Fleury oferece incluem os serviços de análises clínicas, anatomia patológica, e radiologia ou diagnóstico por imagem, conforme apontado por Pedroso (2016). Além destes, o Grupo Fleury também oferece diagnósticos em diferentes especialidades médicas como pneumologia, oftalmologia, dermatologia dentre outros. Em 2016, foram cerca de 62 milhões de exames realizados e 8 milhões de clientes, atendidos por mais de 8,8 mil colaboradores e 1,8 mil médicos.

O Grupo Fleury possui as seguintes linhas de negócio:

- Unidades de Atendimento: são 145 unidades distribuídas nos estados de São Paulo, Rio de Janeiro, Rio Grande do Sul, Pernambuco, Bahia e Paraná, além do Distrito Federal.

- Operações Diagnósticas em Hospitais: envolve a realização de diagnósticos em hospitais parceiros, tanto de análises clínicas quanto de imagem e outras especialidades. Atualmente $\circ$ Grupo atende 22 instituições hospitalares consideradas de alto nível.

- Laboratório de Referência: realização de exames de média e alta complexidade para laboratórios, hospitais e clínicas terceiras em todo o Brasil, 
possibilitando-Ihes a ampliação de sua gama de oferta com qualidade diagnóstica única;

- Medicina Preventiva: dedica-se à oferta de produtos de promoção de saúde para funcionários de várias empresas, de serviços de checkup e vacinação.

- Diagnóstico Dental: em 2012, o Grupo Fleury adquiriu 51\% do Grupo Papaiz. Com mais de 30 anos de existência e especializado em radiologia odontológica, o Grupo Papaiz conta com oito unidades operacionais na região metropolitana de São Paulo e oferece serviços de tomografia, radiografias intra e extrabucais, documentação ortodôntica e modelos de arcada dentária.

Dentre as linhas de negócio do Grupo Fleury, podemos identificar a atuação do grupo na cadeia de valor de prestação de serviços de saúde de Porter e Teisberg (2007), sendo o core business as atividades de diagnóstico, e também nas atividades de monitoramento e prevenção como a linha de medicina preventiva, a exemplo dos serviços de checkup e vacinas.

As linhas de negócio contam com a presença de seis marcas distribuídas pelo Brasil, conforme mostra a figura 20.

Figura 20: Presença das marcas do Grupo Fleury no Brasil

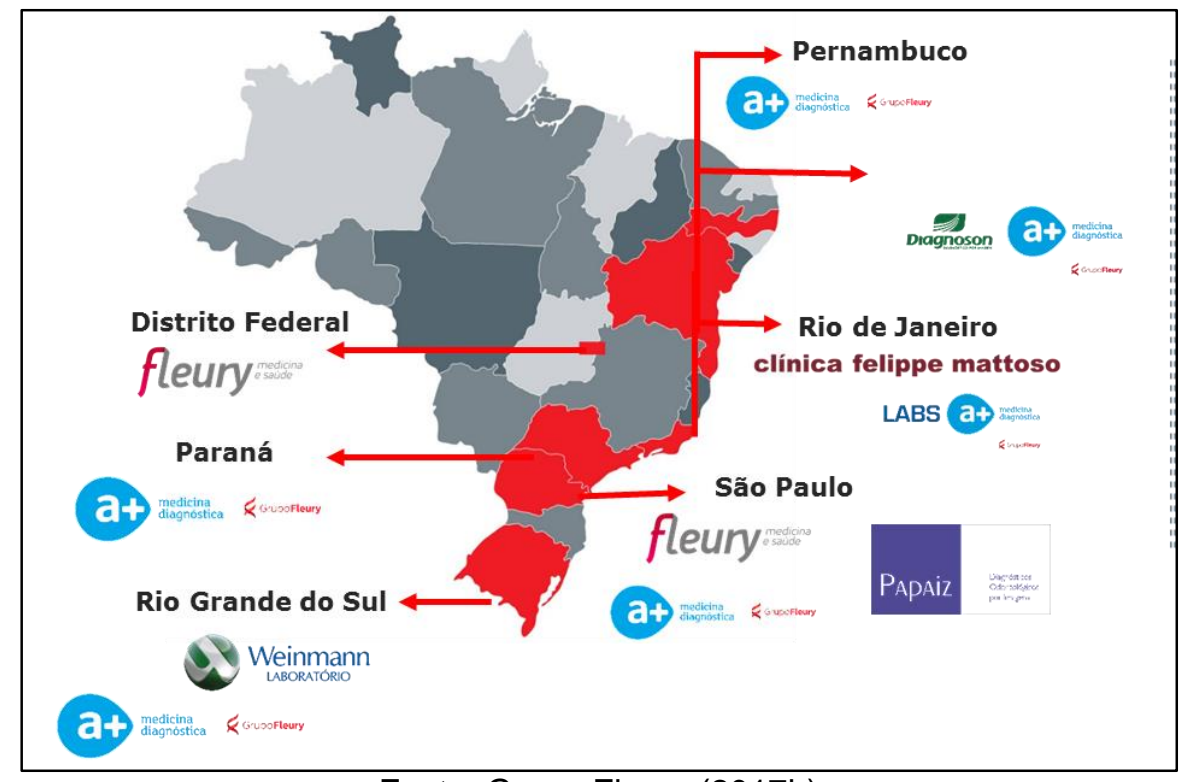

Fonte: Grupo Fleury (2017b)

As 145 unidades estão distribuídas nos estados de São Paulo, Rio de Janeiro, Rio Grande do Sul, Pernambuco, Bahia e Paraná, além do Distrito Federal.

Em cada região o grupo conta com seis marcas que são posicionadas para o atendimento do público premium e intermediário, conforme mostra a figura 21: 
Figura 21: Público alvo das marcas do Grupo Fleury por região

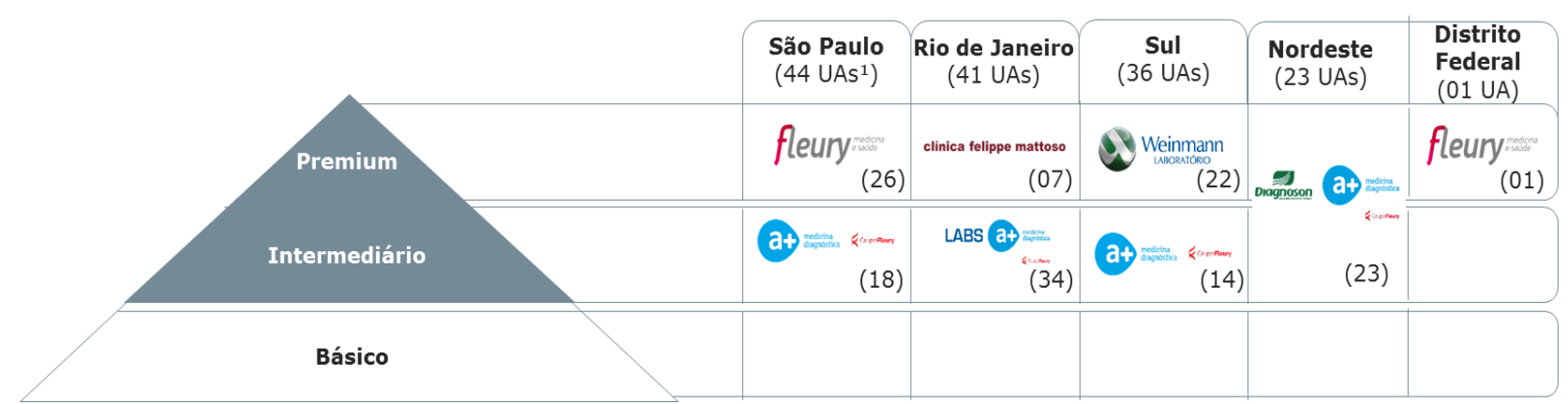

Fonte: Grupo Fleury (2017b)

- A marca Fleury é líder no seguimento premium e está presente em São Paulo, Campinas e no distrito federal. É considerada a melhor e mais confiável marca no Mercado Brasileiro.

- A marca a+ foi lançada em 2011 com o objetivo de ser uma marca nacional focada na captura do segmento intermediário.

- A marca Weinmann é a marca mais lembrada do Rio Grande do Sul, com foco no público premium.

- A marca Clínica Felippe Mattoso é a marca premium no Rio de Janeiro, tradicionalmente forte nos serviços de imagem e em forte crescimento nos últimos anos nos serviços de análises clínicas.

- A marca Labs a+ é a associação estratégica de unificar a marca nacional a+ com a marca tradicional Labs D'Or do Rio de Janeiro.

- A marca Diagnoson a+ também é a associação que unifica a marca nacional a+ com a marca tradicional em exames de imagem chamada Diagnoson, com objetivo de fornecer exames de imagem e análises clínicas no mesmo local (conceito "one-stop-shop").

Estas marcas são resultado do processo de consolidação 27 aquisições ocorridas desde 2002, feitas pelo Grupo Fleury conforme mostra a figura 22. As aquisições são parte de uma estratégia de expansão, ampliando o seu mix de serviços, presença geográfica e base de conhecimento em outras regiões do Brasil. 
Figura 22: Histórico de aquisições do Grupo Fleury

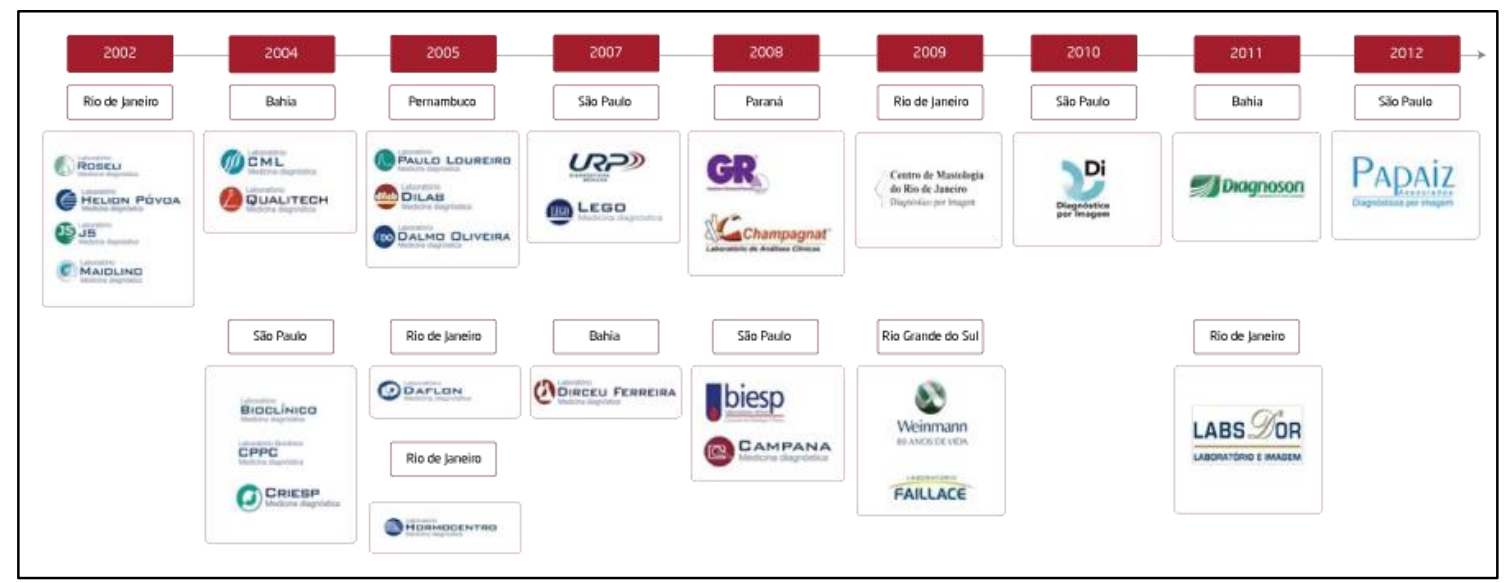

Fonte: Grupo Fleury (2017b)

Basicamente a unificação ocorreu em torno da marca a+, com objetivo de ter uma marca nacional, com posicionamento ao público intermediário com uma proposta de atendimento acolhedora, moderna e descomplicada.

Desde 2009 o Grupo Fleury tornou-se uma empresa de capital aberto, negociando suas ações sob o código FLRY3, no segmento Novo Mercado da BM\&F Bovespa, nível que exige práticas dos mais elevados padrões de governança corporativa.

A estrutura societária e a participação é mostrada na figura 23. Os sócios mais relevante são o Bradesco Seguros, Médicos-Sócios, Médicos-Sócios membros da Integritas Participações, e a private equity Advent International. O restante é negociado em grande parte no free float:

Figura 23: Estrutura Societária do Grupo Fleury

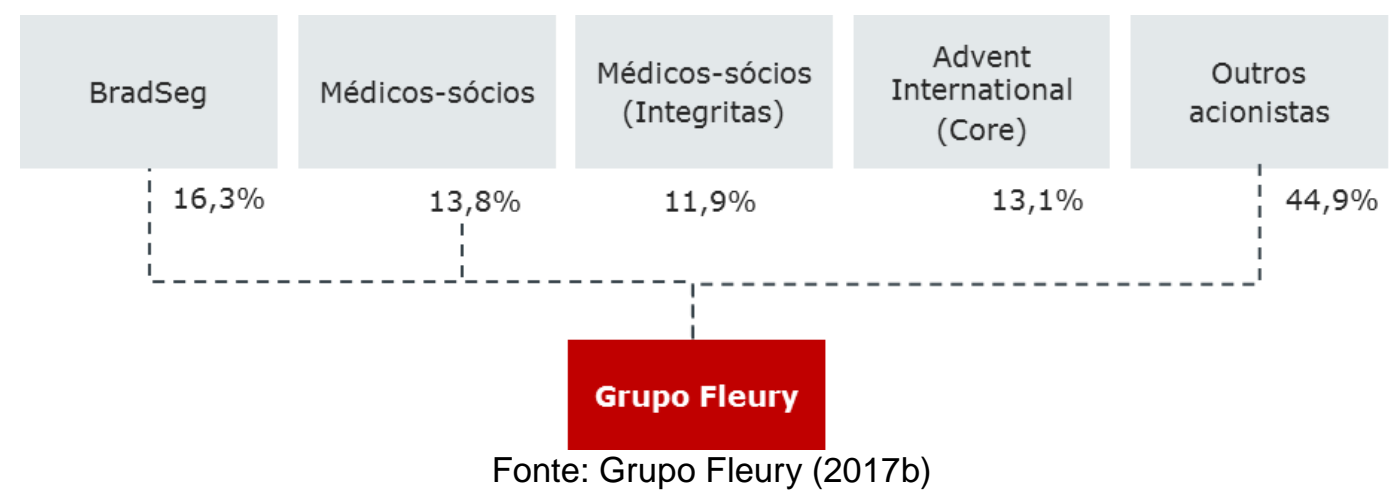

Vinculados ao acordo de acionistas, que envolve regras como por exemplo, a oferta preferencial de venda de ações para os outros signatários do acordo. São eles: 
- Bradesco Seguros: Unidade de negócio de seguros do Banco Bradesco.

- Médicos Sócios: 26 médicos que têm participação direta, sem veículo de investimento.

- Médicos Sócios Integritas: 29 médicos que têm participação indireta por meio do fundo de investimento chamado Integritas.

- Advent International: Fundo de investimento americano que adquiriu participação no Fleury no ano de 2015.

Outros acionistas: demais acionistas não vinculados ao acordo de acionistas, que negociam livremente suas ações no free float.

Já a estrutura organizacional do grupo Fleury (figura 24) é composta nos mais altos níveis de gestão por diretores corporativos e diretores executivos que respondem diretamente ao CEO por suas áreas e estruturas. O CEO por sua vez reponde ao conselho de administração formado por acionistas e conselheiros externos.

Figura 24: Estrutura Organizacional do Grupo Fleury

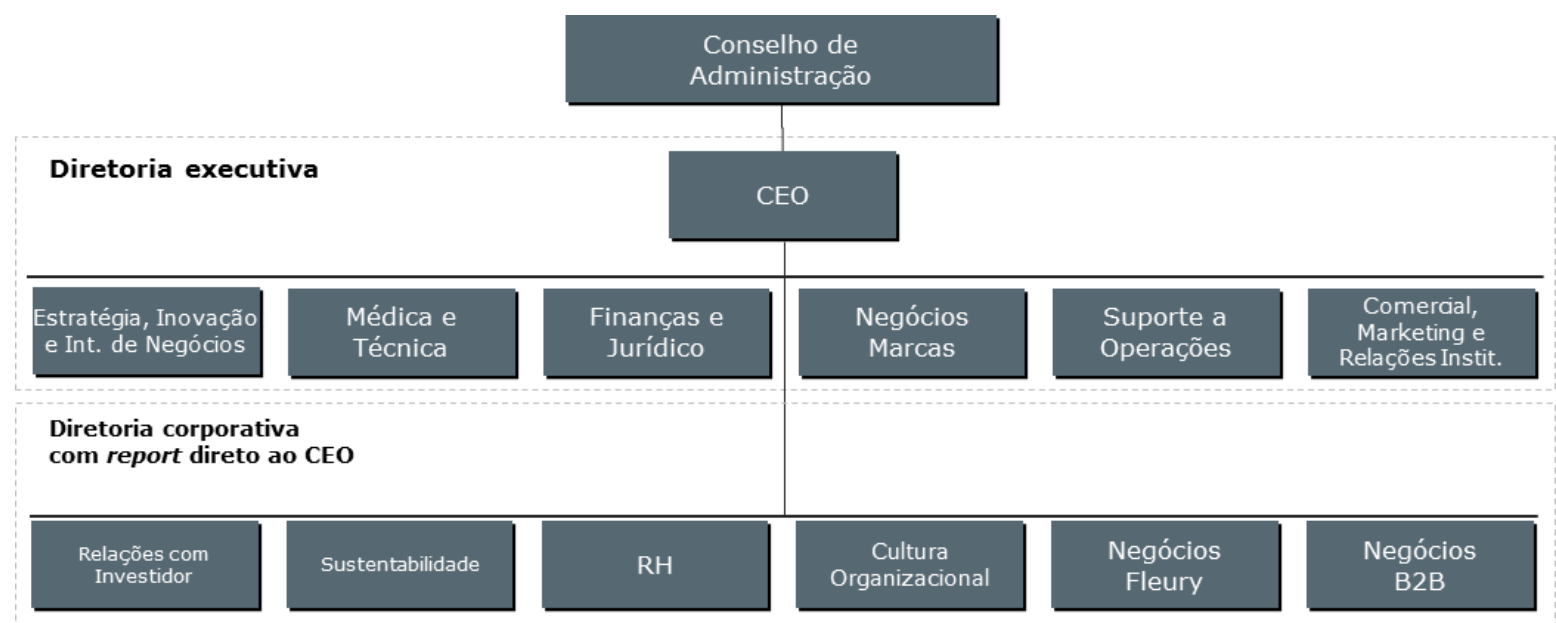

Fonte: Adaptado de Grupo Fleury (2017b) com documentos internos

A inovação ocorre nas diversas áreas da empresa, porém a diretoria executiva de Estratégia, Inovação e Inteligência de negócios tem o papel de gerenciar a inovação em toda organização. Os resultados desta gestão são claramente vistos.

Pelo quarto ano consecutivo, o Grupo Fleury entrou no ranking de Empresas mais Inovadoras do Brasil em 2015, organizado pela AT Kearney e Época Negócios. A empresa ficou classificada em 19이 lugar entre mais de 100 empresas inscritas.

O Grupo Fleury também conquistou a 16 ${ }^{a}$ colocação na classificação geral e o segundo lugar entre as empresas de serviços gerais. As 100 empresas mais 
inovadoras compõem um anuário que circula no Valor Econômico, com reportagens e perfis das dez primeiras colocadas, e as cinco melhores classificadas em nove setores de atividade: indústria, bens de consumo, $\mathrm{TI}$ e telecom, bens de capital, serviços financeiros, infraestrutura e logística, serviços, comércio e farmácia e life sciences.

Figura 25: Marcos de Inovação do Grupo Fleury

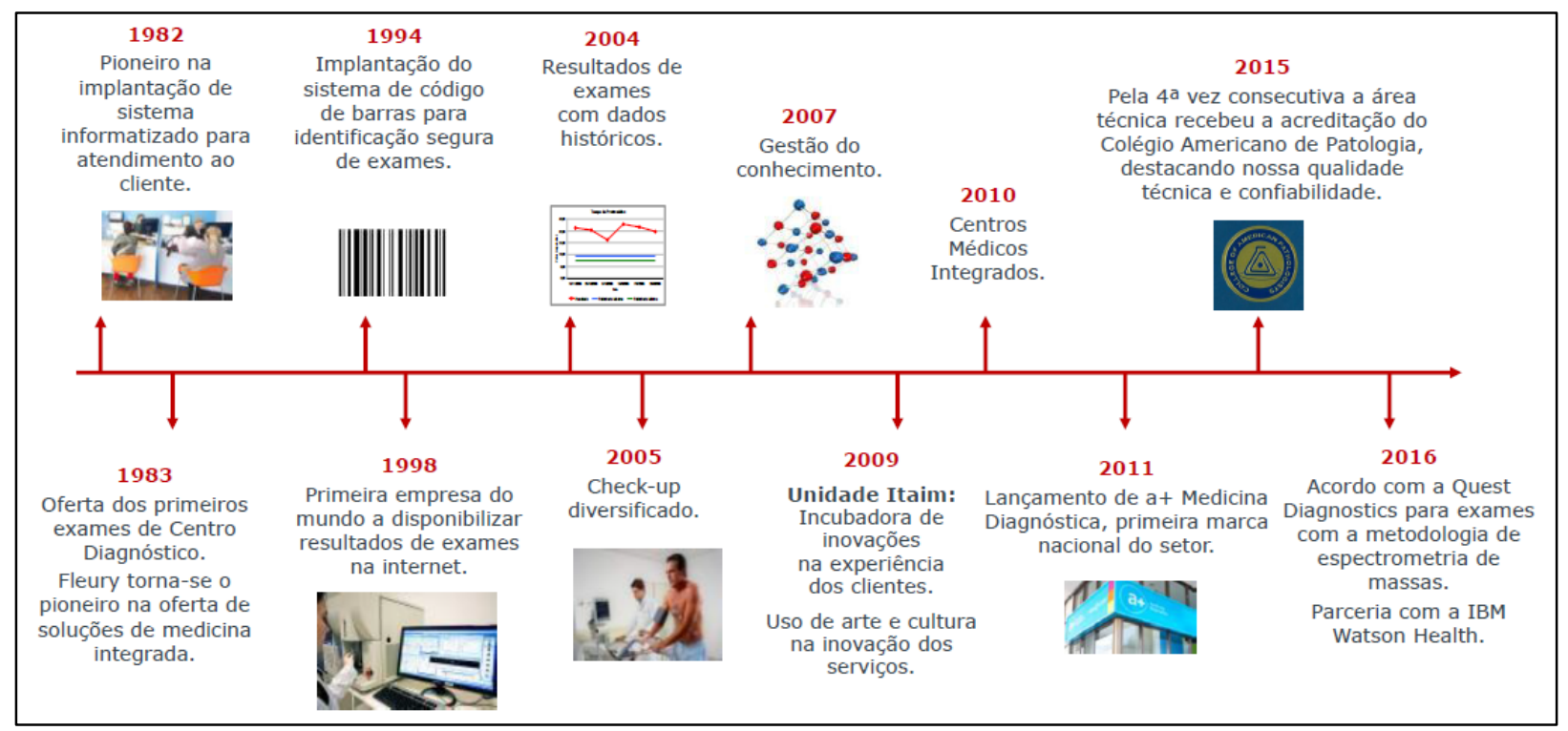

Fonte: Grupo Fleury (2017b)

De fato, conforme podemos observar na figura 25, ao longo dos anos o Grupo Fleury vem apresentando inovações, sendo pioneira no mundo em algumas como a disponibilização dos resultados de exames na internet.

Seu fundador, o médico Gastão Fleury Silveira, iniciou as atividades de laboratório de análises clínicas com o diferencial de excelência nos serviços e na atenção ao cliente e à classe médica. Em 1936 iniciava as primeiras cooperações de pesquisas técnico-científicas com as melhores universidades do País.

Nas décadas seguintes, o Grupo Fleury foi o primeiro a lançar o conceito de Centro Diagnóstico, passando a ofertar os serviços de anatomia patológica e exames de imagem com aos seus clientes uma solução integrada.

Nas décadas de 1980 e 1990, foi pioneiro na implantação de códigos de barras e a disponibilizar os resultados de exames na Internet.

Não menos importante, conforme vemos no gráfico 5, em 2016 o Grupo Fleury lançou 662 novos produtos ou metodologias, gerando cerca de $\mathrm{R} \$ 23$ milhões de reais no ano. Para 2017 está previsto o lançamento de 697 novos produtos ou metodologias. 
Gráfico 5: Número de novos produtos lançados

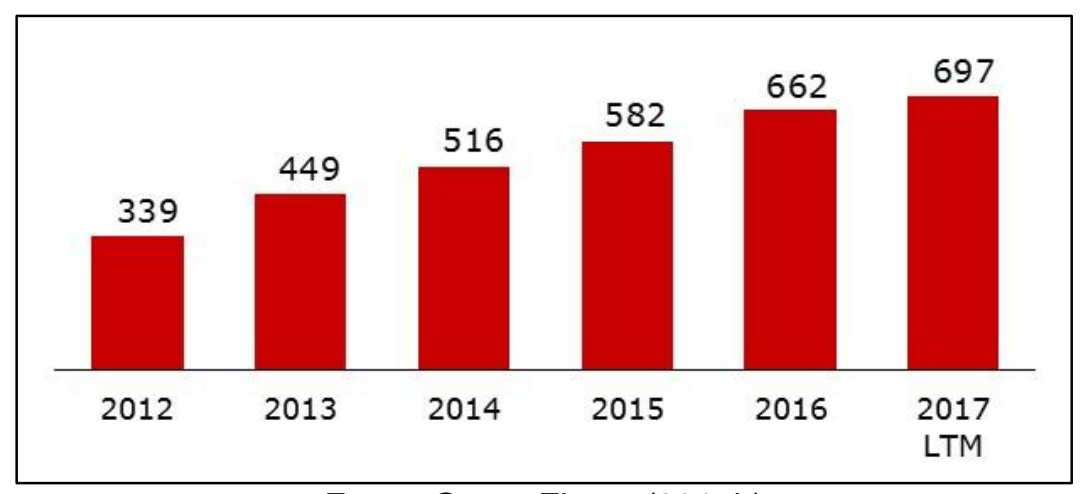

Fonte: Grupo Fleury (2017b)

Também no ano de 2016 foram publicados 54 artigos científicos, 155 reuniões de atualização médica, 25 boletins médicos e mais de 221 trabalhos reunidos na $26^{\text {a }}$ Jornada do Conhecimento, evento interno de valorização do conhecimento.

Muitos desses produtos foram também pioneiros no Brasil como o diagnóstico do virus Influenza, e recentemente o virus Chikungunya.

\subsection{A visão geral de inovação no caso}

A inovação para o Grupo Fleury é definida como "a aplicação de ferramentas e técnicas de gestão que tragam mudanças, grandes ou pequenas e que resultem na introdução de algo novo, adicionando valor aos stakeholders e contribuindo para a geração de conhecimento". Esta definição vai ao encontro do conceito de inovação adotado por Varkey, Horne e Bennet (2008), a qual inovação é a implementação bemsucedida de uma ideia nova, de forma que cria valor convincente para alguns ou todos os stakeholders. No caso, ficou claro a preocupação do grupo em gerar valor por meio da inovação, conforme relata o entrevistado P1:

Entrevistado P1: "Inovação no Fleury é pautado em como fazer o melhor teste para ajudar o médico lá fora, ou para ajudar o cliente, ou para a relação médico paciente, e isso se traduz em valor para a cadeia de valor da saúde"

Esta visão encontrada no caso, de pôr em prática (implantar) a descoberta (nova ideia) e capturar valor por meio dela é também adotada por Drucker (2003), Tidd e Bessant (2015), e Utterberck (1970). 
Neste sentido, o grupo se vê como parte da cadeia de valor, produzindo inovações que geram valor para a cadeia, posição defendida por Porter e Teisberg (2007), conforme relata o entrevistado $\mathrm{P} 1$ :

Entrevistado P1: "Nós somos um pedaço dessa cadeia de valor. Nós estamos dentro de uma equação que tem o financiador, que é o plano de saúde, o demandador que é o médico, e o usuário que é o cliente. Embora nem sempre equilibradas, precisamos maximizar para os três. Se não vai faltar financiamento, ou o médico não estará bem servido, ou o paciente não terá qualidade de vida"

A importância da inovação foi retratada na revisão da literatura como diferencial competitivo das organizações, sendo a principal solução estratégica para que as empresas tenham forças em competir nos mercados atuais e avançar em novos mercados. (DRUCKER, 2003; PROENÇA et al, 2015; TIDD; BESSANT, 2015). Esta visão é contemplada pelo Grupo Fleury, conforme relata o entrevistado P1:

Entrevistado P1: "A inovação é essencial como diferenciação no mercado, como vantagem competitiva, mas no Fleury o patamar é ainda maior, é questão sustentabilidade. Eu só me entendo como uma empresa sustentável no futuro se eu continuar inovando. Não é possível uma empresa de 90 anos olhar para os próximos 90 se não continuar investindo em inovação."

A visão da inovação como motor que mantem o movimento do sistema econômico conforme apontou Schumpeter (1982), também está presente no Grupo Fleury, conforme relata o entrevistado $\mathrm{P} 1$ :

Entrevistado P1: "No grupo a inovação nunca esteve conectada somente com os ganhos marginais nos serviços ou produtos que comercializamos. A inovação sempre foi o motor de crescimento da companhia. Quando olhamos inovação nós pensamos não somente na melhor metodologia, produto, serviço, mas também pensando qual é o futuro daquela metodologia, serviço ou especialidade"

O aumento dos custos no setor de saúde relatados por Barbash e Glied (2010) e Goyen e Debatin (2008) refletem preocupação no caso estudado, conforme relata o entrevistado P3:

Entrevistado P3: "O tempo inteiro está surgindo um monte de coisas novas. O grande problema é quem paga por isso? Que é a questão da 
sustentabilidade do setor de saúde. Como é que eu faço a inovação, gerando valor real à cadeia?"

No entanto, assim como apontado por Christensen, Grossman e Hwang (2009), a inovação pode reduzir custos e melhorar a qualidade de acessibilidade, conforme relata o entrevistado $\mathrm{P} 3$ :

\begin{abstract}
Entrevistado P3: "Há diversos casos em que eu busco uma metodologia mais eficiente e com menor custo. Ou então busco internalizar alguns exames que eu envio para serem processados nos laboratórios do exterior, e assim também reduzo custo, fora as inúmeras inovações nos processos que buscam melhorar nossa eficiência. Certamente a inovação pode reduzir custos, mas não deve reduzir o valor no diagnóstico final ao médico e ao paciente".
\end{abstract}

Esta visão encontrada no caso é corroborada por Porter e Teisberg (2007) que argumentam que o problema não é a inovação em si, mas a utilização correta da inovação na geração de valor ao longo da cadeia. Os autores relatam que um diagnóstico preciso tem importante impacto na geração de valor da cadeia de serviços de saúde. O Grupo Fleury é reconhecido por sua qualidade técnica refletida em diagnósticos completos e precisos, conforme relata o entrevistado P4:

Entrevistado P4: "O médico do paciente quando vê alguma alteração
estranha, ou mesmo quando não se sente seguro, acaba pedindo pra
refazer o exame no Fleury, para ter certeza do resultado. Às vezes o
cliente nem tem acesso, paga particular. Mas no final gera valor, pois
imagina quanto se gasta com um tratamento caríssimo, com base num
diagnóstico incorreto? Pois é claro, o médico confia no Fleury e não
quer errar na conduta do seu paciente."

Portanto, o Grupo Fleury acaba gerando valor ao longo da cadeia proposto por Porter e Teisberg (2007), por meio de sua excelência técnica.

O Grupo Fleury classifica suas inovações em inovações de produto (ou serviço), inovações de processo (técnicos, de atendimento e corporativo), e inovações de novos negócios. Esta classificação é muito semelhante ao apontado por Varkey, Horne e Bennet (2008), que é voltada à serviços de saúde. Assim como os autores, o grupo considera a inovação de produto como o exame que o consumidor está efetivamente pagando. A inovação de processos implica na inovação do método de produção ou de entrega do produto, em especial a parte relacional. E por fim, a 
inovação de novos negócios são mudanças que afetam a estrutura interna ou externa da companhia, e cria um novo modelo de negócios.

Em relação ao grau ou intensidade da mudança de inovação, o grupo classifica a inovação como incremental (ou não disruptiva) e inovação radical (de ruptura, disruptiva), conforme apontado por (FREEMAN; PEREZ, 1988; CHRISTENSEN; BOHMER; KENAGY, 2000; SCHUMPETER, 1982, TIDD; BESSANT, 2015; UTERBACK, 1996).

O quadro 2 mostra os principais achados da visão geral de inovação na empresa:

Quadro 2: Síntese dos achados da visão geral da inovação na empresa

\begin{tabular}{|c|c|}
\hline & VISÃO GERAL DA INOVAÇÃO NA EMPRESA \\
\hline 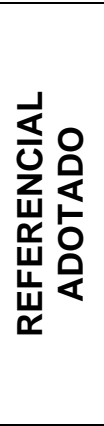 & $\begin{array}{l}\text { Inovação é a introdução de uma nova ideia, implantada, que gera valor. A inovação também } \\
\text { pode ter diferentes tipos (produtos e serviços, processos, marketing etc), graus ou } \\
\text { intensidade (radical ou incremental) e origens (puxada ou empurrada). O objetivo final } \\
\text { daquele que inova é obter vantagens competitivas no mercado atual ou se inserir em novos } \\
\text { mercados. } \\
\text { A inovação em saúde pode reduzir custos e aumentar o valor para o paciente ao longo da } \\
\text { cadeia. (CHRISTENSEN; GROSSMAN; HWANG, 2009; PORTER; TEISBERG, 2007; } \\
\text { SCHUMPETER;1982; DRUCKER, 2003; DOSI, 1982, OCDE, 2004; TIDD; BESSANT, 2015; } \\
\text { VARKEY; HORNE; BENNET ,2008) }\end{array}$ \\
\hline 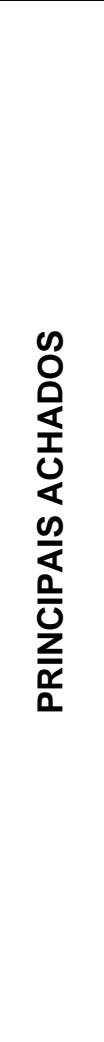 & $\begin{array}{l}\text { - A inovação para o Grupo Fleury é definida como a aplicação de ferramentas e técnicas de } \\
\text { gestão que tragam mudanças, grandes ou pequenas e que resultem na introdução de algo } \\
\text { novo, adicionando valor aos stakeholders e contribuindo para a geração de conhecimento. } \\
\text { - A inovação é uma das competências centrais da companhia, dando vantagem competitiva } \\
\text { no mercado atual. A inovação para o Grupo Fleury é definida como a aplicação de } \\
\text { ferramentas e técnicas de gestão que tragam mudanças, grandes ou pequenas e que } \\
\text { resultem na introdução de algo novo, adicionando valor aos stakeholders e contribuindo } \\
\text { para a geração de conhecimento. } \\
\text { - A inovação é uma das competências centrais da companhia, dando vantagem competitiva } \\
\text { no mercado atual. A inovação é vista na companhia como sinônimo de sustentabilidade, } \\
\text { como o motor de crescimento da companhia. } \\
\text { - A inovação pode reduzir custos, como por exemplo a internalização de exames, a } \\
\text { transferência de tecnologia, e pode também gerar valor por meio de um diagnóstico } \\
\text { preciso e correto, gerando valor para o restante da cadeia. } \\
\text { - O Grupo Fleury classifica suas inovações em inovações de produto (ou serviço), inovações } \\
\text { de processo (técnicos, de atendimento e corporativo), e inovações de novos negócios. } \\
\text { - Em relação ao grau ou intensidade da mudança de inovação, o grupo classifica a inovação } \\
\text { como incremental (ou não disruptiva) e inovação radical (de ruptura, disruptiva). } \\
\text { - A inovação pode ocorrer de maneira "puxada" pelas necessidades do consumidor e do } \\
\text { mercado, como também pode ocorrer de maneira "empurrada" por meio das atividades } \\
\text { de pesquisa e desenvolvimento da empresa. Foi observado que Grupo Fleury a inovação } \\
\text { acontece das duas maneiras. }\end{array}$ \\
\hline
\end{tabular}




\subsection{Estratégia da Inovação}

Conforme visto na revisão da literatura, a estratégia da inovação é a base para as tomadas de decisão ao longo do processo de inovação e deve estar alinhada à estratégia corporativa (DAVILA; EPSTEIN; SHELTON, 2007; WHEELWRIGHT; CLARK, 1992; TIDD; BESSANT, 2015; GOFFIN; MITCHELL, 2005). Foi possível confirmar esta visão no estudo de caso à medida que a estratégia de inovação no Grupo Fleury está intimamente ligada com a estratégia corporativa, ficando explícito nos documentos e falas dos entrevistados.

A missão, visão e valores do grupo Fleury fazem parte da estratégia corporativa, e refletem a essência da organização (quadro 3).

Quadro 3: Missão, visão e valores do Grupo Fleury

\begin{tabular}{|l|l|}
\hline Missão & $\begin{array}{l}\text { Prover soluções cada vez mais completas e integradas para a gestão de saúde } \\
\text { e o bem-estar das pessoas, com excelência, humanidade e sustentabilidade }\end{array}$ \\
\hline Visão & Saúde e bem-estar para a plena realização das pessoas \\
\hline Valores & $\begin{array}{l}\text { 1. Excelência } \\
\text { 2. Respeito } \\
\text { 3. Interdependência } \\
\text { 4. Solidaridade } \\
\text { 5. Voltado ao Cliente } \\
\text { 6. Integridade } \\
\text { 7. Inovação } \\
\text { 8. Eficiência }\end{array}$ \\
\hline
\end{tabular}

Fonte: Grupo Fleury (2017a)

Neste sentido, são estes os principais elementos que alinham a estratégia de inovação à estratégia corporativa, dando também destaque a inovação como um dos 8 valores essenciais da companhia, conforme relata o entrevistado P1:

Entrevistado P1: "Há diversos elementos que conectam a estratégia da inovação com a estratégia corporativa. O principal é a conexão com a missão, visão e valores da companhia. Por exemplo, se eu tiver uma inovação muito interessante, com o melhor pesquisador do mundo, e que pode gerar a melhor patente possível... ok, mas esta inovação está ajudando a nossa missão? Ela promove soluções cada vez mais completas e integradas para a gestão de saúde e o bem-estar das pessoas, com excelência, humanidade e sustentabilidade? Devemos sempre nos perguntar em cada etapa do processo." 
A estratégia de inovação também se relaciona com a estratégia corporativa no que tange as competências centrais do Grupo Fleury (PRAHALAD; HAMEL, 1990). A Figura 26 mostra a inovação, pesquisa e desenvolvimento como uma das competências centrais que levam ao diferencial competitivo.

Figura 26: Mapa de competências do Grupo Fleury

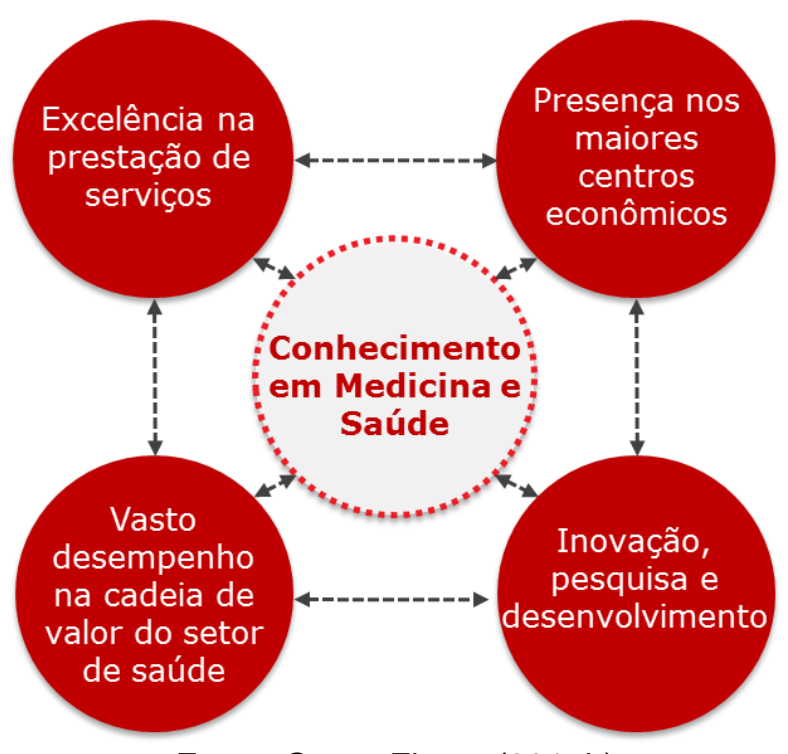

Fonte: Grupo Fleury (2017b)

Conforme apontado por Tidd e Besant (2015), a inovação é vista pela companhia como sendo uma questão de conhecimento, ou seja, é criar novas possibilidades por meio da combinação de diferentes conjuntos de conhecimento. Esse conhecimento pode existir ou não em dado momento, e pode ser explícito ou tácito. Neste sentido, a competência em destaque é o conhecimento em Medicina e Saúde, conforme relata o entrevistado P1:

Entrevistado P1: "Nós somos uma empresa de conhecimento. Qualquer um pode comprar o mesmo equipamento que a gente, qualquer um pode botar uma unidade no mesmo lugar que a gente, qualquer um pode contratar o mesmo pessoal que trabalha aqui e colocar num mesmo lugar e simular o Fleury, mas todos os elementos que geram conhecimento desta companhia, não dá pra comprar. Os processos, as interações, o conhecimento produzido, os tipos de competência gerando conhecimento, o apetite e a capacidade por inovação, conhecimento embarcado utilizado, gerando valor, somente a dinâmica que temos aqui é capaz de produzir"

Os diferenciais competitivos, oriundos das competências centrais são mostrados na figura 27. 
Figura 27: Diferenciais competitivos do Grupo Fleury

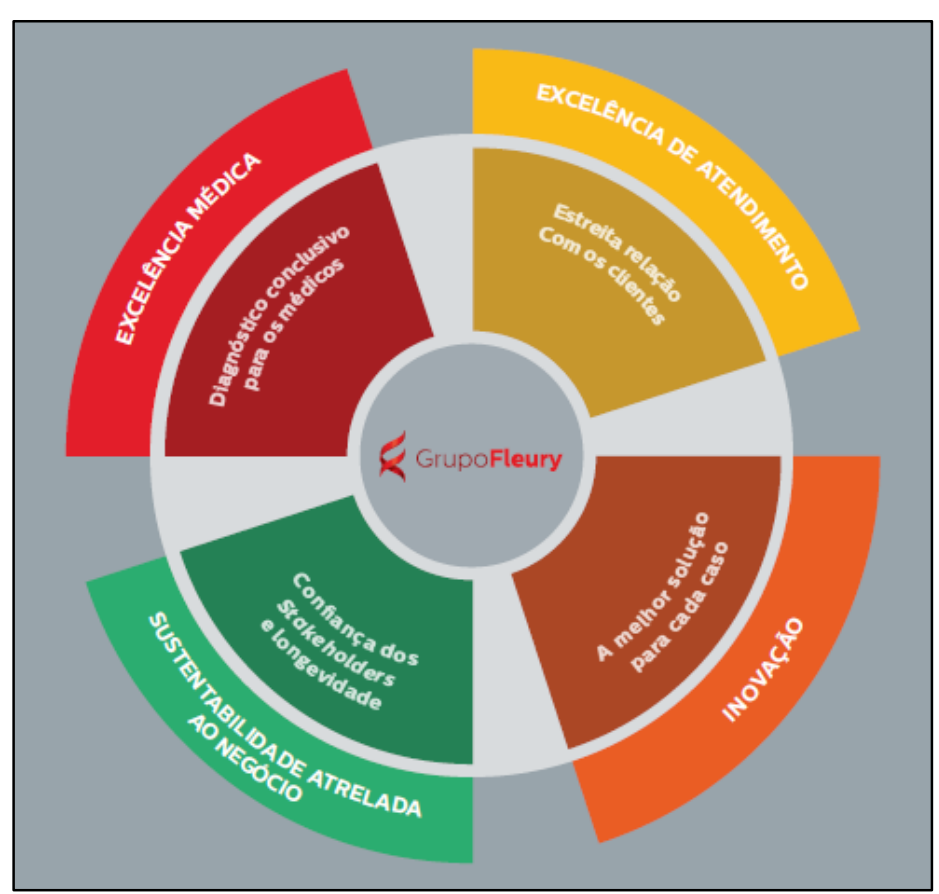

Fonte: Grupo Fleury (2017c)

Desse modo, o Grupo Fleury atua com o posicionamento genérico de diferenciação (PORTER, 1985), atuando com público A, B e C nas principais regiões metropolitanas do Brasil. Seus diferenciais estão ancorados em 4 pilares:

- Excelência Médica: Diagnósticos conclusivos para os médicos;

- Excelência de atendimento: Estreita relação com os seus clientes;

- Inovação: A melhor solução para cada caso;

- Sustentabilidade atrelada ao negócio: Confiança dos stakeholders e longevidade.

Novamente a inovação está presente na estratégia corporativa, como um de seus diferenciais estratégicos. Por meio destes pilares, o Grupo Fleury busca desenvolver uma estreita relação com os clientes e fornecer diagnósticos conclusivos para os médicos.

Quando observamos a estratégia de crescimento, que faz parte da estratégia corporativa, o Grupo Fleury atua na consolidação orgânica do mercado de Medicina Diagnóstica, na expansão de sua presença nas principais regiões econômicas do país, e na ampliação da cadeia de prestação dos serviços de saúde, diferenciando-se por meio da geração de conhecimento e inovação e da excelência no atendimento a seus clientes. Assim, as principais iniciativas que a companhia adota são: 
- Ampliação do portfólio de serviços oferecidos em cada uma de suas marcas, principalmente os serviços de diagnósticos por imagem e de diagnósticos em diferentes especialidades, que acredita possuírem forte tendência de crescimento. A companhia pretende continuar a introduzir diversas inovações em testes, tecnologias e metodologias diagnósticas, bem como renovar constantemente seu parque de equipamentos - um importante foco de investimentos -, permitindo perpetuar 0 reconhecimento em excelência e inovação.

- Expansão da rede de Unidades de Atendimento em todas as marcas e/ou mudança das Unidades de Atendimento para endereços mais estratégicos quando necessário, buscando ampliação, maior qualificação e melhoria da visibilidade da rede em cada uma das marcas, e consequentemente a atração de um maior número de clientes potenciais.

- Ampliação das suas linhas de negócio em operações de diagnósticos em hospitais e soluções em medicina diagnóstica, por meio da expansão do portfólio de serviços e do número de novos clientes para essas linhas de negócio decorrentes de uma melhor estruturação de soluções e gestão dessas linhas de negócio, e pelo reconhecimento da comunidade médica e outros prestadores de serviços de saúde.

- Crescimento por aquisições de outros prestadores de serviços diagnósticos, principalmente na área de diagnóstico por imagem em mercados onde o grupo já atua e em novos mercados com grande número de usuários de planos privados. A companhia pretende continuar o seu histórico bem-sucedido de aquisições seletivas, de maior representatividade e alinhadas com a estratégia de diferenciação, com maior valor agregado e rentabilidade.

Fica claro o alinhamento entre a estratégia corporativa com a estratégia de inovação à medida que o crescimento da companhia passa pela ampliação de portfólio e consequentemente com a inovação de novos produtos, por exemplo, conforme relata o entrevistado $\mathrm{P} 7$ :

Entrevistado P7: "Estratégia de inovação para produtos é alinhada à estratégia da companhia de ampliar portfólio, para que traga um melhor e mais preciso diagnóstico para o paciente e o médico"

A estratégia de inovação também está inserida no acompanhamento de resultados da companhia por meio do Balanced Scorecards (BSC). O Grupo Fleury 
acompanha no nível corporativo, junto à diretoria, os resultados oriundos de inovação, como por exemplo a receita gerada por ela.

Portanto, o alinhamento da estratégia de inovação e a estratégia corporativa se dá por meio da Visão, Missão e Valores da companhia, por suas competências centrais e vantagens competitivas, pela estratégia de crescimento, e pelo acompanhamento de resultados de inovação por meio do BSC corporativo.

A estratégia de inovação é definida no Grupo Fleury em 3 momentos: o diagnóstico, a elaboração de cenários estratégicos e a definição dos direcionadores estratégicos, conforme mostra a figura 28.

Figura 28: Definição da Estratégia da Inovação

\begin{tabular}{|c|c|c|c|}
\hline \multicolumn{2}{|c|}{ Diagnóstico } & $\begin{array}{c}\text { Elaboração de } \\
\text { Cenários Estratégicos }\end{array}$ & $\begin{array}{c}\text { Direcionadores } \\
\text { Estratégicos }\end{array}$ \\
\hline $\begin{array}{l}\text { Análise do Ambiente } \\
\text { Externo }\end{array}$ & $\begin{array}{l}\text { Análise do Ambiente } \\
\text { Interno }\end{array}$ & $\begin{array}{l}\text { Workshops de } \\
\text { Estratégia da } \\
\text { Inovação }\end{array}$ & $\begin{array}{l}\text { Especialidades } \\
\text { Médicas }\end{array}$ \\
\hline $\begin{array}{l}\text { - Análise de Mercado } \\
\text { - Análise da Cadeia } \\
\text { - Tendências da } \\
\text { Saúde }\end{array}$ & $\begin{array}{l}\text { - Performance dos } \\
\text { negócios } \\
\text { - Ambições de } \\
\text { crescimento do } \\
\text { Grupo } \\
\text { - Necessidades de } \\
\text { recursos }\end{array}$ & $\begin{array}{l}\text { - Médicos } \\
\text { - Gestores } \\
\text { - P\&D }\end{array}$ & Temas Estratégicos \\
\hline
\end{tabular}

Fonte: Elaboração Própria

A primeira etapa é de diagnóstico e compreende a análise do ambiente externo e interno.

No ambiente externo, se avalia:

(i) Análise de Mercado: Crescimento econômico, crescimento de mercado, cidades chave;

(ii) Análise da cadeia de saúde: Competidores, movimento de operadoras etc;

(iii) Tendências da saúde: Demográficas e sociais, comportamentais, tecnológicas, econômicas, específicas em saúde e regulatórias.

A análise do ambiente externo contempla:

(i) Performance dos negócios e Especialidades: Crescimento e Rentabilidade;

(ii) Ambições de crescimento do Grupo: Taxa de crescimento ambicionada pela direção nos próximos anos;

(iii) Mapa das necessidades de recursos: Necessidades atuais dos negócios, como recurso humanos, financeiros e tecnológicos. 
O item de maior relevância nesta etapa de diagnóstico acaba sendo as tendências. Cada macro tendência, se deriva em múltiplas tendências, conforme Figura 29:

Figura 29: Desdobramento das tendências da saúde
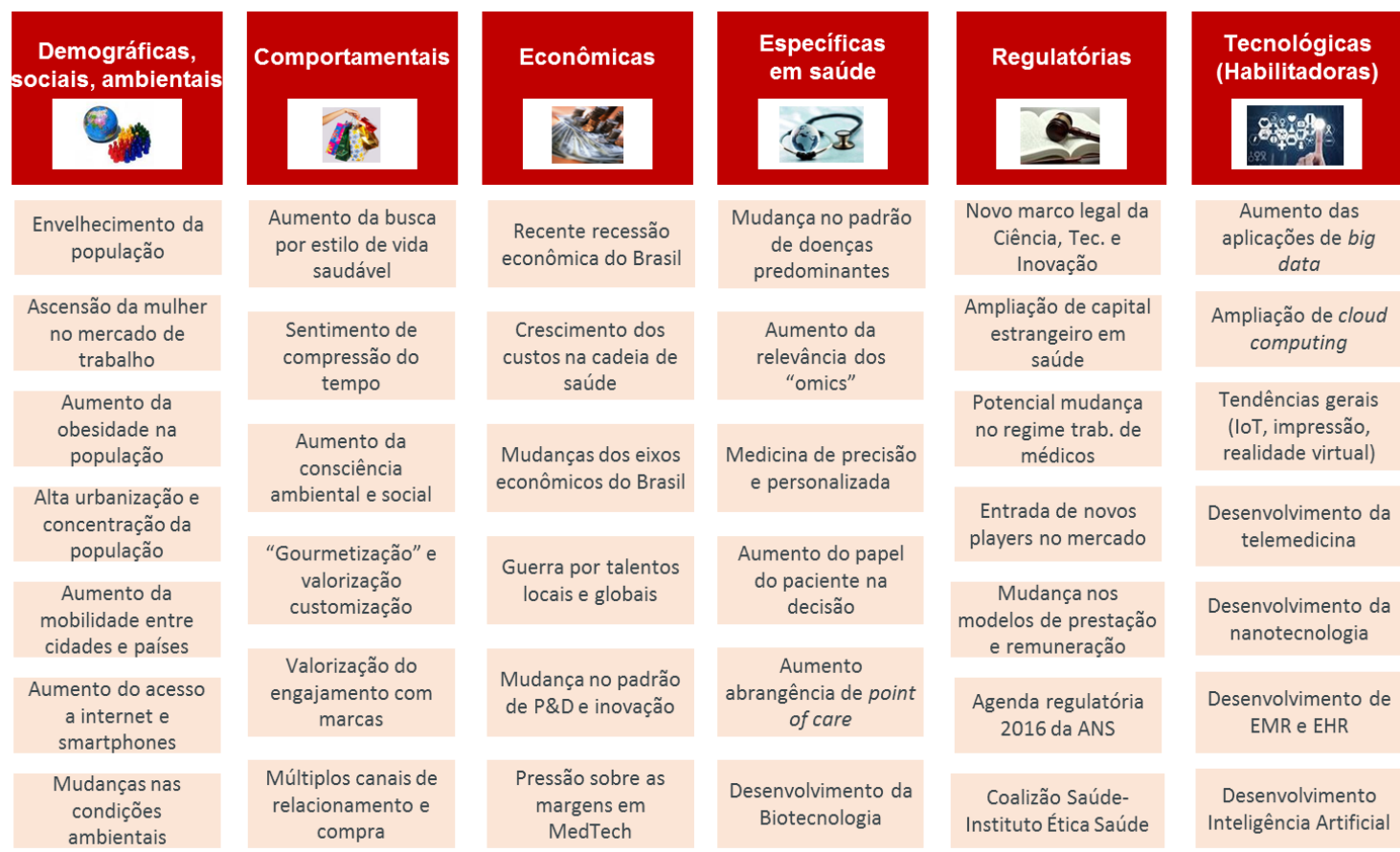
saudável

Recente recessão econômica do Brasil

Mudança no padrão de doenças predominantes

\section{Sentimento de compressão do} tempo

Crescimento dos
custos na cadeia de
saúde

\section{Aumento da}

consciência

ambiental e social

"Gourmetização" e

valorização

customização

Valorização do engajamento com marcas

Múltiplos canais de relacionamento e compra

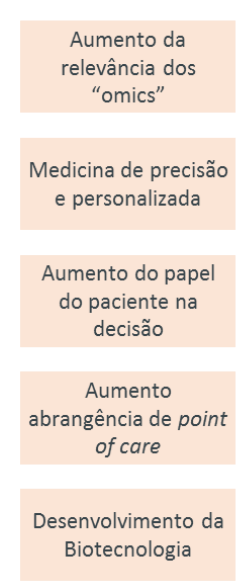

Novo marco legal da

Ciência, Tec. e Inovação

Ampliação de capital estrangeiro em saúde

Potencial mudança no regime trab. de

Mudanças dos eixos econômicos do Brasil médicos

Aumento das aplicações de big data

Ampliação de cloud computing

Tendências gerais (IoT, impressão, realidade virtual)

Entrada de novos players no mercado

Guerra por talentos locais e globais

Mudança no padrão de P\&De inovação
Pressão sobre as margens em

Mudança nos modelos de prestação e remuneração

Desenvolvimento da telemedicina

Desenvolvimento da nanotecnologia

Agenda regulatória 2016 da ANS

Desenvolvimento de EMR e EHR

Coalizão SaúdeInstituto Ética Saúde

Desenvolvimento Inteligência Artificial

Fonte: Material interno compartilhado

E por fim, as implicações de tendência são analisadas. Na Figura 30 temos o exemplo de como se deriva em implicações as tendências demográficas: 
Figura 30: Implicações das tendências mapeadas

\begin{tabular}{|c|c|c|}
\hline Tendência & Caracterização & Implicações \\
\hline $\begin{array}{l}\text { Envelhecimento } \\
\text { da população }\end{array}$ & $\begin{array}{l}\text { - População }+60 \text { anos deve crescer } 50 \% \text { até } 2025 \text {, } \\
\text { representando } 11 \% \text { da população (vs. } 8 \% \text { hoje) } \\
\text { - Maior concentração de mulheres nessa faixa } \\
\text { etária, } 80 \text { homens para cada } 100 \text { mulheres } \\
\text { - Nova população idosa é mais exigente, com } \\
\text { maior poder aquisitivo, familiar com novas } \\
\text { tecnologias e provendo parte da renda familiar }\end{array}$ & $\begin{array}{l}\text { - Mais suscetíveis a doenças crônicas, cardiorrespiratórias e câncer } \\
\text { - Requerem atendimento mais acessível e têm maior restrição de locomoção } \\
\text { - Parcela maior de idosos não tem plano de saúde vs. PEA... } \\
\text { - } \quad \text {...participação crescendo nos planos (redução de } 3 \text { para } 2 \text { jovens por idoso em } 15 \text { anos } \\
\text { - Procedimentos em idosos requerem cuidados e infra específica } \\
\text { - } \quad \text { Nova população idosa atendida por mais serviços de prevenção }\end{array}$ \\
\hline $\begin{array}{l}\text { Ascensão da } \\
\text { mulher no } \\
\text { mercado de } \\
\text { trabalho }\end{array}$ & $\begin{array}{l}\text { - Crescimento de } 2 \text { pp na participação de mulheres } \\
\text { - Do mercado de trabalho nos últimos } 10 \text { anos } \\
\text { casal reduziu de } 2 \text { para } 1,6 \text { nos últimos } 10 \text { anos } \\
\text { - Projeção da queda no número de crianças na } \\
\text { população brasileira nos próximos } 20 \text { anos (500 } \\
\text { mil crianças a menos a cada ano) }\end{array}$ & $\begin{array}{l}\text { - Diminuição da taxa de fertilidade por casal e aumento de gravidezes tardias } \\
\text { - Potencial redução do volume total de exames pré-natal } \\
\text { - Mães com maior renda e autonomia no processo de compra e decisão } \\
\text { - Maior tendência p/gravidez complexa e acompanhamento mais completo } \\
\text { - Aumento das jornadas duplas e sentimento de falta de tempo das mulheres } \\
\text { - Preferência por serviços eficientes e customizados }\end{array}$ \\
\hline $\begin{array}{c}\text { Aumento da } \\
\text { obesidade da } \\
\text { população }\end{array}$ & $\begin{array}{l}\text { - OMS aponta a obesidade como um dos maiores } \\
\text { problemas de saúde pública do mundo } \\
\text { - } 53 \% \text { dos brasileiros acima do peso vs. } 43 \% \text { em } \\
2016 \text { (maior entre homens) e brasileiros obesos } \\
\text { passou de } 12 \% \text { para } 18 \% \text { (maior entre mulheres) } \\
\text { - Prevalência é maior na população de } 35 \text { a } 64 \\
\text { anos, e quanto menor a escolaridade }\end{array}$ & $\begin{array}{l}\text { - Mais suscetíveis a doenças crônicas, especialmente diabetes e hipertensão } \\
\text { - Aumento na busca de cirurgias bariátricas } \\
\text { - Maior demanda por serviços de nutrologia e endocrinologia } \\
\text { - Maior adesão a serviços e medicamentos associados ao emagrecimento } \\
\text { - Atendimento de obesos requer equipamentos diferenciados } \\
\text { - Obesos requerem atendimento mais acessível e inclusivo }\end{array}$ \\
\hline
\end{tabular}

Fonte: Material interno compartilhado

Após o levantamento das tendências, diversos workshops são elaborados para construção de cenários estratégicos, ou seja, caminhos estratégicos que a companhia pode seguir. Esta prática de construção de cenários foram apontadas por Tidd e Bessant (2015) como o método mais utilizados nas empresas para explorar um conjunto de possibilidades. Assim como ocorre no caso, os autores reconhecem esta técnica como descrições consistentes de futuro, com base em hipóteses e interpretações oriundas de análises quantitativas e qualitativas como condutores sociais, tecnológicos, econômicos e ambientais.

Em seguida, a diretoria executiva escolhe os cenários estratégicos, chegando enfim aos drivers que direcionarão a inovação na companhia. Os dois drivers estratégicos são:

(i) Especialidades Médicas Estratégicas: São especialidades médicas consideradas prioritárias nas atividades de inovação. Como exemplo temos a Oncologia, considerada uma especialidade estratégica.

(ii) Temas estratégicos: São temas, áreas de conhecimento, ou mesmo projetos considerados estratégicos para o grupo. Como exemplo temos o projeto Genômica. 
Os drivers inclusive podem estar interconectados, conforme comenta 0 entrevistado P3:

\begin{abstract}
Entrevistado P3: "Genômica é uma coisa que eu vou desenvolver, porque tem futuro e não sei o quê. Os testes de genômica nós vamos colocar. Eu cruzo o que é teste de genômica com as especialidades que eu estou priorizando. A gente vai desenvolver genômica na cardiologia, na oncologia dessa forma"
\end{abstract}

Desse modo, após os drivers serem definidos, a estratégia de inovação é desdobrada para as diversas áreas. Em P\&D por exemplo, ocorre na sequência diversos workshops para a definição de um roadmap que suporte a estratégia de inovação.

Ao longo dos processos de ideação, seleção e difusão, os drivers serão os norteadores.

Esta forma que a empresa define a estratégia de inovação vai ao encontro com aquilo que é apontado na literatura, onde há análise estratégica de fatores externos como o mercado, movimento de competidores, mudanças das tendências tecnológicas, mudanças nos hábitos e necessidades dos clientes, mudanças no ambiente de negócios, bem como os fatores internos como as marcas e linhas de negócio que a empresa quer crescer (GOFFIN; MITCHEL, 2005; TIDD; BESSANT, 2015). 
Quadro 4: Síntese dos achados em Estratégia de Inovação

\begin{tabular}{|l|l|}
\hline & \multicolumn{1}{|c|}{ ESTATÉGIA DE INOVAÇÃO } \\
\hline & $\begin{array}{l}\text { A estratégia de inovação é a base para as tomadas de decisão ao longo do processo de } \\
\text { inovação, bem como deve estar alinhada à estratégia corporativa. Análise estratégica de } \\
\text { fatores externos como o mercado, movimento de competidores, mudanças das tendências } \\
\text { tecnológicas, mudanças nos hábitos e necessidades dos clientes, mudanças no ambiente de } \\
\text { negócios, bem como os fatores internos como as marcas e linhas de negócio que a empresa } \\
\text { quer crescer, influenciam na definição da estratégia de inovação (DAVILA; EPSTEIN; SHELTON, } \\
2007 ; \text { WHEELWRIGHT; CLARK, 1992; GOFFIN; MITCHEL, 2005; TIDD; BESSANT, 2015). }\end{array}$ \\
\hline - O grupo apresenta uma estratégia de inovação alinhada à estratégia corporativa de \\
diferenciação. \\
- A estratégia da inovação é alinhada com a estratégia corporativa, refletindo-a nos elementos \\
de visão, missão e valores sendo que a inovação é um dos valores da companhia. \\
- A estratégia de inovação também se relaciona com a estratégia corporativa no que tange as \\
competências centrais do Grupo Fleury, levando ao diferencial competitivo de oferecer a \\
melhor solução para cada caso diagnóstico. \\
- A estratégia da inovação é acompanhada pelo BSC corporativo mensalmente. \\
- A estratégia da inovação é definida pelo planejamento estratégico por meio de estudos que \\
envolvem diversas áreas. \\
- A estratégia corporativa de crescimento possui como um de seus elementos a ampliação de \\
portfólio e serviços por meio da introdução de inovações em medicina diagnóstica. \\
- A estratégia de inovação é definida em 3 etapas: \\
o Diagnóstico do ambiente externo (Mercado, Cadeia de Saúde, Tendências) e interno \\
(Performance dos negócios e especialidades, Ambições de crescimento, Mapa das \\
necessidades de recursos). \\
O Elaboração de cenários estratégicos e discussão em workshops com stakeholders. \\
o Escolha da diretoria executiva dos cenários estratégicos. \\
- Por fim se chega aos drivers estratégicos que direcionam a companhia inteira, sendo eles: \\
Especialidades Médicas Estratégicas; Temas estratégicos.
\end{tabular}

Fonte: Elaboração Própria

\subsection{O Processo}

Conforme destacado por Thakur, Hsu e Fontenot (2012), o processo de inovação em serviços de saúde possui forte interação dos stakeholders. Esta interação foi observada no estudo em serviços de medicina diagnóstica, em especial no processo de ideação, conforme previa o modelo de Hansen e Birkshaw (2007).

Os médicos externos são parte fundamental do processo de inovação, pois solicitam aos pacientes a realização dos exames, ou seja, eles possuem o papel de prescritores e acabam influenciando os pacientes na escolha do prestador (VARGAS, 2006), conforme suas necessidades de se oferecer o melhor diagnóstico (OMACHONU; EINSPRUCH, 2010). Portanto, eles definem qual exame ou mesmo a metodologia a ser utilizada, confirmando seu papel fundamental nesse processo de 
inovação conforme apontou Burns et al (2002), García-Goñi, Maroto, Rubalcaba (2007) e Bohrer e Vargas (2009).

Os médicos internos também influenciam diretamente no processo de inovação. A inserção dos médicos internos nas universidades é um dos fatores que influenciam no processo de ideação. Dos quase 1800 médicos do Grupo Fleury, 1367 são especialistas, 178 possuem mestrado, 160 possuem doutorado e 71 possuem pós doutorado/livre docência. Envolvidos no meio acadêmico diariamente, os médicos do Fleury também são pesquisadores, e estão envolvidos na busca pela inovação. Neste sentido, as universidades também são consideradas pelo grupo como fortes influenciadoras no processo de inovação, conforme já havia sido apontado por Pisano (2006), Chaves e Albuquerque (2006) e Albuquerque e Cassiolato (2002). O Grupo Fleury possui um relacionamento histórico com as universidades. Em 1936 iniciava as primeiras cooperações de pesquisas técnico-científicas com as melhores universidades do País. Esta importância é relatada pelos entrevistados P5 e P11:

Entrevistado P5: "A universidade e a relação com o Fleury também é antiga. Nossos fundadores era professores universitários, hoje em dia muitos médicos ainda são. Muita pesquisa é feita em conjunto com a universidade, muito conhecimento é gerado."

Entrevistado P11: "Nós Somos uma empresa de conhecimento, lideranças médicas e conexão com o universo científico. Eu entendo que o fato de a gente ter lideranças médicas em todos os níveis e conectados com a academia influencia o processo de inovação, pois se não tiver alguém com uma conexão científica muito forte, com 0 que está acontecendo, a gente não vai conseguir mapear o futuro do nosso negócio"

Os clientes também acabam influenciando o processo de inovação em medicina diagnóstica, mas em especial para novos processo, principalmente processos de atendimento. No caso estudado assim como apontado por Omachonu e Einspruch (2010), os clientes têm necessidade de melhoria na sua experiência como ter um atendimento personalizado, melhoria no bem-estar psicológico, redução do tempo de espera tanto para agendar um exame como para realizá-lo, redução dos atrasos na liberação de laudos.

Conforme relatado pelo entrevistado $\mathrm{P} 3$, a influência dos clientes no processo de inovação ocorre em menor escala, dado que a escolha pelo serviço é ainda bastante influenciada pelo médico do cliente. No entanto, este cenário está mudando 
e o cliente está cada vez mais participativo na escolha de seu prestador, buscando aqueles que atendam às suas necessidades.

\begin{abstract}
Entrevistado P3: "O cliente, hoje, ainda é muito influenciado pelo médico, mas cada vez mais está buscando informação. Essa questão do empoderamento do paciente é exatamente isso: o indivíduo que lê e que quer saber sobre novas tecnologias no setor de saúde. Veja quantas revistas nas bancas falam das novas tendências de saúde. Isso tudo ele acaba sendo influenciado e influenciando o setor para mudar e inovar conforme suas necessidades."
\end{abstract}

Esta visão é confirmada pela literatura com SEKI et al (2003) que reforça que o cliente está cada vez mais associando à qualidade do atendimento, em sua experiência como um todo (PEDROSO, 2016). Desse modo, é desejo da empresa entender e capturar ideias dos clientes finais também.

Assim conforme apontado por Pedroso (2010); Chaves e Albuquerque (2006), e Gadelha (2003) para o setor de saúde em geral, os fornecedores, em especial a indústria farmacêutica, de equipamentos eletrônicos, e materiais de consumo, também são considerados atores influenciadores no processo de inovação em medicina diagnóstica. Porém, os fornecedores de próteses e órteses, mencionados por Pedroso (2010) não foram identificados no estudo, uma vez que é fraca a atuação deles nas atividades de medicina diagnósticas. No estudo ainda surgiu, a influência de outros fornecedores não citados pelos autores, como fornecedores de infraestrutura e contratação de serviços (facilities, manutenção, TI). Estes fornecedores podem sugerir desde uma nova tecnologia na infraestrutura da unidade de atendimento, até um novo serviço diferenciado de copeira, limpeza e estacionamento para o cliente premium. Há bastante proximidade na relação do Grupo Fleury com os fornecedores na busca de gerar valor conforme relata o entrevistado P1:

Entrevistado P1 "Quando se fala em inovação, a relação com fornecedores não pode ser transacional mas sim de geração de valor agora e para o futuro, compartilhamento de conhecimento e competências."

Outro ponto interessante é que devido à seriedade e o compromisso do Grupo Fleury com a qualidade, os processos de homologações de equipamentos e materiais servem de referência para outros players. Assim, os fornecedores buscam validar 
suas inovações e tecnologias introduzindo no Grupo Fleury, para terem facilidade na introdução em outros players do mercado, conforme relata o entrevistado P9:

Entrevistado P9: "A gente tem um relacionamento muito próximo com os fornecedores, isso a equipe foi buscando ao longo dos anos, foi adquirindo através de homologações, através de visitas em feiras. Então, isso é muito constante, eles apresentam sempre para a gente, eles buscam trazer para o Fleury antes. Existe essa preocupação em validar no Fleury. Eles sabem que todo nosso processo de homologação traz uma seriedade muito grande, então, uma vez homologado para entrar no Fleury, eles sabem que têm portas abertas em outros players também "

Os órgãos reguladores, em especial a ANVISA e a ANS acabam influenciando o Grupo Fleury, na medida que modificam ou criam novas leis ou regulamentos conforme apontado por Albuquerque e Cassiolato (2002); Omachonu e Einspruch (2010); Vargas, (2006); e Windrum e García-Goni (2006). Por exemplo, a utilização de um equipamento de imagem ou um kit comercial de reagente químico para os exames de Análises Clínicas deve ter registro na ANVISA. No caso, quando um determinado exame não possui um kit comercial registrado na ANVISA, o Grupo Fleury acaba desenvolvendo internamento o seu próprio kit, gerando uma inovação. Para tal, é necessário seguir rígidas normas de validação do exame.

Entrevistado P3: "Eu não vou fazer testes que a Roche me vende um kit já aprovado na ANVISA. Então, o nosso nicho de P\&D é muito restrito. Por quê? Porque tem a questão regulatória, eu tenho que fazer testes que eu posso desenvolver in house, mas tem uma série de regulamentações com relação à ANVISA que devemos seguir"

Conforme relatado pelo entrevistado P3, a ANVISA cumpre o seu papel e ajuda a estabelecer padrões mínimos de qualidade no setor, mas por vezes acaba restringindo a inovação por conta do burocrático e lento processo de aprovação de equipamentos e kits. Foi apontado por Curtis e Schulman (2006) que a regulamentação quando se torna rígida, inibe a inovação.

Entrevistado P3: Um dos problemas que os grandes fornecedores colocam é que o processo regulatório no Brasil é demorado. Mas, de certa forma, a partir do momento em que a ANVISA regulamenta, ela também ajuda no sentido de que se pode confiar... Mas é um processo ainda demorado. Que quando é aprovado, a inovação já pode estar ultrapassada. Por exemplo, para lançarmos o produto EOS, o fornecedor demorou anos até conseguir o registro na ANVISA. 
A ANS também acaba influenciando o processo de inovação, dado que pode incluir ou retirar procedimentos do acesso de cobertura das operadoras (Vargas, 2006). Com o objetivo de padronizar as denominações dos procedimentos e desenvolver uma codificação clínica comum, a ANS criou a Terminologia Unificada da Saúde Suplementar (TUSS), também chamada de tabela TUSS. Com o objetivo de reduzir riscos econômicos para o setor, a ANS também definiu aqueles exames que obrigatoriamente devem ser cobertos pelas operadoras. Este exames são incluídos no Rol de Procedimentos e Eventos em Saúde, ou também chamado de rol da ANS.

\begin{abstract}
Entrevistado P3: "A discussão da ANS é mais no sentido de se ela vai incorporar uma nova tecnologia no hall de procedimentos para tornar obrigatório o pagamento pelas operadoras. Ela tem um papel no sentido de avaliar e também restringir, pela questão de sustentabilidade, a incorporação de novas tecnologias."
\end{abstract}

Todos os exames pertencentes ao rol da ANS possuem código na tabela TUSS, porém nem todos os exames pertencentes a tabela TUSS estão no rol da ANS. Periodicamente o rol da ANS é revisto, no entanto, o processo para um exame entrar no rol da ANS é bastante burocrático, pois envolve diversas questões que vão desde a relevância clínica do exame até o seu impacto econômico no gasto futuro com as operadoras. O Grupo Fleury possui muitos exames que são novos para o mercado, e que ainda não pertencem ao rol da ANS ou nem mesmo possuem código TUSS. Eles são comercializados na maioria das vezes como exames particulares, desse modo com volume reduzido, impactando por vezes os custos fixos da companhia. Desse modo, exames que já possuem rol ANS, são mais fáceis de se provarem viáveis financeiramente e seguirem com maior facilidade no processo de inovação. Por outro lado, novos produtos que estão fora do rol ANS podem não ser viáveis financeiramente. Logo, a inovação para metodologias de exames presentes no rol ANS acaba sendo incentivada.

As operadoras também acabam exercendo influência no processo de inovação, dado que buscam reduzir seus custos com a sinistralidade, criando políticas de restrição ao acesso dos serviços ofertados. Isso ocorre tanto na decisão da operadora por credenciar ou não determinado produto oferecido pelo Grupo Fleury, como também por meio das modalidades de coparticipação que os planos de saúde oferecem. Na modalidade de coparticipação, o usuário arca com parte do custo do 
serviço ofertado. Sendo assim, as operadoras acabam influenciando o surgimento de inovações que resultem em menor custo. Esta pressão por redução de custos foi observada nos hospitais por Vargas (2006) e é relatada pelo entrevistado P3:

Entrevistado P3: "É claro que a operadora vai buscar o melhor produto ao menor custo. Mas por vezes um produto mais caro, uma metodologia melhor de diagnosticar algo, pode reduzir os custos dela lá na frente. Então nós precisamos mostrar que aquela inovação faz sentido no ponto de vista econômico. Se eu já sei antecipadamente que ela tem interesse em uma inovação, isso já facilita que eu invista e avance com as pesquisas. Como diferencial pra marca Fleury isto funciona bem, mas no geral ela quer reduzir custos. Se eu for vender só como particular, o meu público é muito restrito. Não consigo diluir volume e meu custo se eleva [...] mas sinceramente, a gente faz a inovação independente da operadora. "

Os órgãos representativos também acabam influenciando a ideação (Albuquerque e Cassiolato, 2002). O Grupo Fleury participa de entidades setoriais e de classe, nacionais e internacionais, integrando-se às discussões sobre temas de interesse do setor médico e para o desenvolvimento socioeconômico brasileiro. Seu posicionamento e suas propostas são expressos de forma transparente, objetiva, e fundamentados em seus valores e princípios de sustentabilidade. O Grupo Fleury também participa do conselho e nas Câmaras Técnicas e jurídicas, Associação Brasileira de Medicina Diagnóstica (Abramed) e busca dentre outros objetivos, contribuir para reunir, produzir, sistematizar e disseminar o conhecimento interdisciplinar no do setor. Também contribui para o aperfeiçoamento da legislação setorial. O Grupo Fleury também faz parte da Sociedade Brasileira de Patologia Clínica/ Medicina Laboratorial, com o objetivo de prover e estimular a melhoria da qualidade dos serviços, avaliando, sugerindo e incorporando novas tecnologias. Visa integrar pessoas e organizações que se dedicam à área científica e profissional de Medicina Laboratorial.

O Grupo Fleury também tem participação em diversos outros comitês como AMB, SINDHOSP, ABIMED entre outros, buscando debater novos avanços da saúde.

Por fim, além dos órgãos reguladores e representativos, foi também destacado pelo Entrevistado P3 o órgão do ministério da ciência e tecnologia:

Entrevistado P3: "Eu colocaria mais um órgão, que é o ministério da ciência e tecnologia. A gente aqui tem recurso financeiro da FINEP, que vem do ministério da ciência e tecnologia para incentivo de 
inovação da empresa. Especificamente o programa que a gente tem financia inovação de forma ampla. Então, o MCT por meio desses programas de apoio à inovação da empresa, tem a Lei do Bem."

O Grupo Fleury possui financiamento da FINEP (Financiadora de Estudos e Projetos), para apoiar financeiramente projetos de inovações tecnológicas. O Grupo Fleury também recebe incentivos fiscais por meio da Lei 11.196/05, mais conhecida como a "Lei do Bem", em que empresas que investem em pesquisa e desenvolvimento de inovação tecnológica recebem este incentivos.

O Grupo Fleury possui dois processos de inovação estabelecidos: 1) Processo de novos produtos; 2) Processo de novos processos. Ambos tratam prioritariamente de inovações incrementais e estão alinhados ao modelo hegemônico por hora adotado por esta pesquisa (HANSEN; BIRKISHAW, 2007). Já as inovações radicais, não possuem processos estabelecidos e podem ser tanto do tipo produtos, processos, e novos negócios. As inovações radicais são tratadas como projetos especiais, conduzidas por uma equipe apartada da operação.

\subsubsection{Ideação}

Conforme apontado por DOSI (1982) a inovação pode ocorrer de maneira "puxada" pelas necessidades do consumidor e do mercado, como também podem ocorrer de maneira "empurrada" por meio das atividades de pesquisa e desenvolvimento da empresa. Foi observado que no Grupo Fleury a inovação acontece das duas maneiras. Pelo lado da inovação "puxada", os principais consumidores do Fleury são os médicos, clientes finais e operadoras conforme apontado por Pedroso (2016). Cada um deles possui suas necessidades conforme já apontado por Omachonu e Einspruch (2010), e são capturadas por meio de técnicas diversas. As necessidades médicas são capturadas principalmente pelos médicos internos, que possuem um forte relacionamento com os médicos externos. As necessidades dos clientes são capturadas por meio de pesquisas do tipo survey enviadas eletronicamente, pela técnica de focus group, pela observação do comportamento do cliente nas unidades, pelas pesquisas de satisfação e reclamação, e pelas análises internas do comportamento do consumidor (VARKEY; HORNE; BENNET, 2008; GOFFIN; MITCHELL, 2005; TIDD; BESSANT, 2015). Já as necessidades das operadoras são capturadas principalmente pela equipe comercial. Pelo lado da inovação "empurrada", o Grupo Fleury não somente possui atividades de 
pesquisa e desenvolvimento como possui um departamento dedicado a estas atividades. As inovações "empurradas" são normalmente dirigidas pela equipe de Pesquisa e Desenvolvimento, também chamado de P\&D no Grupo.

O processo de inovação de novos produtos no caso estudado segue basicamente o modelo de stage gates de Cooper e Edgett (2001), iniciando-se com a etapa de ideação, ou o que os autores chamam de etapa de descoberta que envolvem pesquisas técnicas, novas tecnologias, análise das necessidades dos clientes etc. Estas atividades no Grupo Fleury, são conduzidas principalmente pelos assessores médicos e técnicos, que além de estarem bem próximos do cliente médico, também estão envolvidos no meio acadêmico diariamente, conforme aponta o entrevistado P3:

Entrevistado P3: "Quando a gente fala que é importante o vínculo que a gente ainda tem com a universidade, é porque esses médicos, no geral, não estão simplesmente fazendo uma prática médica. Além da prática do dia a dia, eles estão vendo o que tem de novo."

Os assessores médicos e técnicos são pesquisadores e muitos são professores de universidades, que estão antenados com tudo o que acontece de novo em medicina diagnóstica. Desse modo, a geração de ideias ocorre de maneira natural, por estarem envolvidos com pesquisa nas universidades, lendo artigos e publicações científicas e também participando de congressos nacionais e internacionais. O Fleury ainda incentiva estas atividades por meio de programas que serão detalhados na sub seção 6.5 .

Como ferramenta para gerar ideias, o Grupo Fleury possui fóruns médicos semanais, onde os assessores médicos participam trazendo para discussão em grupo as novidades do setor, tendências futuras, pesquisas clínicas, entre outros temas que acabam gerando discussão e propostas de inovação. Este encontro é chamado de Fórum de Estratégia Médica. Ele ocorre uma vez por semana na unidade Paraíso com os médicos coordenadores de exames de imagem. Também ocorre uma vez por semana na sede do Jabaquara o encontro com médicos assessores de exames de análises clínicas.

Entrevistado P3: "temos o fórum de estratégia médica onde discutimos inovações e tendências da medicina. Nós colocamos todo mundo junto para ver o que faz sentido ou não. Tem desde pautas médicas até pautas de tendências das especialidades, o que faz sentido e como é que a gente traz essa inovação. Então, acabou criando um arcabouço que favorece todas essas discussões sobre inovação e sua captura." 
Esta inserção dos médicos internos nas universidades é uma das formas de se gerar ideias. O Grupo Fleury possui um relacionamento histórico com as universidades. Em 1936, iniciava-se as primeiras cooperações de pesquisas técnicocientíficas com as melhores universidades do País.

Entrevistado P3: "Você sabe muito bem que historicamente a gente sempre teve uma visão de que os principais médicos nasceram na universidade e vieram para o Fleury. Isso foi fundamental para que a gente trouxesse essa visão de como a gente poderia, ao longo do tempo, ir cada vez mais ganhando com a inovação, porque a gente percebia o valor disso."

Entrevistado P5: "A universidade e a relação com o Fleury também é antiga. A motivação em querer fazer parte desse grupo e poder aplicar na prática o que você via lá."

Estas cooperações se intensificaram ao ponto de se criar em 2009 a área de Pesquisa e Desenvolvimento da empresa. A área de P\&D é outra fonte de inovação da empresa. Ela é composta por 4 plataformas de pesquisa: Cromatografia, Imunologia e Citometria de Fluxo, Biologia Molecular e Bio Informática. A escolha destas plataformas é explicada pelo entrevistado P3:

Entrevistado P3: "A gente escolheu aquelas áreas, que têm alguns
diferencias, por exemplo, que você não tem o kit comercial. A
espectrometria de massa não existe kit. Os testes são todos
desenvolvidos in house na Cromatografia do P\&D [...] ou seja, eu não
vou escolher me desenvolver em áreas em que há grandes
laboratórios produzindo kits comerciais de boa qualidade. Eu não vou
competir com o P\&D da Roche. Sabe por quê? Porque P\&D consome
muito dinheiro, são milhões realmente, para você validar, você ter
registro na ANVISA, você ter tudo. Esse é o business dele, o meu
business não é fazer isso."

Cada plataforma é formada por um grupo de pesquisadores médicos, assessores científicos, técnicos e estagiários. Os grupos se reportam ao coordenador técnico, que por sua vez se reporta à gerência de $P \& D$, que por fim se reporta à diretoria executiva, conforme o organograma da figura 31 : 
Figura 31: Estrutura Organizacional de P\&D

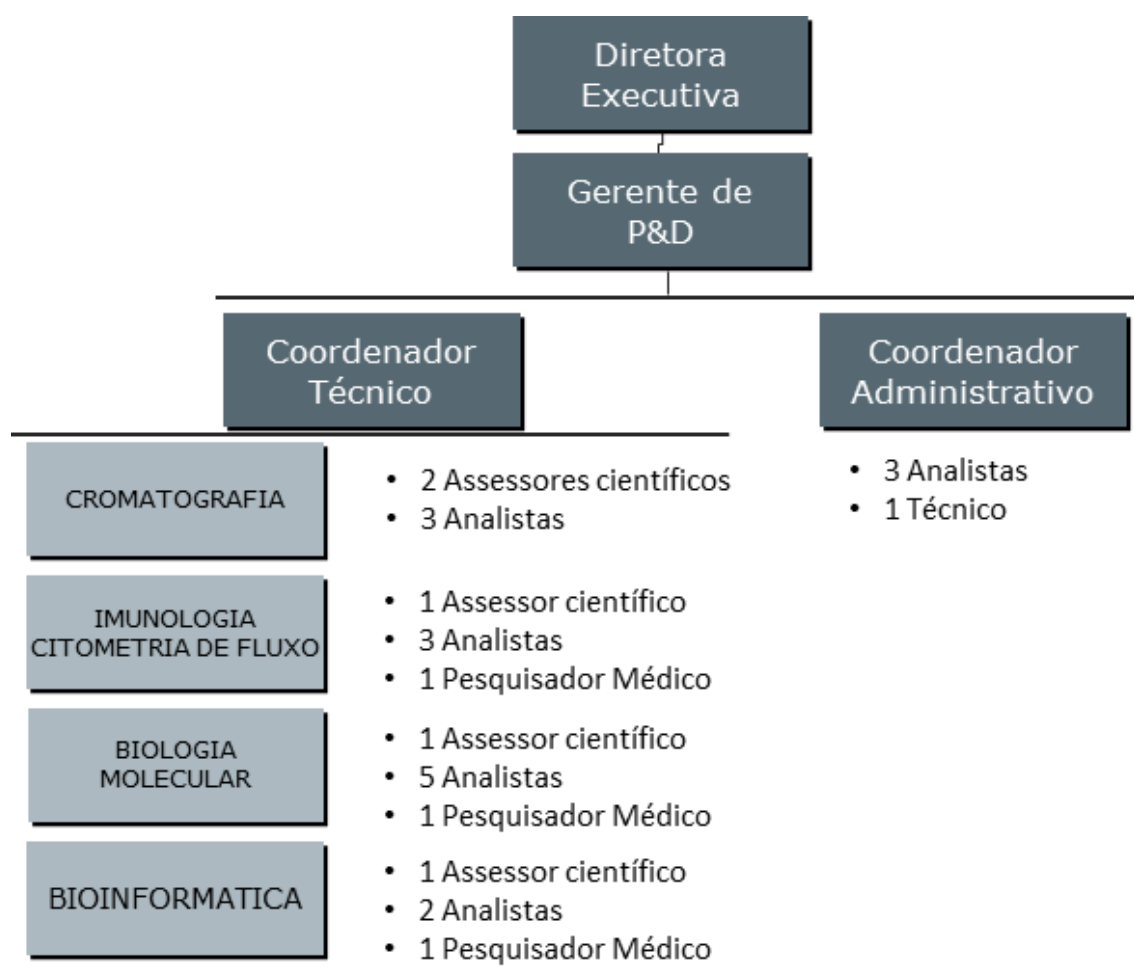

Fonte: Documentos internos compartilhados

Em 2015, 107 projetos de pesquisa e desenvolvimento estavam em andamento no P\&D. Itens de vanguarda estão sendo desenvolvidos e com o aumento de recursos financeiros para inovação, proveniente do aporte de $R \$ 155$ milhões realizado com apoio da Financiadora de Estudos e Projetos (Finep) para o triênio 2014/2016, a área deve ampliar ainda mais sua atuação nos próximos anos.

Há também outras fontes geradoras de ideias para novos produtos que entram por meio de programas provenientes de inovação aberta para os fornecedores, chamada pública das universidades, workshop em hospitais, rastreamento de patentes, entre outros. Enfim, uma gama de fontes geradoras de ideias. A equipe de $P \& D$ e os assessores médicos e técnicos são responsáveis por trazerem para dentro do Grupo, cadastrando o novo produto em um formulário online disponibilizado na rede interna. Este formulário faz parte de um sistema específico para acompanhar este processo chamado Chanel.

No momento do cadastro do novo produto, o idealizador preenche uma série de perguntas relacionadas à ideia como o grau de novidade do produto (novo para empresa, para o brasil ou para o mundo), os benefícios que ele poderá trazer (redução de custo, redução no prazo de entrega, menor dependência do fornecedor, aumento 
da qualidade, manutenção da posição de vanguarda do Grupo), a relevância técnica e clínica, e também uma orientação preliminar referente aos dados de mercado como volume estimado de venda, estimativa de custos e preços, vantagens competitivas, potenciais clientes e praças a serem ofertados, dentre outras informações muito importantes sobre o produto, que servirão de base para a próxima etapa.

A principal dificuldade encontrada nesta etapa está no fato dos idealizadores se sentirem inseguros no fornecimento de algumas informações, seja pelo grau de inovação, ou mesmo pela falta de experiência neste tipo de atividade. Como forma de suporte, o Grupo Fleury possui as áreas de Estratégia de Produtos e Inteligência de Mercado que fornecem informações solicitadas pelo dono do projeto. Esta é a etapa de ideação de novos produtos.

Já para as inovações de processos, os colaboradores internos são aqueles que possuem maior influência na fase de ideação, sejam eles processos relacionais de front office, claramente caracterizado no grupo como processos de atendimento, ou processos de back office, caracterizado no grupo como processos técnicos ou corporativos. Esta visão de processos de front office e back office é citada por Caon e Corrêa (2006), conforme apontado na literatura. Para gerenciar todas estas ideias oriundas dos colaboradores, no ano de 2007 o grupo Fleury implantou o programa Central de Ideias. O programa Central de Ideias é uma plataforma digital utilizada para a geração e a para a primeira avaliação coletiva da ideia. Esta plataforma é mais focada nas melhorias de processos (técnicos, atendimento e corporativo).

O Central de ideias é similar a uma rede social, e encoraja os colaboradores a incluírem ideias e discutirem juntos cada uma delas. O processo se inicia com os colaboradores que identificam uma necessidade não satisfeita. Por exemplo, pode ser uma necessidade do cliente na qual um operador identificou no front office, ou uma melhoria na metodologia do processamento técnico de um exame. Pode também ser uma melhoria nos processos corporativos, como processo de vendas, compras etc.

Mantendo o alinhamento estratégico, as ideias devem gerar valor para a cadeia. Neste sentido, a etapa de ideação pode ocorrer com inclusão de ideias na plataforma de maneira livre, ou com temas direcionados pela estratégia. Estes temas também podem ser derivações dos temas direcionadores das estratégias. Atualmente os temas são: 
- Bem estar do Colaborador: Ideias para promover o bem estar e a valorização de seus colaboradores, a fim de melhorar seu rendimento e satisfação com o trabalho;

- Melhoria em Processos e Qualidade: Ideias para otimizar os processos da área técnica, atendimento ou corporativo, a fim de otimizar o tempo e/ou melhorar a qualidade dos serviços prestados;

- Experiência do Cliente: Ideias que melhorem a experiência dos clientes do Grupo Fleury durante todo o processo de atendimento, desde o agendamento do exame até a retirada dos resultados;

- Otimização de Recursos: Ideias que promovam a economia e/ou a otimização de recursos utilizados pelo Grupo Fleury, ou sejam eles financeiros, ambientais, físicos ou outros que o colaborador considera relevante;

- Responsabilidade Social e Ambiental: Ideias que promovam a preservação do meio ambiente e/ou colaborem com a sustentabilidade social a partir de ações que podem ser tomadas pelo Grupo Fleury;

O colaborador então faz a submissão das ideias por meio de um formulário eletrônico disponível dentro da plataforma, onde deve-se explicar os objetivos da ideia, os benefícios esperados, e as necessidades que seriam suprimidas ou problemas que seriam resolvidos. Para estimular o processo de ideação ocorrem campeonatos entre equipes e distribuição de prêmios. Há uma moeda virtual chamada "inoves" que o colaborador ganha ao sugerir novas ideias. Os usuários (investidores) também podem ganhar inoves comentando e investindo nas ideias que estão no Mercado. A ideia pode ser ou não valorizada, variando o rendimento dos inoves investidos. Além disso, o investidor ganha quando a ideia é implantada e ele investiu a favor, ou quando a ideia não é implantada e ele investiu contra. A quantidade de inoves atribuídos em cada situação é dada conforme definido a priori pelo sistema.

Desse modo, o Central de Ideias acaba sendo uma fonte geradora de ideias, com uma avaliação coletiva inicial.

Além desta importante fonte de inovação de processos, os clientes acabam sendo uma fonte geradora de inovação de processos, em especial processos de atendimento. No Fleury, há uma área destinada a trabalhar com projetos de melhoria nos processos de atendimento. Esta equipe também acaba gerando ideias se 
utilizando basicamente de dois métodos de captura: (i) Reclamações e Sugestões da Ouvidoria; (ii) Observação do comportamento do cliente nas unidades.

A Ouvidoria é a instância dedicada ao tratamento de sugestões e reclamações dos clientes. O Grupo Fleury disponibiliza folhetos de sugestões e reclamações em suas unidades, bem como o telefone da ouvidoria, onde os clientes podem expressar suas necessidades. Além disso, há a pesquisa de satisfação, enviada eletronicamente por e-mail, onde o cliente pode dar uma nota de 0 a 10 e inserir comentários sobre o serviço prestado. Em 2015, a empresa recebeu 20.690 sugestões e reclamações. Estas informações são preciosas para inovações de processo, por exemplo. Há uma equipe dedicada a analisar cada uma das sugestões e reclamações, e assim sugerir inovações nos processos. A equipe de projetos circula as unidades identificando gaps e oportunidades de melhoria. Conversando com os coordenadores, com os clientes, e analisando os indicadores de atendimento como NPS, Reclamações e FANFs, e também vendo ao vivo a reação do cliente a determinados processos. Há um cronograma de visitas semanais no qual as unidades mais críticas em indicadores são priorizadas. Lá ele conversa com os colaboradores, captando sugestões e novas ideias, e observa também o atendimento e o comportamento dos clientes:

Entrevistado P8: "Então, essa visita e essa entrevista são muito valiosas, porque você ouve a verdade do colaborador. Aquilo que não está bom, aquilo que está dando problema, aquilo que eles não estão conseguindo fazer eles confessam, eles contam. A gente não faz diretamente uma pesquisa com o cliente, mas como a gente vivencia e presencia vários atendimentos, a gente fica observando e capta ali como está sendo a discussão do cliente com os colaboradores".

Áreas de interface também acabam sugerindo inovações (equipe de estratégia e inovação, as áreas de negócios e operações, o financeiro por conta do recebimento), normalmente ideias mais complexas.

Fornecedores também sugerem inovação em processo, como por exemplo os fornecedores de $\mathrm{TI}$ que buscam automatizar processos de atendimento, ou mesmo fornecedores de materiais que buscam melhorias nos processos de enfermagem.

No entanto, estas ideias chegam diretamente às equipes de processos, que registram tudo em um banco de ideias em ferramentas básicas como Excel e levam para a discussão com a gestão a fim de serem avaliadas. 
Os colaboradores das áreas técnicas utilizam o Central de Ideias para novos processos técnicos. Para estimular, há semanalmente uma reunião em cada seção técnica para acompanhamento de resultados, onde a inovação faz parte da pauta e rápidas seções de brainstorming são realizadas.

\title{
6.4.2 Conversão
}

A conversão compreende todos os processos necessários para transformar a ideia em realidade, e envolve seleção e avaliação, e desenvolvimento e implantação (Hansen; Birkinshaw, 2007).

A seleção e avaliação das ideias geradas na etapa anterior pode ocorrer de forma individualizada ou colegiada. No caso de novos produtos, a avaliação é colegiada, na forma de um fórum chamado de fórum de novos produtos. No caso de novos processos, há uma avaliação colegiada feita de maneira interativa entre os colaboradores, e em seguida uma avaliação individual do gestor.

A seleção e avaliação de novos produtos é considerada uma importante etapa, conforme aponta o entrevistado P3:

\begin{abstract}
Entrevistado P3: "Na medicina a quantidade de informação nova que surge na literatura é imensa. Como é que diante de tantas possibilidades eu vou filtrar aquilo que importa? [...] portanto, a seleção é necessária devido aos recursos escassos. Olha, a partir do momento em que surge uma ideia, cadastra-se esse produto para que a gente possa fazer uma avaliação se a gente vai seguir no fluxo ou não. Por quê? Porque a gente tem recurso escasso, a gente tem pessoas escassas e, principalmente, porque em algum momento a gente começou a criar a ideia de priorização"
\end{abstract}

A conversão de novos produtos segue o modelo de stage gates de Cooper e Edgett (2001). Após a etapa de ideação (descoberta) e submissão da ideia pelo formulário eletrônico disponível no Chanel, passa-se para a primeira avaliação, que no caso estudado é garantir que a ideia está alinhada à estratégia de inovação e que todos os campos de informação estão minimamente coerentes. Quem faz este trabalho inicial é a própria equipe de administrativa de P\&D. Caso o formulário esteja incompleto, ou incoerente, ou mesmo se a ideia esteja fora da estratégia de inovação, a equipe entra em contato e informa as alterações necessárias. Comparativamente ao modelo de stage gates, esta etapa tenta muito mais corrigir uma ideação mal feita, do que de fato eliminar ideias. No entanto, esta etapa de fato não se deve eliminar 
ideias, e sim buscar alternativas para melhorar a ideia. As informações do projeto são enviadas por e-mail a todos os participantes das avaliações, que farão basicamente 3 estudos: estudo de viabilidade técnica, financeira e comercial. Em seguida ocorrem as 3 etapas de investigação preliminar, investigação detalhada e business case de uma só vez. Desse modo, a área técnica da empresa avaliará tecnicamente o produto, ou seja, se o produto possui relevância clínica comprovada, se há know how e recursos físicos e humanos dentro da empresa para desenvolvê-lo e implanta-lo ou se há alguma necessidade especial para atender ao projeto. Questões operacionais da front office também são investigadas neste momento, a fim de garantir que a parte relacional do cliente estará contemplada. A área comercial avaliará a viabilidade comercial do produto, onde junto com a área de Inteligência de Mercado, dará seu parecer baseado em estudos levantados de representatividade de mercado, potencial de crescimento, se o produto possui código TUSS ou está no rol da ANS, e se há interesse dos clientes em adquirir o produto. Por fim, a área de Custos e Planejamento Financeiro avaliará a viabilidade financeira do projeto, baseado nos estudos rentabilidade, em que são levantados dados financeiros como VPL, Payback, ROI e valor do investimento. No entanto, algumas inovações não são centradas apenas na questão financeira. Mas muito mais se o investimento vai gerar conhecimento para a companhia e fazer com que isso seja alavancado para outras áreas conforme aponta o entrevistado P1:

Entrevistado P1: "Lógico que está implícito que a empresa irá gerar valor, mas creditar a uma inovação se aquele investimento é positivo ou não, a decisão é muito mais estratégica. Ela se relaciona muito mais se o investimento vai gerar conhecimento para a companhia e fazer com que isso seja alavancado para a área que se destina e outras áreas, e isso vai continuar gerando conhecimento para a companhia"

Independentemente do resultado financeiro a inovação é um driver importante para a companhia, portanto é possível ter projetos aprovados sem necessariamente serem viáveis financeiramente, conforme aponta o entrevistado P3:

Entrevistado P3: "a inovação por si só é um driver importante do nosso negócio. Por quê? Porque eu posso não fazer muito dinheiro em um produto específico, mas se ele fizer sentido para aquele grupo de médicos que encaminham os pacientes, eles acabam trazendo como um todo uma receita interessante. [...] há estratégia quando não há 
retorno financeiro? Claro. Isso aqui é importante para o cardiologista. O cardiologista é o segundo maior grupo que encaminha receita para a gente. Eventualmente, eu vou vender pouco desse exame, mas se eu conseguir, com isso, mostrar para esses cardiologistas que eu sou uma empresa inovadora e que quando ele precisa fazer aquele teste eu vou ter, faz sentido no todo. Então, é mais ou menos isso"

O gate 3 de aprovação ocorre então de maneira colegiada na "Reunião Prévia de Produtos", onde o projeto será apresentado para aprovação no nível de analistas, coordenadores e gerentes. Nesta reunião estão as áreas técnicas, comercial, P\&D, estratégia de produtos, planejamento financeiro, inteligência de mercado, negócios, marketing e médicos assessores. Neste momento, o projeto pode ser reprovado, solicitado alguma alteração ou informação e levado novamente na próxima reunião, ou o projeto pode ser aprovado e seguir para a outra aprovação colegiada onde reúne adicionalmente a outra reunião, os gerentes seniores das respectivas áreas, já com o parecer das respectivas áreas. Esta decisão também é colegiada e se chama "Reunião de Aprovação", comparável ao terceiro gate. Aprovado o projeto na reunião de aprovação, passa-se à quarta etapa de desenvolvimento. Há produtos que podem necessitar ou não de desenvolvimento. Aqueles que necessitam, vão para P\&D para serem desenvolvidos, e aqueles que não necessitam de desenvolvimento já entram na etapa de implantação. Comparado ao modelo de stage gates, não há o quarto gate. Se elege o líder do projeto na equipe de P\&D, sendo este o responsável pelo desenvolvimento bem como report do projeto no sistema.

Caso o desenvolvimento tenha um resultado insatisfatório, o proponente indica o término da validação e o projeto deverá ser tratado como concluído (sem implantação). Os treinamentos do front office também são realizados nesta etapa.

Um dos documentos desenvolvidos nesta etapa é o POP, procedimento operacional, onde toda a parte relacional e técnica do produto será documentada. Este documento é feito em conjunto com a área médica, as áreas de processos de atendimento e processos técnicos. Na etapa de desenvolvimento a parte relacional é planejada conforme entrevistado P3:

Entrevistado P3: "Aí, você resolveu fazer a ressonância do cérebro. Tem que chegar processos e falar "Quais protocolos eu sigo?". A equipe de processos senta com médicos que treinam a equipe para fazer aquilo, ou "eu vou colher um exame de AC que é novo...". A enfermagem pergunta "Em que tubo? - Tubo normal. - Beleza! - Ah, não. Tem que ter um tubo especial. - Que tubo especial?". Ela vai e 
valida o tubo especial para colocar na rotina [...] Quando a gente coloca um produto novo, ele passou por todo esse processo, de ponta a ponta. Então, alguém precisa olhar esse fluxo inteiro e fazer com que isso aconteça. Então, o processo em si é complexo. Por isso que eu digo, quando nós fazemos a inovação, não fazemos a inovação de produtos, fazemos a de serviço, sendo que o produto está embutido nele. [...] nosso produto é um serviço na ponta. Não adianta a gente ter uma IG escrita em algum lugar etc. e tal. Não existe algo físico tangível. É o serviço na ponta, você tem que encaminhá-lo de ponta a ponta. O que a gente chama de produto aqui, é o serviço. É o serviço de ponta a ponta.

Após o desenvolvimento em P\&D, o produto segue para implantação. Nesta etapa são disparadas as tarefas que cada área deve concluir para que se possa implantar o produto. Estas tarefas incluem toda a de ativação em sistema, como por exemplo, quais informações o cliente precisa saber, como ele vai realizar o exame, dentre outros pontos que são discutidos pelas equipes processos de atendimento e processos técnicos de CD e enfermagem, desde a etapa de investigação preliminar até o desenvolvimento. Também é definido o médico assessor que ficará responsável pelo produto.

A instrução geral do exame (IG) será disponibilizada no sistema para consulta do cliente, a elaboração dos custeios, elaboração da precificação, máscara de laudos, liberação em sistema, disponibilização de agendas etc. Quando todas as tarefas são finalizadas, passa-se ao lançamento do produto, ou a quinta etapa do modelo, que é o lançamento do produto. A equipe de Suporte Operacional define a data de implantação e dispara um comunicado a toda a empresa informando que o produto será disponibilizado.

Normalmente este processo todo leva muito tempo, o entrevistado 3 relata:

Entrevistado P3: "Por isso demora tanto todo esse negócio. Até você amarrar tudo isso com todo mundo... No dia em que você lança o produto, tem que estar todo mundo treinado. Então, vai tempo. Tem que ver se tem kit ou não, tem que abrir cadastro do kit, o fornecedor tem que fornecer aquele negócio, você tem que comprar o equipamento, você tem que treinar a equipe. Quer dizer, é uma quantidade variável muito grande para você colocar um produto."

De modo semelhante a inovação de produtos ocorre na inovações de processos. As etapas de seleção e avaliação ocorrem de maneira colegiada no central de ideias, no primeiro momento, e depois passa a ser individual. 
No caso das inovações de processos que entram pelo Central de Ideias, elas sofrem duas avaliações sistêmicas. A primeira é do coordenador do programa, que avalia se a ideia já foi proposta em algum momento anteriormente, e se está alinhada à estratégia da empresa. Em seguida a ideia vai para a "bolsa" onde ocorre a segunda avaliação em que todo o grupo pode investir moedas "inoves" nas melhores ideias. Somente as ideias que receberam mais investimentos é que passarão para implantação. Esta é uma forma democrática de avaliar as ideias que os colaboradores mais acreditam. Sendo uma ideia que recebeu investimento por parte dos colaboradores, ela é direcionada ao gestor responsável para fazer a avaliação final, desenvolver se for necessário e implantar a ideia.

Desse modo, as ideias do Central de Ideias se juntam as outras ideias oriundas dos diferentes stakeholders conforme apresentado na etapa de ideação e organizadas em planilhas Excel para a avaliação na área final.

Lá ocorrerá a última avaliação, que poderá levar em consideração questões como a viabilidade financeira, ou técnica para implantar a ideia, assim como produtos. Para isso ele conta com o apoio de outras áreas para ajudá-lo nessa avaliação.

\footnotetext{
Entrevistado P8: "Na seleção e avaliação de novos processos, unimos o que vem do Central de ideias com ideias que recebemos diretamente de fornecedores, clientes e outros stakeholders. Então temos uma lista de projetos que priorizamos junto com a diretoria da área conforme urgência, viabilidade técnica, retorno financeiro, e o que estimamos que trará satisfação para o cliente. Normalmente são priorizados aqueles projetos que ajudarão a melhorar algum processo com indicador crítico."
}

Algumas ideias dependem de investimentos (equipamentos, materiais etc). Dependendo do grau de investimento, tanto para novos produtos como para novos processos, a avaliação financeira sobe para um maior nível de decisão colegiada. No Fleury há os Fóruns de Aprovação de Projetos (FAP), em três níveis: Descentralizado, Corporativo e Executivo. Cada nível tem autonomia de aprovar determinados valores de investimentos. Quando o investimento ultrapassa o valor máximo do Fórum, a aprovação sobe para o próximo nível. Por exemplo, quando um novo equipamento gera um novo produto, ele segue o processo de novos produtos, e na etapa de avaliação ele é levado aos fóruns superiores.

Entrevistado P3: "Se gera um produto, então segue o fluxo de produtos. A compra de um equipamento só faz sentido se, atrelado a 
ele, tiver um produto, um teste diagnóstico. A menos que seja o end of life. Por quê? Porque ele é simplesmente troca."

Em processos, mesmo na parte relacional ao longo da experiência do cliente (PEDROSO, 2016), há uma preocupação de se investir naquilo que de fato gera valor para o cliente:

Entrevistado P3: "quando a gente fala de experiência do cliente, o que a gente quer é colocar aquilo que agrega valor e não simplesmente hotelaria, porque senão você pode ir por esse lado. A gente precisa ter um equilíbrio muito grande. Se eu coloco ele em uma suíte é porque ele vai fazer uma limpeza intestinal... Faz sentido? Faz sentido ou não faz sentido. Esse equilíbrio, às vezes, é tênue. Por quê? Porque se você só dá hotelaria sem o resto, você não agrega valor. Tudo custa. As escolhas que você vai fazer tem que ser com base naquilo que agrega valor para o paciente, que faz sentido ou não. $E$ ele percebe isso."

Após a seleção da ideia de novos processos, ocorre o desenvolvimento e implantação, que normalmente envolve etapas de homologação e de testes. Os testes são realizados inicialmente com voluntariados internos e em seguida com voluntariados externos, como clientes.

Entrevistado P9: "A homologação de fato comprova se o projeto atende a mudança. Primeiro se faz o teste internamente com 20 voluntários, e depois toma a percepção deles. Em seguida se faz 0 teste na ponta. Com um grupo de clientes, e que se questiona ao final do processo, como foi a experiência... se o material foi satisfatório, fácil de manusear, ou se a dor foi reduzida etc. Isso tudo é registrado em planilhas de acompanhamento."

Quando o teste do novo processo está relacionado a um fator relacionado à saúde do paciente, então o projeto deve passar pelo comitê de ética:

Entrevistado P9: "Por exemplo, se eu estou fazendo um teste que estou homologando um frasco novo para a coleta do vírus HPV, eu vou precisar fazer uma coleta além da coleta que eu já faço. Então, para o cliente, isso é perceptível. Eu vou usar o frasco que eu já tenho e vou usar outro frasco. Normalmente, isso acontece quando eu não tenho voluntário, porque eu preciso fazer uma amostra grande, eu não consigo voluntários que tenham a variedade em termos de contato com a doença. Eu preciso ter essa população diferenciada, eu preciso colocar isso na rotina. Eles aprovam e a gente tem um termo de consentimento do cliente dizendo que a gente vai colher uma amostra a mais, que essa amostra vai ser usada para testar o material que a gente pretende usar dentro do grupo. Então, depende muito do impacto que isso tem no cliente. Quando eu tenho uma amostra a mais 
para ser coletada, eu vou gerar um impacto. Os clientes que vão falar ‘Eu prefiro não participar’”.

É na etapa de desenvolvimento que também ocorre alguma correção ou ajuste da ideia inicial, após ser homologada ou testada com o cliente.

Por fim, após estar homologado, testado e aprovado, vamos à parte de implantação.

Para a implantação, na maioria das vezes, para inovações em processos de atendimento ou de enfermagem, é necessário treinar e engajar a equipe pois se a equipe de front office não compra a ideia, é um fracasso logo de cara. É necessário vender o conceito, mostrar que vai mudar para melhor.

Entrevistado P8: "a gente acompanha essa equipe local, faz o engajamento que é importantíssimo, porque eles têm que comprar a ideia, senão você já tem um fracasso logo de cara. Você tem que vender o conceito, tem que mostrar como vai funcionar aquilo na prática. $E$ a gente acompanha os primeiros dias também, porque se vem e só traz e fala 'faz ai que eu volto mês que vem para ver' acaba que as pessoas deixam de fazer 'ah, esqueci de usar', 'ah, esqueci de falar para o cliente"'

A presença no acompanhamento de resultados é fundamental, principalmente no início da mudança, pois corre o risco de a mudança ocorrer nos primeiros dias, e em seguida voltar a fazer o processo antigo.

Entrevistado P8: "primeiras mudanças e ajustes, as pessoas 'Ah, me falaram e depois eu esqueci. Depois ninguém mais cobrou e eu deixei de fazer'. Se perde."

Finalizado o processo de implantação, caso a ideia originou-se pelo Central de Ideias, a gestão então sinaliza em sistema que o projeto foi implantado e o idealizador é premiado com mais inoves, e caso não seja aprovada a ideia, ele recebe uma justificativa do gestor.

\subsubsection{Difusão}

A fase de difusão ocorre tanto dentro como fora do Grupo Fleury. Sendo assim, o Grupo Fleury possui diversos canais de difusão da inovação, tanto para difusão interna, como para a difusão externa. 
Um dos canais de difusão externa são os médicos assessores que realizam as assessorias médicas, nas quais seus especialistas entram em contato com médicos solicitantes dos exames para discussão de casos e envio de relatórios integrados. Neste momento, os médicos do Fleury atualizam o médico cliente sobre alguma inovação recente na companhia, como um novo produto ou processo. Em 2016, foram prestadas 187 mil consultorias médicas (assessorias), e para o ano de 2017 é previsto 192 mil, conforme previsto no Gráfico 6:

Gráfico 6: Número de Consultorias Médicas Realizadas (em milhares)

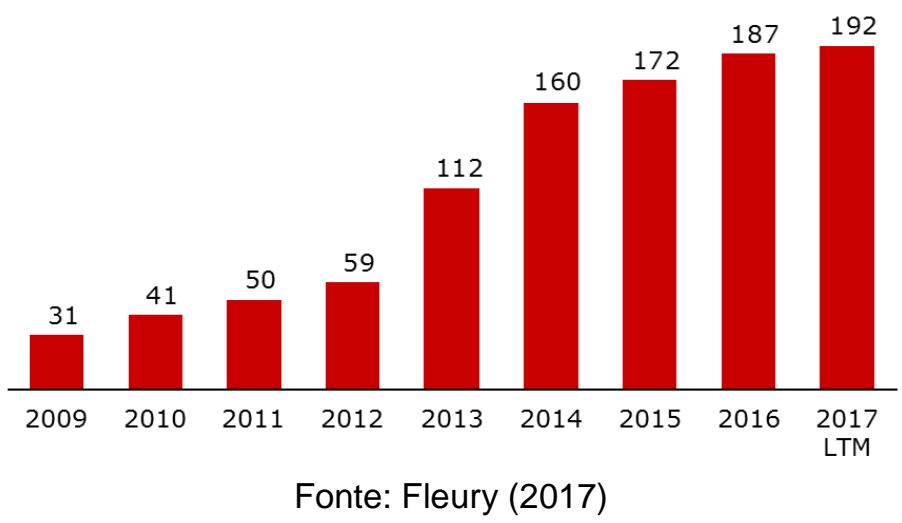

Outra forma de difusão da inovação são por meio dos eventos levando conteúdo educacional. Em 2015, por exemplo, o Grupo Fleury participou de 40 eventos, impactando cerca de 4,9 mil médicos. Pelo segundo ano consecutivo, participou do Congresso da Sociedade de Cardiologia do Estado de São Paulo (Socesp), promovendo simpósio internacional sobre a saúde do coração da mulher, que recebeu mais de 700 participantes. O Grupo também participou no Congresso da Sociedade Paulista de Ginecologia, quando seu estande foi visitado por mais de 2 mil profissionais.

Nestes eventos, o grupo leva seus médicos assessores para explicar sobre as inovações que o grupo realiza. O papel do médico na difusão é fundamental, e ter nomes reconhecidos e atuantes na academia acaba fazendo diferença neste momento, conforme aponta o entrevistado P3:

Entrevistado P3: "a medicina em si ainda carrega um tom de dogmatismo. Essa coisa de ser um médico de referência, ainda é assim. Quando a gente está falando de inovação, uma coisa é um médico bom falar de inovação e outra coisa é um médico que é o bambam-bam. Então, a gente tem os melhores não só para estimular a produção da equipe, mas para trazer a sua validação pelo 
conhecimento e experiência que ele tem e difundir isso pela comunidade [...] Quando os nossos médicos colocam um teste e falam que foi validado, os médicos acreditam que a gente seguiu todo o rigor, porque isso foi construído ao longo do tempo".

O Fleury também realiza alguns jantares onde convida alguns de seus médicos clientes para compartilhar conhecimento em medicina. Lá, por meio de palestras expositivas, são discutidos alguns temas relevantes com foco específico (ex: endocrinologistas), mostrando também aquilo que há de mais novo oferecido pelo Fleury.

Recentemente o Grupo montou uma área de relacionamento médico, composta por assessores técnicos que visitam médicos clientes com o objetivo de estreitar o relacionamento, entendendo melhor as necessidades dos médicos e propondo soluções e mostrando os diferencias do Fleury.

Os médicos clientes contam ainda com revistas de conteúdo científico das marcas Fleury, Weinmann, Felippe Mattoso, a+Medicina Diagnóstica, Labs a+ e Diagnoson a+ com edições trimestrais. Nestas revistas há sempre informações aos médicos sobre os novos produtos, ou unidades ou mesmo diferenciais técnicos oferecidos pelo Grupo Fleury. A tiragem total das publicações chega a 97,4 mil exemplares e todas podem ser acessadas no site das marcas.

No site da marca também há conteúdo exclusivo para os médicos, onde ele pode acessar dentre outras coisas, os lançamentos de novos produtos.

Também há publicação para o público leigo. Clientes da marca Fleury Medicina e Saúde contam com a Revista Fleury, com edições bimestrais onde podem saber sobre as inovações do Fleury.

Olhando agora o cliente operadora, o Grupo Fleury conta com uma equipe comercial que atua na difusão de novos produtos. Este é um trabalho por vezes difícil pois como já mencionado, muitas operadoras não aceitam contratar a cobertura de um novo produto sem que este esteja contemplado do Rol da ANS ou tenha pelo menos código TUSS. Desse modo, a maioria dos produtos são lançados sem credenciamento, sendo vendidos apenas no preço particular. Isto faz parte do posicionamento de diferenciação que o Grupo Fleury possui, conforme aponta o entrevistado P3: 
up lento no início e leva a saber que a receita vinda de novos produtos e serviços inicialmente, enquanto você não contrata a operadora, é menor. Hoje, nós temos uma estratégia de fazer a inovação, colocar como particular no início, e se a operadora não cobre, depois negociamos com ela a partir do momento que a gente mostra todo valor. Porque se você ficar esperando que o produto entre no rol da ANS para então ser credenciado, aí a inovação já ficou pra trás. Nós estamos muito mais a frente disso."

O Grupo Fleury tem um posicionamento de ser uma empresa de inovação, e portanto, esta dificuldade com as operadoras deve ser analisada dentro de um contexto de diferenciação e oferta de um mix completo ao cliente:

Entrevistado P3: "Olha o posicionamento de você se colocar como empresa de inovação, pode por vezes gerar um problema: Hoje tenho um monte de produtos que não têm cobertura da ANS e se você olha o resultado desse produto, pode não ser interessante financeiramente. No posicionamento faz sentido e é por isso que a gente não pode olhar para o produto de forma isolada. Eu sempre falo isso e bastante. Ou seja, o Fleury tem diversos produtos que não estão no hall da ANS justamente por a gente ter esse posicionamento de vanguarda. Talvez não seja financeiramente viável, mas em um posicionamento de inovação faz todo sentido. Inicia-se o plano de divulgação do produto pela área de Marketing e então o produto é lançado para o público. Nesta etapa destaca-se dificuldades em vender o produto para as operadoras. Ocorre que boa parte das inovações não constam na lista de exames de cobertura obrigatória das operadoras. Logo, não há um interesse imediato de contratação por parte delas, sendo o motivo da contratação muito mais voltado para planos diferenciados, que mesmo assim levam um tempo maior de negociação. Sendo assim, quando ocorre o lançamento, boa parte das operadoras ainda não contrataram os produtos. Como consequência os resultados não aparecem tão rapidamente."

Quando focamos na difusão interna, o grupo Fleury possui uma área de comunicação interna que busca manter todos os seus colaboradores atualizados sobre as novidades do grupo Fleury. O principal meio de comunicação é o portal virtual chamado Point. Em formato de rede social, o portal é a principal ferramenta de interação entre os colaboradores e a Companhia. Lá o colaborador pode fazer parte de comunidades e ficar sabendo o que ocorre em determinadas áreas ou assuntos. Por exemplo, ele pode participar da comunidade do P\&D e se manter atualizado sobre os lançamentos de produtos. Pode também acompanhar as comunidades de processos de atendimento e saber o que tem de novo por lá. Além deste portal, 
também há em todas as unidades inclusive nos prédios administrativos, murais informativos que são atualizados semanalmente. Há também o e-mail da comunicação interna, e a ferramenta de troca de mensagens WhatsApp que também é utilizada pelo grupo para difundir informação e por vezes utilizada para difundir a inovação. Outros mecanismos menos padronizados como reuniões de atualização, momentos informais entre outras formas também são utilizados.

Há também a difusão mais técnica e não tanto informacional, como por exemplo caso haja um novo processo ou alteração no processo atual, os documentos técnicos devem ser alterados e comunicados sobre a alteração. Estes documentos podem ser Instruções de Trabalho (ITR), Procedimento Operacional Padrão (POP), Instrução Geral do Exame (IG), por exemplo. Normalmente a comunicação é feita pelo e-mail da área que teve mudanças.

Uma das maneiras de realizar a difusão das inovações dentro da organização é por meio do evento chamado Jornada do Conhecimento. Inicialmente chamada de "Encontro Científico", é um evento anual do Grupo Fleury com o objetivo de integrar as diversas áreas da corporação, onde os profissionais compartilham o conhecimento produzido na sua atuação na empresa.

Entrevistado P5: "a Jornada do Conhecimento começou como uma reunião de discussão de casos clínicos entre os médicos. Foi então que se pensou: vamos ter um espaço para apresentar isso para toda organização para as pessoas trocarem conhecimento?"

O evento surgiu em 1990 e em 2011 recebeu o nome atual, Jornada do Conhecimento, uma vez que ampliou seu enfoque incluindo os projetos das áreas administrativas. Normalmente a Jornada do Conhecimento dura duas semanas e os trabalhos são expostos na forma de totens ou apresentados oralmente.

Os trabalhos são divididos em duas categorias, científicos e casos administrativos, e estas em subcategorias. Os trabalhos científicos são subdivididos em:

- Melhorias em processos técnicos existentes (MPT): melhorias de fluxos; melhorias incrementais; melhorias em produtos;

- Desenvolvimento de novas metodologias (DNM): desenvolvimento de produtos inovadores e/ou novos produtos; novas metodologias e inovações tecnológicas; 
- Trabalhos originais derivados de projetos de pesquisa (PESQ): dados derivados de estudos prospectivos observacionais ou experimentais de disciplinas básicas ou ensaios clínicos;

- Relatos de casos (RC): descrições de casos raros ou de desfecho não habitual, apresentação incomum de doenças ou variações anatômicas, casos cuja investigação diagnóstica (laboratorial e/ou com exames de imagem) teve grande impacto em sua conclusão ou manejo;

- $\quad$ Estudos epidemiológicos (EPI): estudos retrospectivos, séries históricas e dados derivados de análises de bancos de dados; Já os trabalhos administrativos são subdivididos em:

- Processos Principais (macroprocessos chave): trabalhos diretamente ligados à cadeia de valor da empresa com o foco final no cliente; atividades essenciais da organização.

- Apoio: trabalhos com o objetivo principal de melhorar as operações de suporte e/ou apoio da empresa, mas que não são diretamente ligados ao cliente. Trabalhos envolvendo processos de suporte às ações de gestão e aos processos primários tendo impacto direto na atuação destas áreas. Devem garantir a perenidade e execução das atividades principais do grupo.

- Gestão: trabalhos envolvendo o gerenciamento, a coordenação, o controle e/ou o monitoramento dos processos primários e/ou de apoio com o objetivo de orientá-los de forma a permitir que atinjam suas metas operacionais, financeiras, regulatórias e legais.

Os trabalhos são inicialmente avaliados por pelo menos três membros da comissão avaliadora para determinar sua elegibilidade para apresentação oral ou totem. A comissão avaliadora pode sugerir a reclassificação do trabalho em categoria diferente da escolhida pelo autor, de acordo com seu conteúdo;

É feita a divulgação da programação com a lista dos trabalhos selecionados para a apresentação oral ou totem, o local, a data e o horário das apresentações nos meios de comunicação interna

Outra comissão de examinadores avalia os trabalhos no dia da apresentação. Os examinadores definem os melhores trabalhos baseados na originalidade, conhecimento sobre o tema, metodologia, apresentação e contribuição para o Grupo 
Fleury. Os trabalhos mais bem avaliados recebem prêmios em dinheiro conforme as categorias e subcategorias em uma cerimônia especial ao final do evento.

Abaixo temos a síntese dos principais achados do processo de novos produtos e processos:

Quadro 5: Síntese dos achados em Processos de Novos Produtos

\begin{tabular}{|c|c|}
\hline & PROCESSO DE NOVOS PRODUTOS \\
\hline 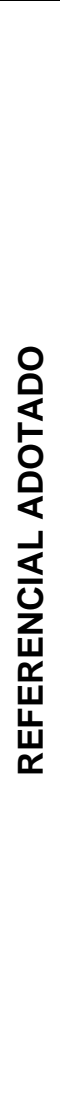 & $\begin{array}{l}\text { Alguns atores são relevantes e influenciam no processo de inovação em saúde: (i) orgãos } \\
\text { reguladores; (ii) médicos; (iii) pacientes; (iv) fornecedores; (v) universidades; (vi) operadoras } \\
\text { de saúde (ALBUQUERQUE; CASSIOLATO, 2002; BURNS, 2002; CHAVES; ALBUQUERQUE, 2006; } \\
\text { GADELHA, 2003; GARCÍA-GOÑI; MAROTO; RUBALCABA, 2007; OMACHONU; EINSPRUCH, } \\
\text { 2010; PEDROSO, 2010; PISANO, 2006; THAKUR; HSU; FONTENOT, 2012; VARGAS, } \\
\text { 2006;WINDRUM; GARCÍA-GOÑI, 2008). } \\
\text { A inovação é um processo integrado, composto por três etapas fundamentais, sendo cada } \\
\text { uma destas um elo da cadeia de valor da inovação: } \\
\text { - A ideação é o processo de geração de ideias que podem surgir internamente, dentro da } \\
\text { unidade de negócio ou entre as unidades, e externamente com universidade, fornecedores, } \\
\text { clientes, médicos etc. Ela pode surgir por meio de técnicas (brainstorming, observação direta } \\
\text { do consumidor, pesquisas, etc). } \\
\text { - A conversão compreende todos os processos necessários para transformar a ideia em } \\
\text { realidade, e envolve seleção e avaliação, onde diferentes critérios e priorização podem ser } \\
\text { utilizados como o alinhamento estratégico, viabilidade técnica e comercial, mercado } \\
\text { potencial, diferenciação, retornos financeiros, riscos etc. O desenvolvimento e a implantação } \\
\text { envolvem etapas de prototipagem, testes, experimentação e análise em um processo } \\
\text { iterativo. Engloba também o desenvolvimento da parte operacional do serviço, monitorando } \\
\text { a aceitação ou não do cliente. Nesta etapa também é desenvolvido o plano de marketing, } \\
\text { treinamentos, vendas, operações e qualidade, para em seguida serem implantados. } \\
\text { - A difusão é a disseminação da inovação dentro e fora da organização, capturando valor por } \\
\text { toda a cadeia. Ela envolve tanto a parte comercial externa, como também a parte interna de } \\
\text { comunicação com os colaboradores. (HANSEN; BIRKINSHAW, 2007; VARKEY; HORNE; } \\
\text { BENNET, 2008; GOFFIN; MITCHELL, 2005; TIDD; BESSANT, 2015; COOPER; EDGETT 1999) }\end{array}$ \\
\hline
\end{tabular}


Segue o padrão do modelo stage gates

Ideação:

- Fontes principais são médicos e técnicos assessores e o departamento de P\&D. Técnicas principais são pesquisas nas universidades, busca em artigos e publicações científicas, e participação em congressos nacionais e internacionais.

- Há encontros semanais chamado de Fórum de Estratégia Médica, para discussão de tendências, pesquisas nos quais ocorrem discussões e a geração de propostas de inovação.

- A inserção dos médicos nas universidades é uma das formas de se gerar ideias.

- Equipe de P\&D desenvolve produtos principalmente onde não há kits comerciais.

- Todos os novos produtos são cadastrados no sistema chamado Chanel, onde é preenchido com informações básicas sobre o produto como grau de novidade, benefícios, relevância técnica e estimativas de custo e preço.

\section{Conversão:}

- Seleção e avaliação é feita de maneira colegiada no chamado Fórum de Novos Produtos envolvendo diversas áreas.

- Os critérios de seleção e avaliação são alinhamento estratégico, avaliação comercial, técnica e financeira.

- Há produtos inviáveis financeiramente, mas que estrategicamente são aprovados. A parte relacional é desenvolvida com as áreas de processos de enfermagem e de atendimento na etapa de desenvolvimento. A parte técnica de desenvolvimento é feito pelo P\&D seguindo os padrões regulatórios. Os treinamentos são realizados nessa etapa, quando necessários.

- A implantação envolve a subida de todas as informações aos sistemas, a disponibilização dos materiais e equipes médicas.

Difusão:

- A difusão externa ocorre principalmente pelos médicos assessores que realizam assessorias, divulgam os produtos em eventos e congressos, e pela equipe de relacionamento médico composta de assessores técnicos que visitam os médicos clientes com objetivo de estreitar o relacionamento apresentando as soluções do Fleury.

- Além disso há materiais de divulgação como revistas para clientes e médicos, comunicação nos sites e redes sociais. Além é claro de uma equipe de vendas que credenciam os produtos para as operadoras.

- Pelo posicionamento do Grupo, muitos produtos são muito inovadores, e não possuem código TUSS ou estão no rol da ANS. Na difusão interna, o Grupo possui uma área de comunicação interna que divulga os novos produtos pelo portal virtual chamado Point. Também há murais, e-mails informativos e ferramentas de troca de mensagem utilizadas para estes fins.

$$
\text { Fonte: Elaboração Própria }
$$


Quadro 6: Síntese dos achados em Processos de Novos Processos

\begin{tabular}{|c|c|}
\hline & PROCESSO DE NOVOS PROCESSOS \\
\hline 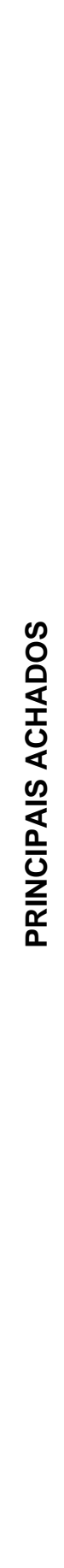 & 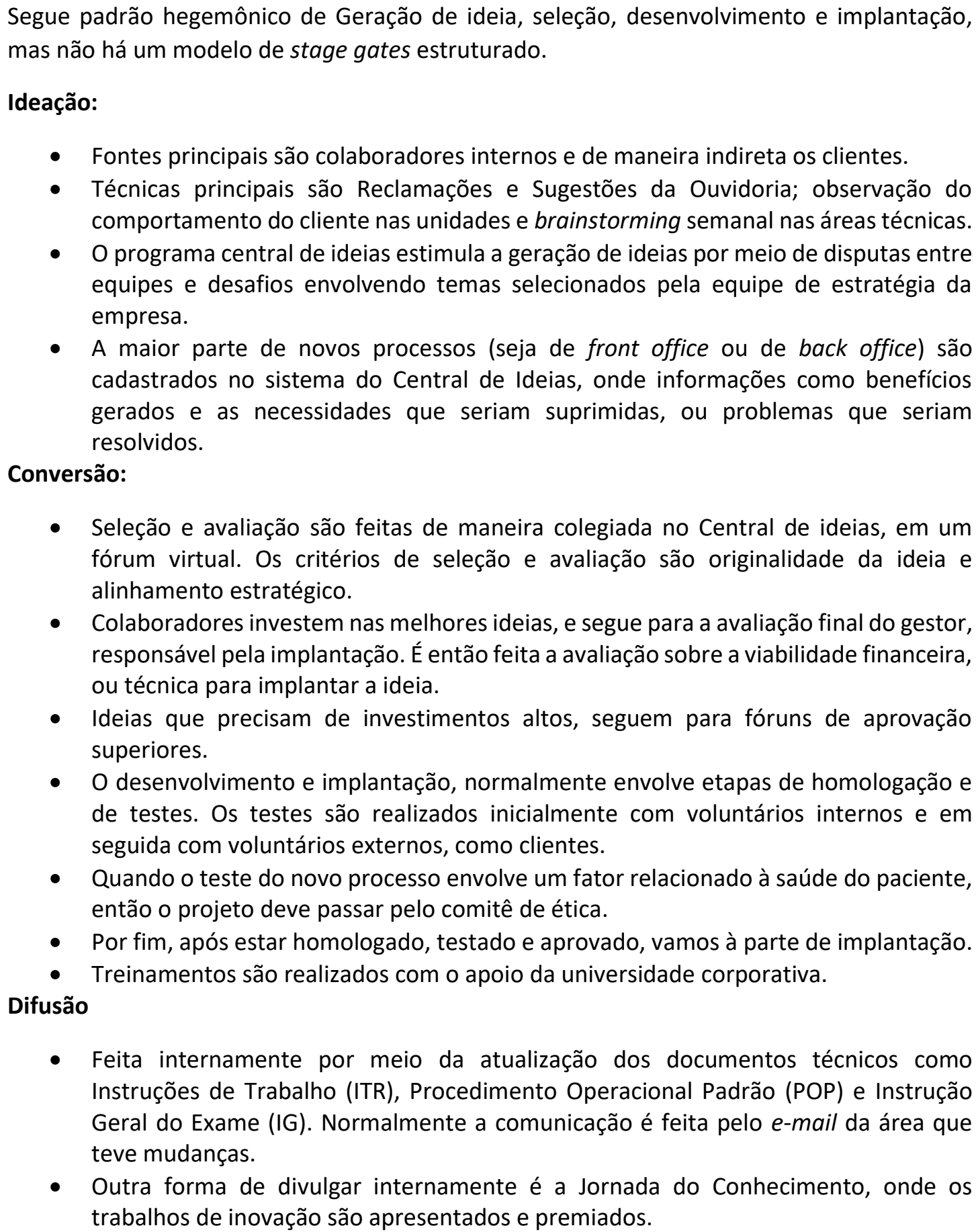 \\
\hline
\end{tabular}

Fonte: Elaboração Própria 


\subsection{Pessoas e Organização}

A cultura de inovação do Fleury é histórica. A busca por inovação por meio do envolvimento acadêmico com as universidades e a realização de pesquisas já eram práticas de seus fundadores. O Dr.Gastão Fleury foi professor do laboratório da Faculdade de Medicina da Universidade de São Paulo (USP), e o primeiro chefe do laboratório central do Hospital das Clínicas, quando foi inaugurado em 1945. Já o Dr.Walter Leser era professor da Escola Paulista de Medicina, e o fundador do laboratório de medicina preventiva, além de ter sido secretário de saúde de São Paulo. Ambos tinham um perfil inovador, conforme aponta o entrevistado 5 :

Entrevistado P5: "A história mostra que a inovação está desde o início com seus fundadores Gastão Fleury e Walter Leser, buscando novas metodologias ou coisas que pudessem fazer do Fleury líder de mercado. O sonho de se fazer uma medicina diferente."

Conforme os anos foram passando, novos médicos associados eram convidados a participar da companhia, agregando o seu conhecimento, tendo o mesmo perfil de buscar coisas diferentes que pudessem agregar valor. Se depois de um tempo esse valor era consolidado por meio de novos exames, metodologias etc, os médicos eram convidados a se tornarem sócios efetivos, comprando cotas da companhia.

Entrevistado P4: "Para chamar os sócios, o Fleury levava em consideração dois pontos: primeiro, o médico tinha que ter relacionamento e segundo, nós considerávamos importante o cara estar na universidade. A faculdade de medicina ainda é um centro gerador de conhecimento e você se aproveita desse centro. É coisa menor com outras profissões, mas na medicina continua sendo. Tem geração de conhecimento, e também tem relacionamento."

Não somente os médicos, mas os técnicos também eram convidados com base nesse conhecimento acadêmico. Para entrar no Fleury "Era não só exigido, mas muito referenciado você ter uma inserção acadêmica", relata o entrevistado P3.

Portanto, foi em cima destes pilares de geração de conhecimento e relacionamento no meio acadêmico que a cultura de inovação do Fleury foi formada.

O Grupo Fleury possui uma biblioteca onde se pode evidenciar a existência de uma série de teses de faculdade como a Escola Paulista de Medicina que foram feitas 
no Fleury. O cientista ou o médico que queria desenvolver um novo produto ou uma nova dosagem, mesmo que ela não tivesse um emprego comercial imediato, recorria ao Fleury para utilizar expertise das pessoas e a contribuição em inovação.

A companhia incentivou desde sempre o conhecimento acadêmico. Mesmo os médicos que não atuam nas áreas técnicas, mas sim no atendimento, são incentivados a se desenvolver na pesquisa e inovação acadêmica.

Entrevistado P4: "Todos nós trabalhamos também na universidade. Temos ótimos alunos de pós-graduação, gente fazendo mestrado e doutorado. E como a bolsa da pós-graduação é muito pequena, e para este aluno sobreviver sem precisar dar plantão muito longe, na periferia etc. Nós temos o costume até hoje de chamar estes pesquisadores para trabalhar como médico de atendimento no Fleury. Assim ele fica aqui das $7 \mathrm{~h}$ às $13 \mathrm{~h}$. Onde de fato até às $10 \mathrm{~h}$ ele tem muito trabalho, mas depois o movimento das unidades fica mais tranquilo e ele pode até estudar ou escrever a tese dele."

Ao passo que pessoas que tinham este perfil de inovação, esse valor dado à pesquisa e à academia, ficava mais fácil a união de pessoas que possuem os mesmos valores, atraindo colaboradores de uma maneira natural.

Entrevistada P5: "Eu mesma cheguei aqui porque eu era da Unifesp e muitos dos meus professores eram médicos do Fleury, e você começa a ter uma admiração muito grande muito mais pelo que era feito aqui".

Entrevistada P5: "Apostava-se muito nesse potencial acadêmico. Nessa coisa da pesquisa, da inovação de uma forma diferente. A gente, de alguma maneira, já participava de muitos projetos dentro da academia. Então, você tinha esse duplo vínculo. Acho que isso foi ajudando nessa constituição, desse olhar de inovação. [...] Na minha contratação eles disseram 'Está tudo certo'. - Mas eu não tenho muita experiência. - Mas a gente adora quem tem história acadêmica. Então, de alguma maneira você vai fazer a diferença aqui’".

Esta cultura de inovação deve refletir nos recursos humanos, incluindo processos de seleção e recrutamento, treinamentos periódicos da equipe e métodos adequados de avaliação." (SEIKI et al, 2003)

Desde o processo de seleção, o Fleury busca colaboradores que estejam conectados com a inovação. 
Entrevistada P3: "Procuramos sempre nos processos de recrutamento este valor de inovação. É fundamental estar o tempo inteiro olhando o que há de novo."

Este valor inerente ao grupo é colocado em prova nos processos seletivos, nas dinâmicas de grupo e nas entrevistas. Segundo o entrevistado P1, quando se atrai pessoas conectadas com a inovação, outras são atraídas por elas:

\footnotetext{
Entrevistado P1: "À medida que traz pessoas conectadas, você atrai outras pessoas também conectadas com inovação. É um círculo virtuoso. Então você cria as condições, atrai as pessoas, elas tem clareza porque geram inovação, contaminam 0 ambiente de relacionamento e de negócios e você consegue trazer mais e mais talentos de inovação."
}

Devido à sua história e ao ambiente que proporciona, o Grupo Fleury acaba sendo um lugar bastante atrativo para aqueles que buscam a inovação:

Entrevistado P5: "Para alguém de fora que está na academia, o Fleury é visto como um centro de inovação, e a gente consegue atrair esses talentos."

Como exemplo, o Programa de Trainees do Grupo Fleury tem por objetivo atrair e desenvolver futuras lideranças que demostrem alto potencial de crescimento conforme sua aderência aos valores do Fleury, em especial o valor da inovação. O processo seletivo é rigoroso e disputado. É esperado deste grupo de talentos um perfil questionador e criativo, que ajude a empresa a pensar "fora da caixa". Ao final da seleção, ficam aqueles que possuem um perfil de liderança alinhado à cultura do grupo. O programa tem duração de dois anos, onde os trainees participam de ações de desenvolvimento educacional em suas áreas funcionais, de negócios e comportamentais, que aceleram o desenvolvimento profissional deles. Todo o processo de desenvolvimento é acompanhado pela Universidade Corporativa, onde cursos são oferecidos por consultorias externas e pelas próprias lideranças internas. Os trainees passam por diversas áreas, desenvolvendo projetos estratégicos e inovadores para a companhia. O desenvolvimento dos trainees é mensurado em ciclos de desempenho, onde a performance e a aderência aos valores são avaliados.

A Universidade Corporativa do Grupo Fleury foi criada com o objetivo de atrair, treinar e manter seus talentos. Hoje ela possui sede em São Paulo e uma unidade no Rio de Janeiro a qual dissemina conhecimento e os valores da organização. A 
instituição já foi considerada a melhor do Brasil no setor de saúde, segundo o prêmio Cubic Awards (Corporate University Best-in-Class), concedido pela empresa americana IQPC (International Quality Productivity Center), especializada em reconhecer iniciativas globais de educação empresarial.

O Grupo Fleury também acredita no desenvolvimento interno de seus talentos e na busca contínua pela produtividade e alto desempenho de seus colaboradores. O objetivo é que o colaborador reflita nos valores da companhia como a inovação, excelência e respeito. Portanto, as políticas de desenvolvimento organizacional procuram fazer uma conexão direta entre a estratégia corporativa e a cultura interna.

Desde o momento que o colaborador ingressa no Grupo Fleury, ele já participa de um programa de integração chamado Programa Intersomos. Trata-se de um jogo que tem como objetivo proporcionar uma visão geral dos desafios do Grupo Fleury e o que cada um pode fazer para possibilitar o protagonismo e a interdependência das áreas a serviço do cliente. Neste jogo é trabalhado os valores do Grupo Fleury, sendo um deles a inovação.

Por meio de um diálogo ilustrado, tem como objetivo sensibilizar todos os colaboradores para a importância de inovar no encantamento do cliente, do negócio de saúde a partir do conhecimento sobre o que a empresa faz (processos) e como faz (cultura).

Todos os anos os colaboradores são submetidos à avaliação pela metodologia Nine Box, no que é chamado o ciclo de desempenho do colaborador. Neste momento, o colaborador é avaliado pela performance conforme acordada nas suas metas pactuadas, e também ao grau de aderência à cultura, que são os comportamentos que refletem os valores do Grupo Fleury. Um dos valores é a inovação. Desse modo, são mapeados os colaboradores que apresentam maior aderência ao valor inovação. Estes colaboradores, segundo a companhia, apresentam maior potencial de crescimento para a empresa e, portanto, além de serem considerados elegíveis à promoções em seu plano de carreira, eles também podem receber cursos de desenvolvimento financiados pelo Fleury.

Entrevistado P1: "Uma vez que isso [um modelo de atração de talentos inovadores] está estabelecido, você tem que simplesmente fazer com que a coisa não morra. Precisa garantir a capacidade de se desenvolver; que ela tenha 0 ambiente suficiente para que isso 
aconteça. Criar um ambiente para que o conhecimento seja utilizado e alavancado [...] Estabelecer que os ambientes criem este círculo virtuoso e que esteja gerando e capturando valor pela organização, faz parte da nossa cultura"

Em 2015, o Grupo Fleury destinou aos programas de educação e treinamento o montante de $\mathrm{R} \$ 5$ milhões - média de $\mathrm{R} \$ 624$ por colaborador. Foram cerca de 433 mil horas - média de 50,6 horas por empregado. Mais de 2,1 mil atividades educacionais foram conduzidas pela Universidade Corporativa, com aumento da participação média por colaborador (10 atividades/colaborador, ante 7,3 atividades/colaborador do ano anterior).

Para se desenvolver, os colaboradores podem participar de programas de capacitação para o desempenho da função, aculturamento e engajamento. São diversos cursos ou propostas desenhadas para atender às necessidades do Grupo e ocorrem nas salas da Universidade Corporativa, nas unidades ou mesmo de maneira online, por meio do ensino a distância. Como exemplo, lançado em 2015, o projeto Educação em Saúde se destina à oferta de cursos de aprimoramento e desenvolvimento de acadêmicos e profissionais de saúde, nos quais se abordam temas atuais mantendo o público atualizado sobre as tendências do mercado. Estes cursos são semanais e demostram a preocupação dos fundadores com o desenvolvimento científico e a vocação na formação de talentos.

A universidade corporativa também possui parcerias com outras instituições, fornecendo aos colaboradores do Fleury descontos em cursos de línguas, cursos técnicos e mesmo de pós graduação.

Para os médicos, o Grupo Fleury oferece o Programa de Aperfeiçoamento Médico em Diagnóstico de Imagem, destinado a médicos recém-formados. O programa tem como principal objetivo aprofundar o conhecimento sobre exames de imagem por meio de aulas teóricas e práticas, ministradas por corpo docente altamente especializado e com experiência acadêmica nas diversas especialidades. Também busca orientar para o desenvolvimento de projetos de pesquisa visando a publicação e a apresentação de trabalhos científicos, além de sedimentar os protocolos de exame nas mais diversas indicações clínicas. Após a conclusão do programa, muitos desses médicos permanecem no Grupo, integrando o quadro de profissionais. 
Há dois programas de incentivo à inovação destinados aos médicos internos. O primeiro deles é o Programa de Excelência Médica (Proex). Neste programa, os médicos são incentivados a participar de atividades acadêmicas como palestras, aulas, apresentação de trabalhos em congressos, publicações de artigos e obtenção de títulos acadêmicos. O médico ganha uma pontuação para cada atividade que ele realizar. Esta pontuação é revertida no seu plano de carreira dentro do Grupo Fleury. Aqueles médicos que tiverem mais pontos são promovidos a posições seniores, e de liderança. Isso tudo é acompanhado com uma maior remuneração.

O outro programa é o Programa de Reconhecimento Médico (Promed). Neste programa a pontuação é conseguida via agendamentos preferenciais (quando o cliente pede que 0 atendimento seja feito por aquele médico), número de assessorias realizadas a médicos externos e pacientes, número de relatórios integrados e referências elogiosas àquele profissional. A assessoria é uma forma de difundir a inovação para fora da empresa.

Para todos os colaboradores e médicos, o Fleury também incentiva a participação nos congressos, simpósios acadêmicos, feiras e eventos. Todos os custos do colaborador ou do médico, passagem, hospedagem e alimentação são pagos pelo Fleury. Algumas regras e políticas devem ser seguidas, e o colaborador deve apresentar algum trabalho nestes eventos acadêmicos. A participação em feiras e eventos também é custodiada pelo Fleury. Ele deve trazer ideias sobre as principais inovações apresentadas nestes eventos.

Entrevistado P3: Se eu quero que ele vá para o congresso para trazer novidade, eu preciso ajudá-lo e incentivá-lo a ir."

Anualmente $\circ$ Grupo Fleury realiza 0 evento chamado Jornada do Conhecimento, quando durante duas semanas os colaboradores podem expor seus trabalhos, em grande maioria relacionados à inovação, e então são avaliados por uma comissão julgadora para apresentarem no formato de totem ou oralmente. No dia da apresentação uma segunda comissão avalia os trabalhos baseados na originalidade, conhecimento sobre o tema, metodologia, apresentação e contribuição para o Grupo Fleury. Os trabalhos mais bem avaliados recebem prêmios em dinheiro conforme as categorias e subcategorias em uma cerimônia especial ao final do evento.

Outro método de incentivo é o programa Central de ideias, que premia aqueles que geraram mais ideias, ou tiveram mais ideias implantadas. Além disso a 
participação do programa permite que o colaborador acumule moedas chamada de "inoves" as quais ele pode trocar por prêmios.

Também com o objetivo de incentivar as inovações de fornecedores por meio do relacionamento com a empresa, o Grupo Fleury possui o Programa de Excelência em Relacionamento com a Cadeia de Fornecedores (PERC), que faz parte do Banco de Melhores Práticas do Instituto Ethos e do Banco de Melhores Práticas do Prêmio ECO, da Câmara de Comércio Americana (Amcham). Neste programa, os fornecedores são avaliados trimestralmente sendo que uma das dimensões avaliadas é a Criatividade e Inovação do fornecedor, que envolve apresentação de ideias e sugestões com foco na otimização de processos, redução de custos, ganhos anuais de valor agregado e custo evitado. O fornecedor deve registrar suas ideias na plataforma da Central de Ideias para que sejam avaliadas. Anualmente são premiados aqueles que possuem melhor avaliação.

A edição de 2015 contou com 60 empresas participantes; foram implementadas 83 ideias apresentadas, que trouxeram ganho de $R \$ 483.858,64$ ao Grupo Fleury. Abaixo temos os principais achados da etapa de pessoas e organizacional: 
Quadro 7: Síntese dos achados em Pessoas e Organização

\begin{tabular}{|c|c|}
\hline & PESSOAS E ORGANIZAÇÃO \\
\hline 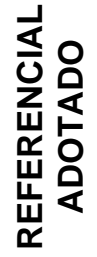 & $\begin{array}{l}\text { Pessoas e organização são a pedra fundamental da inovação. Aspectos motivacionais } \\
\text { (sistemas de incentivos), contratação e desenvolvimento profissional, e cultura organizacional } \\
\text { são elementos chave para o processo de inovação. (SEKI et al, 2003; DAVILA; EPSTEIN; } \\
\text { SHELTON, 2007; GOFFIN; MITCHELL, 2005; TIDD; BESSANT, 2015). }\end{array}$ \\
\hline 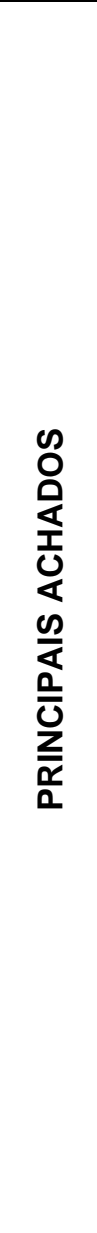 & $\begin{array}{l}\text { - A cultura de inovação é formada historicamente com os valores de inovação presentes em } \\
\text { - Em cus fundadores e médicos associados. } \\
\text { cultura de inovação foi formaḑão de conhecimento e relacionamento acadêmico que a } \\
\text { - A companhia sempre incentivou o conhecimento acadêmico, por meio de pesquisas - } \\
\text { conjuntas com as melhores universidades do país. } \\
\text { - No ambiente acadêmico de pesquisa que o Fleury contratou seus primeiros funcionários. } \\
\text { - Esta cultura reflete até hoje nos processos de seleção, onde se privilegia aqueles } \\
\text { candidatos ligados à pesquisa e inovação, e de preferência de boas universidades. } \\
\text { - O ambiente de inovação atrai naturalmente outros interessados que possuem o mesmo } \\
\text { perfil inovador. } \\
\text { - Há programas de recrutamento específico de candidatos com perfil inovador, como é o caso } \\
\text { do Programa de Trainees. } \\
\text { - O desenvolvimento ocorre com o apoio de uma universidade corporativa, onde se oferece } \\
\text { diversas atividades e cursos para os colaboradores. } \\
\text { - Programas de aperfeiçoamento médico também são oferecidos na universidade } \\
\text { - Arporativa. } \\
\text { valor de inovação. } \\
\text { - Colaboradores que se destacam nas avaliaçães são recompensados financeiramente ou } \\
\text { por meio de cursos especiais de desenvolvimento. } \\
\text { - Há programas de incentivo médico para participação em atividades acadêmicas, e para } \\
\text { atividades de relacionamento, colaborando com o processo de ideação e difusão } \\
\text { especialmente. } \\
\text { - O reconhecimento e compartilhamento de conhecimento também ocorre em um evento } \\
\text { anual onde os melhores trabalhos relacionados à inovação são premiados. } \\
\text { - As inovações de processos são incentivadas por meio do programa Central de Ideias, onde } \\
\text { há torneios o colaborador pode trocar moedas chamadas de inoves por prêmios. } \\
\text { - Os fornecedores também são incentivados a inovar por meio do programa PERC, que } \\
\text { premia os fornecedores conforme algumas categorias, sendo uma delas a inovação. }\end{array}$ \\
\hline
\end{tabular}

Fonte: Elaboração Própria 


\section{CONSIDERAÇÕES FINAIS}

Esta dissertação buscou responder a pergunta de pesquisa: como ocorre a gestão da inovação em um caso de Medicina Diagnóstica? Para isso teve como objetivo aprofundar a compreensão sobre a gestão da inovação em uma empresa de medicina diagnóstica, entendendo as etapas do processo de inovação (ideação, conversão e difusão), entendendo como a estratégia da inovação se insere no processo de gestão da inovação, e entendendo como que pessoas e organização se inserem na gestão da inovação.

A pesquisa evidenciou que a inovação é considerada o motor de crescimento, sendo sinônimo de sustentabilidade. Também evidenciou que a inovação pode reduzir custos e aumentar a qualidade, além de gerar valor para o restante da cadeia. No caso estudado, a inovação pode ser do tipo produto (ou serviço), processo, e novos negócios, com o grau de inovação incremental ou radical, e pode ocorrer tanto de maneira "puxada" pelas necessidades dos consumidores e do mercado, como também pode ser "empurrada" pelas atividades de pesquisa e desenvolvimento.

Em relação ao objetivo de entender como a estratégia da inovação se insere no processo de gestão da inovação, a pesquisa evidenciou que a estratégia de inovação é alinhada à estratégia corporativa de diferenciação, refletindo-a nos elementos de visão, missão e valores da companhia. Também se evidenciou que a inovação está presente nas competências centrais, levando a um diferencial competitivo de melhor solução diagnóstica. A estratégia de inovação é definida pelo planejamento estratégico e envolve etapas de diagnóstico, do ambiente externo e interno, a elaboração de cenários estratégicos, a escolha destes cenários e, por fim, a definição de drivers que direcionam inovação da companhia inteira, sendo os drivers mais importantes as especialidades médicas estratégicas e temas estratégicos.

Em relação ao objetivo de entender o processo de inovação, foi evidenciado os atores influenciadores no processo como órgãos reguladores, em especial a ANS e a ANVISA, médicos (internos e externos), pacientes, fornecedores e universidades. A influência das operadoras de saúde ocorre mas de fato não altera na decisão de lançamento de produtos. Isso se deve ao fato do posicionamento da empresa em ser uma referência em inovação. Sendo assim, com ou sem cobertura os exames novos são lançados, independentemente. Além destes atores influenciadores encontrados 
na literatura, outros atores foram citados como a influência dos órgãos representativos, que podem sugerir a incorporação de novas tecnologias no mercado, e debater avanços na saúde. E também foi citado o Ministério da Ciência e Tecnologia, dado que pode influenciar a inovação por meio do financiamento, como por exemplo através da FINEP, e incentivos fiscais, como por exemplo a Lei do Bem.

Ainda em processos, foi evidenciado no caso dois processos estruturados de inovação: processo de novos produtos e de novos processos. O processo de novos produtos é muito alinhado ao modelo de stage gates, enquanto que o processo de novos processos é mais alinhado ao modelo hegemônico. A etapa de ideação ocorre com geração de ideias tanto por fontes internas (numa mesma unidade de negócio e inter unidades) como externas. A geração de ideias é principalmente influenciada pelos médicos e técnicos assessores, pela área de $P \& D$ e pelos próprios colaboradores. Algumas ferramentas foram evidenciadas, como técnicas de brainstorming, observação do comportamento dos clientes e pesquisa. $\mathrm{Na}$ etapa de conversão a seleção e a avaliação pode ser feita de maneira colegiada ou individual, por meio de fóruns que podem ser inclusive virtuais. Os critérios de seleção e avaliação evidenciados foram o alinhamento estratégico, as análises financeiras, técnicas e comerciais. No desenvolvimento e implantação, foi evidenciado o desenvolvimento da inovação tanto no back office como no front office (relacional), e também a aplicação de pilotos e testes de protótipos antes da efetiva implantação da inovação. Foram destacados os treinamentos e acompanhamentos também como sendo essenciais nessas etapas. Por fim, a etapa de difusão ocorre externamente, por meio da equipe comercial junto às operadoras, e com a equipe de médicos e técnicos assessores, junto aos clientes médicos, além dos canais de divulgação como eventos e congressos. A divulgação com clientes finais se dá muito mais por meio dos sites, redes sociais, e revistas. Já internamente a comunicação ocorre principalmente na forma de murais e portais virtuais de comunicação, na atualização de documentos técnicos, e por meio de eventos internos de divulgação do conhecimento, premiação e reconhecimento.

Em relação ao objetivo de entender como pessoas e organização se inserem no processo de gestão da inovação, a pesquisa evidenciou que a cultura influencia o processo de gestão da inovação. O caso evidenciou que a cultura de inovação formada historicamente sobre os pilares de geração de conhecimento e relacionamento acadêmico nas universidades levou a empresa a uma posição 
reconhecida de inovação. A pesquisa evidenciou que a empresa busca gerenciar seus recursos humanos capturando pessoas alinhadas ao valor da inovação desde a fase de contratação, passando por treinamentos e desenvolvimento, avaliação constante, reconhecendo e premiando estes colaboradores. Não somente os colabores internos recebem incentivos e reconhecimentos, como também há incentivos a fornecedores, médicos e universitários por meio de programas específicos.

Sendo assim, entende-se que o estudo cumpriu seu objetivo principal de aprofundar a compreensão sobre a gestão da inovação em uma empresa de medicina diagnóstica. É claro que, sendo um estudo de caso único, não é pretensão deste generalizar os resultados encontrados nesta pesquisa. Portanto, com o objetivo de dar continuidade e ampliar o conhecimento desta pesquisa, sugere-se: (i) aplicar a pesquisa em outras empresas de medicina diagnóstica, de diferentes portes e tipos de gestão (público ou privado), comparando os resultados obtidos; (ii) aplicar a pesquisa em outros serviços de saúde, como por exemplo em hospitais, comparando os resultados obtidos; (iii) realizar uma estudo quantitativo sobre o tema de gestão da inovação (em medicina diagnóstica ou serviços de saúde), analisando o uso e grau de maturidade das práticas encontradas na literatura; (iv) propor uma metodologia, ou modelo para gestão da inovação em medicina diagnóstica ou serviços de saúde. 


\section{REFERÊNCIAS BIBLIOGRÁFICAS}

ALBUQUERQUE, E.M.; CASSIOLATO, J.E. As especificidades do sistema de inovação do setor saúde. Revista de Economia Política, v. 22, n.4, p. 134-151, 2002.

ANDRADE, M. V.; MAIA, A. C. Demanda por planos de saúde no Brasil, Anais do XXXIV Encontro Nacional de Economia, ANPEC - Associação Nacional dos Centros de Pós-graduação em Economia, 2006.

ANS TABNET. Agência Nacional de Saúde Suplementar (ANS). Disponível em: <http://www.ans.gov.br/anstabnet/> Acesso em: 10 mar. 2017.

ANS. Mapa Assistencial da Saúde Suplementar 2015. Disponível em: $<$ http://www.ans.gov.br/images/stories/Materiais_para_pesquisa/Materiais_por_assu nto/mapa_assistencial_2016007.pdf> Acesso em: 10 mar. 2017.

AURIEMO, C.C.; ROSENFELD, L.G.M. A Medicina Diagnóstica no Brasil. In: AMORIM, M.C.S.; PERILLO, E.B. da F. Para entender a Saúde no Brasil. São Paulo: LCTE, 2006.

BARBASH, G. I.; GLIED, S. A. New Technology and Health Care Costs - The Case of Robot-Assisted Surgery. The New England Journal of Medicine, v.363, n.8, p.771-774, 2010.

BAREGHEH, A.; ROWLEY, J.; SAMBROOK, S. Towards a multidisciplinary definition of innovation. Management Decision, v.47, n.8, p.1323-1339, 2009.

BECKER, A.A. A gestão do laboratório de análises clínicas por meio de indicadores de desempenho através de utilização do Balance Scorecard [dissertação]. Porto Alegre: Escola de Engenharia, Universidade Federal do Rio Grande do Sul; 2004.

BOHRER, C. T.; VARGAS, E. R.. Innovation in hospital services from a perspective of technical operations: case studies in university hospitals. In: International Conference on Innovation and Management, 7th, 2009, Wuhan-China. Disponível em: <http://www.pucsp.br/icim/ingles/downloads/papers/TL_036\%20.pdf>. Acesso em: 20 mai. 2016.

BRASIL. Constituição (1988). Constituição da República Federativa do Brasil. Organização de Alexandre de Moraes. 16.ed. São Paulo: Atlas, 2000 
BURNS, L.R.; DEGRAAF, R.A.; DANZON, P.M.; KIMBERLY, J.R.; PAULY, M.V. The Wharton School study of the health care value chain. In: BURNS, L.R., editor. The health care value chain: producers, purchasers and providers. San Francisco: JosseyBass; 2002.

CAMPANA, G.A.; FARO, L.B.; GONZALEZ, C.P.O.; Fatores competitivos de produção em medicina diagnóstica: da área técnica para o mercado. Jornal Brasileiro de Patologia e Medicina Laboratorial v.45, n.4, p. 295-303, 2009.

CAMPANA, G.A.; OPLUSTIL, L.B.; GONZALEZ, C.P.O.; Tendências em medicina laboratorial. Jornal Brasileiro de Patologia e Medicina Laboratorial, v.47, n.4, p. 399-408, 2011.

CAMPOS, E.F.; GONTIJO, M.C.F.; OLIVEIRA, P.J.; CHAVES, S.R.; LAUDARES, P., editores. A cadeia de valor em saúde: uma proposta de reorganização da atenção na saúde suplementar. Belo Horizonte: Unimed Federação Minas; 2009.

CHAVES, V.C.; ALBUQUERQUE, E.M. Desconexão no sistema de inovação no setor de saúde: uma avaliação preliminar do caso brasileiro a partir de estatísticas de patentes e artigos. Economia Aplicada, São Paulo, v.10, n.4, p.523-539, 2006.

CHESBROUGH, H. W. The era of open innovation. MITSloan Management Review, v. 44, n. 3, p. 35-41, 2003.

CHRISTENSEN, M.C.; BOHMER, R.; KENAGY, J. Will disruptive innovations cure Health Care? Harvard Business Review, v.78, n.5, p.102-112, 2000.

CHRISTENSEN, M.C.; GROSSMAN, J.H.; HWANG, J. Inovação na gestão da saúde: a receita pra reduzir custos e aumentar a qualidade. Porto Alegre: Bookman, 2009.

CNES. Cadastro nacional de estabelecimentos de saúde. CNESNet: Secretaria de Atenção à Saúde. Disponível em: <http://cnes.datasus.gov.br/> . Acesso em: 10 mar. 2017.

COOPER, R.G., Stage-Gate Systems: A New Tool for Managing New Products. Business Horizons, v.33, n.3, p. 44-56, 1990.

COOPER, R.G.; EDGETT, S. J. Product development for the service sector lessons from market leaders. New York: Basic Books, 1999. 
CORRÊA, H.L.; CAON, M. Gestão em Serviços: lucratividade por meio de operações e de satisfação dos clientes. São Paulo: Atlas, 2006.

COSTA, L.S. Inovação nos serviços de saúde: apontamentos sobre os limites do conhecimento. Cadernos de Saúde Pública, v.32, supl.2 Rio de Janeiro, 2016.

CURTIS, L.H., SCHULMAN K.A. Overregulation of health care: musings on disruptive innovation theory. Law and Contemporary Problems, v.69, n.4, p.195-206, 2006.

DAVILA, T.; EPSTEIN, M.J.; SHELTON, R. As regras da inovação. Porto Alegre: Bookman, 2007.

DJELLAL, F.; GALLOUJ, F. Mapping innovation dynamics in hospitals. Research Policy, v.34, n.6, p. 817-835, 2005.

DJELLAL, F.; GALLOUJ, F. Innovation in hospitals: a survey of the literature. European Journal of Health Economics, v.8, n.3, p.181-193, 2007.

DOCHERTY, M. Primer on "Open innovation": Principles and Practice. PDMA Visions Magazine, v. 30, n.2, p. 13-15, 2006.

DOSI, G. Technological paradigms and technological trajectories: a suggested interpretation of the determinants and directions of technical change. Research Policy, v.11, n.3, p.147-167, 1982.

DRUCKER, P. F. Inovação e o espírito empreendedor: prática e princípios. São Paulo: Pioneira Thomson, 2003.

EISENHARDT, K. M. Building Theories from Case Study Research. Academy of Management Review, v. 14, n.4, p. 532-550, 1989.

FAULKNER, A.; KENT, J. Innovation and Regulation in Human Implant Technologies: Developing Comparative Approaches. Social Science and Medicine, v. 53, n.7, p. 895-913, 2001.

FITZSIMMONS, J.A.; FITZSIMMONS, M.J. Administração de serviços: Operações, estratégia e tecnologia da informação. 6ed Porto Alegre: Bookman, 2011.

FREEMAN, C.; PEREZ, C. Structural crisis of adjustment: business cycles and investment behavior. In: DOSI, G; FREEMAN, C.; NELSON, R.; SILVERBERG, G. Technical change and economic theory. London: Pinter, 1988. 
FORSMAN, R. W. Why is the laboratory an afterthought for managed care organizations? Clinical Chemistry, v.42, n.5, p. 813-816, 1996.

GADELHA, C.A.G. O complexo industrial da saúde e a necessidade de um enfoque dinâmico na economia da saúde. Ciência Saúde Coletiva, v.8, n.2, p.521-535, 2003.

GADREY, J. Emprego, produtividade e avaliação do desempenho dos serviços. In: SALERNO, M (ed). Relação de serviço. Produção e Avaliação. São Paulo: SENAC São Paulo, 2001.

GADREY J.; GALLOUJ, F.; WEINSTEIN, O. New modes of innovation: how services benefit industry. International Journal of Service Industry Management, v.6, n.3, p.4-16, 1995.

GALLOUJ, F. Innovating in reverse: services and the reverse product cycle. European Journal of Innovation Management, v.1, n.3, p.123-138, 1998.

GALLOUJ, F.; SAVONA, M.; Innovation in services: a review of the debate and research agenda. The Journal of Evolutionary Economics, v.19, n.2, p. 149-172, 2009.

GALLOUJ, F.; WEINSTEIN, O. Innovation in services. Research Policy, v.2, n.4, p. 537-556, 1997.

GALLOUJ, F.; WINDRUM, P. Services and service innovation. Journal of Evolutionary Economics, v. 19, n.2, p. 141-148, 2009.

GARCÍA-GOÑI, M.; MAROTO, A; RUBALCABA, L. Innovation and motivation in public health professionals. Health Policy, v.84, n.2, p.344-358, 2007.

GIL, A. C. Como elaborar projetos de pesquisa. São Paulo: Atlas, 2008.

GOES, J.B.; PARK, S.H. Interorganizational links and innovation: the case of hospital services. Academy of Management Journal, v.4, n.3, p.673-696, 1997.

GOFFIN, K.; MITCHELL, R. Innovation Management: strategy and implementation using the pentathlon framework. London: Palgrave Macmillan, 2005.

GOYEN, M., DEBATIN, J. F. Healthcare costs for new technologies. European Journal of Nuclear Medicine and Molecular Imaging, v. 36, n.1, p. 139-143, 2008. 
GRECO, P.; EISENBERG, J.M. Changing Physicians' Practices. New England Journal of Medicine, v.329, n.17, p.1271-1273, 1993.

GRUPO FLEURY. A Inovação no Grupo Fleury. Disponível em: <http://www.grupofleury.com.br/SitePages/inovacao/default.aspx>. Acesso em: 10 mar. 2017a.

GRUPO FLEURY. Apresentação institucional 1T17. Apresentações Institucionais. Disponível em: $<$ http://ri.fleury.com.br/fleury/web/conteudo_pt.asp?idioma=0\&conta=28\&tipo=28886 >. Acesso em: 10 mar. 2017b.

GRUPO FLEURY. Relatório Anual de Sustentabilidade 2015. Relatórios Anuais de Sustentabilidade.

$<$ http://ri.fleury.com.br/fleury/web/conteudo_pt.asp?idioma=0\&conta=28\&tipo=44526 >. Acesso em: 10 mar. 2017c.

HANSEN, M. T.; BIRKINSHAW, J. The innovation value chain. Harvard Business Review, v. 85, n. 6, p. 121-130, 2007.

HERZLINGER, R. E. Why Innovation in Health Care is so Hard. Harvard Business Review, v.84, n. 5, p. 58-66, 2006.

HILL, P. On Goods and Services. The review of Income and Wealth, v.23, n.4, p.315338, 1977.

IBGE. Estatísticas da saúde: assistência médico-sanitária 2009. Ministério do Planejamento, Orçamento e Gestão. Rio de Janeiro: 2010.

IBGE. Contas Nacionais Trimestrais: Indicadores de Volume e Valores Correntes. Ministério do Planejamento, Orçamento e Gestão. Rio de Janeiro: 2016.

IESS, Instituto de Estudos de Saúde Suplementar. A cadeia de saúde suplementar no Brasil, Avaliação de Falhas de Mercado e Propostas de Políticas, 2016.

JOHNSTON, R.; CLARK, G. Administração de Operações e Serviços. Editora Atlas: São Paulo, 2012.

KNOTTNERUS, J.A.; VAN WEEL, C.; MURIS, J.W.M. Evaluation of diagnostic procedures. BMJ Quality \& Safety, v. 324, n. 7335, p. 477-480, 2002. 
MARCONI, M.A.; LAKATOS, E.M. Fundamentos de metodologia científica. São Paulo: Atlas, 2007

MARTINS, L.O. O seguimento de Medicina Diagnóstica no Brasil. Rev. Fac. Ciênc. Méd. Sorocaba, v. 16, n. 3, p. 139-145, 2014.

MARTINS, L. O.; AMORIM, M.C.S.; LAS CASAS, A.L. Demanda e Produtividade em Medicina Diagnóstica: Um Estudo de Caso. Revista Pensamento \& Realidade, v. 27, n.3, p.19-35, 2012.

MONTANHA JUNIOR, I.R.; LEONEL, C.E.L.; OGLIARI, A.; DIAS, A.; GEISLER, L. Importância, Definição e Modelos de Inovação. In: CORAL, E.; OGLIARI, A.; ABREU, A.F. (Ed.). Gestão Integrada da Inovação: Estratégia, Organização e Desenvolvimento de Produtos. São Paulo: Atlas, 2008.

NEVES, J.L. Pesquisa Qualitativa: Características, usos e possibilidades. Caderno de pesquisas em administração, v.1, n.3, p.1-5, 1996

OCDE. Manual e Oslo: Proposta de Diretrizes para Coleta e Interpretação de Dados sobre Inovação Tecnológica. Tradução: Financiadora de Estudos e Projetos - FINEP. 3. ed. 2004. Disponível em: <http://www.finep.gov.br/images/apoio-efinanciamento/manualoslo.pdf>. Acesso em: 05 mai. 2014

OMACHONU, V.K.; EINSPRUCH, N.G. Innovation in healthcare delivery systems: a conceptual framework. The Innovation Journal: The Public Sector Innovation Journal; v.15, n.1, p.1-20, 2010.

PANTALEÃO, L.H.; ANTUNES JÚNIOR, J.A.V.; PELLEGRIN, I. A inovação e a curva da Riqueza. In: Simpósio de Engenharia de Produção, XIV, 2007, Bauru. Anais Eletrônicos do XIV SIMPEP. Bauru: Universidade Estatual Paulista- Unesp, 2007.

PEDROSO, M.C.; Um modelo de gestão estratégica para serviços de saúde. 2010. 423f. Tese (Doutorado). Faculdade de Medicina da Unniversidade de São Paulo. Programa de Medicina Preventiva, São Paulo, 2010.

PEDROSO, M.C.; Apêndice B - Estudo de Caso: Grupo Fleury: experiência dos clientes em serviços de saúde. In: PEDROSO, M.C.; Um modelo de gestão estratégica para serviços de saúde. 2016. 409f. Tese (Livre-Docência). Faculdade de Economia, Administração e Contabilidade da Universidade de São Paulo. São Paulo, 2016.

PEDROSO, M.C.; MALIK, A.M. As quatro dimensões competitivas da saúde. Harvard Business Review. Ed. Brasil, v.89, n.3, p. 54-63, 2011. 
PEDROSO, M.C.; MALIK, A.M. Cadeia de Valor da saúde, um modelo para o sistema de saúde brasileiro. Ciência \& Saúde Coletiva, v.17, n.10, p.2757-2772, 2012.

PISANO, G.P. Science business: the promise, the reality and the future of biotech. Boston: Harvard Business School Press; 2006.

PORTER, M. E. The Competitive Advantage: Creating and Sustaining Superior Performance. NY: Free Press, 1985.

PORTER, M. E.; TEISBERG, E. O. Redefining Competition in Health Care. Harvard Business Review, v. 82, n.6, p.65-76, 2004.

PORTER, M. E.; TEISBERG, E. O. Repensando a saúde: estratégias para melhorar a qualidade e reduzir custos. Porto Alegre: Bookman; 2007

PRAHALAD, C. K.; HAMEL, G. The Core Competence of the Corporation. Harvard Business Review, v.68, n.3, p.79-91, 1990.

PROENÇA, A.; LACERDA, D.P.; ANTUNES JR, J.A.V.; TÁVORA JR, J.L.; SALERNO, M.S. Gestão da inovação e competitividade no Brasil: da teoria para a prática. Porto Alegre: Bookman, 2015.

ROTHWELL, R. Towards the Fifth-generation Innovation Process. International Marketing Review, v. 11, n.1, p. 7-31, 1994.

SALERNO, M. A seu serviço: interrogações sobre o conceito, os modelos de produção e o trabalho em atividades de serviços. In: SALERNO, M (ed). Relação de serviço. Produção e Avaliação. São Paulo: SENAC São Paulo, 2001.

SAVIOTTI, P.P.; METCALFE, J.S. A theoretical approach to the constrution of technological output indicators. Research Policy, v.13, p.141-151, 1984.

SCHUMPETER, J. A. A teoria do desenvolvimento econômico. São Paulo: Abril Cultural, 1982.

SCHUMPETER, J.A. Capitalismo, Socialismo e democracia. Rio de Janeiro: Zahar, 1984.

SEKI, M.; JÚNIOR, P. G. P.; SEKI, M. O.; NIYAMA, F. P.; CARUSO, M. C.; PASCHOALETTO, M. C. D. L.; SEKI, M. O.; SELLMANN, S. A. S.; VIVAN, R. H. F.; 
RUIZ, L. P. A inovação de valores nos laboratórios clínicos. Jornal Brasileiro de Patologia e Medicina Laboratorial. Rio de Janeiro, v. 39, n. 3, p. 211-214, 2003.

SHOSTACK, L.G. Breaking Free from Product Marketing. Journal of Marketing, v. 41, n. 1, p. 73-80, 1977.

SILVA, D.O.; BAGNO, R.B.; SALERNO, M.S. A inovação como processo de gestão: análise crítica da literatura. In: PROENÇA et al (org). Gestão da inovação e competitividade no Brasil: da teoria para a prática. Porto Alegre: Bookman, 2015.

SILVA, D.O.; BAGNO, R.B.; SALERNO, M.S. Modelos para a gestão da inovação: revisão e análise da literatura. Production, v. 24, n. 2, p. 477-490, 2014.

SILVA, D. O. Proposta para análise da gestão da inovação em serviços hospitalares: um estudo no Hospital Mãe de Deus - Porto Alegre, RS. Dissertação (Mestrado). Programa de Pós-Graduação e Engenharia de Produção e Sistemas: Universidade o Vale do Rio dos Sinos, São Leopoldo, 2011.

SUNDBO, J.; GALLOUJ, F. Innovation as a loosely coupled system in services. International Journal of Services Technology and Management, v.1, n.1, p. 15-36, 2000.

SUNDBO, J.; GALLOUJ, F. Innovation in services in seven European countries: the results of work packages 3-4 of the SI4S project. (Research Report) Universitè Lille 1, CLERSE; Roskilde University. 1998.

THAKUR, R.; HSU, S.; FONTENOT, G. Innovation in healthcare: Issues and future trends. Jornal of Business Research. v. 65, n.44, p. 562-569, 2012.

TIDD, J.; BESSANT, J. Gestão da inovação. 5. ed. Porto Alegre: Bookman, 2015.

UTTERBACK, J. Process of Innovation - a Study of Origination and Development of Ideas for New Scientific Instruments. IEEE Transactions on Engineering Management, v.18, n. 4, p.124-131, 1971.

UTTERBACK, J. Dominando a Dinâmica da Inovação. Rio de Janeiro: Qualitymark Editora Ltda. 1996.

VARGAS, E.R. A dinâmica da inovação em serviços: o caso dos serviços hospitalares no Brasil e na França. Tese (Doutorado em Administração), Programa de Pós-Graduação em Administração. Universidade Federal do Rio Grande do Sul, porto Alegre, RS, 2006. 
VARGAS, E.R. Serviços, inovação e desenvolvimento local. Revista de Economía Política de las Tecnologías de la Información y Comunicación, v.11, n.1, p. 1-26, 2009.

VARKEY, P.; HORNE, A.; BENNET, K. E. Innovation in health care: a primer. American Journal of Medical Quality, v. 23, n.5, 382-388, 2008.

WHEELWRIGHT, S.C.; CLARK, K. B. Revolutionizing product development: quantum leaps in speed, efficiency, and quality. New York: The Free Press, 1992

WINDRUM, P.; GARCÍA-GONI, M. A neo-Schumpeterian model of health services innovation. Research Policy, v. 37, n. 4, p. 649-672, 2008.

ZARIFIAN, P. Mutação dos sistemas produtivos e competências profissionais: a produção industrial de serviço. In: SALERNO, M. (ed). Relação de serviço. Produção e Avaliação. São Paulo: SENAC São Paulo, 2001a.

ZARIFIAN, P. Valor, organização e competência na produção de serviço - esboço de um modelo de produção de serviço. In: SALERNO, M. (ed). Relação de serviço. Produção e Avaliação. São Paulo: SENAC São Paulo, 2001b.

ZEITHAML, V.A.; BITNER, M. J.; Marketing de Serviços: a empresa com foco no cliente. 2를 Edição. Porto Alegre: Bookman, 2003.

ZEITHAML, V.A.; PARASURAMAN, A.; BERRY, L.L. Problems and Strategies in Service Marketing. Journal of Marketing, v.49, p.33-46, 1985.

YIN, R.K. Estudo de Caso: Planejamento e Método. 4. Ed. São Paulo: Bookman, 2010. 


\section{APÊNDICES}

\section{APÊNDICE 1: PROTOCOLO DE PESQUISA}

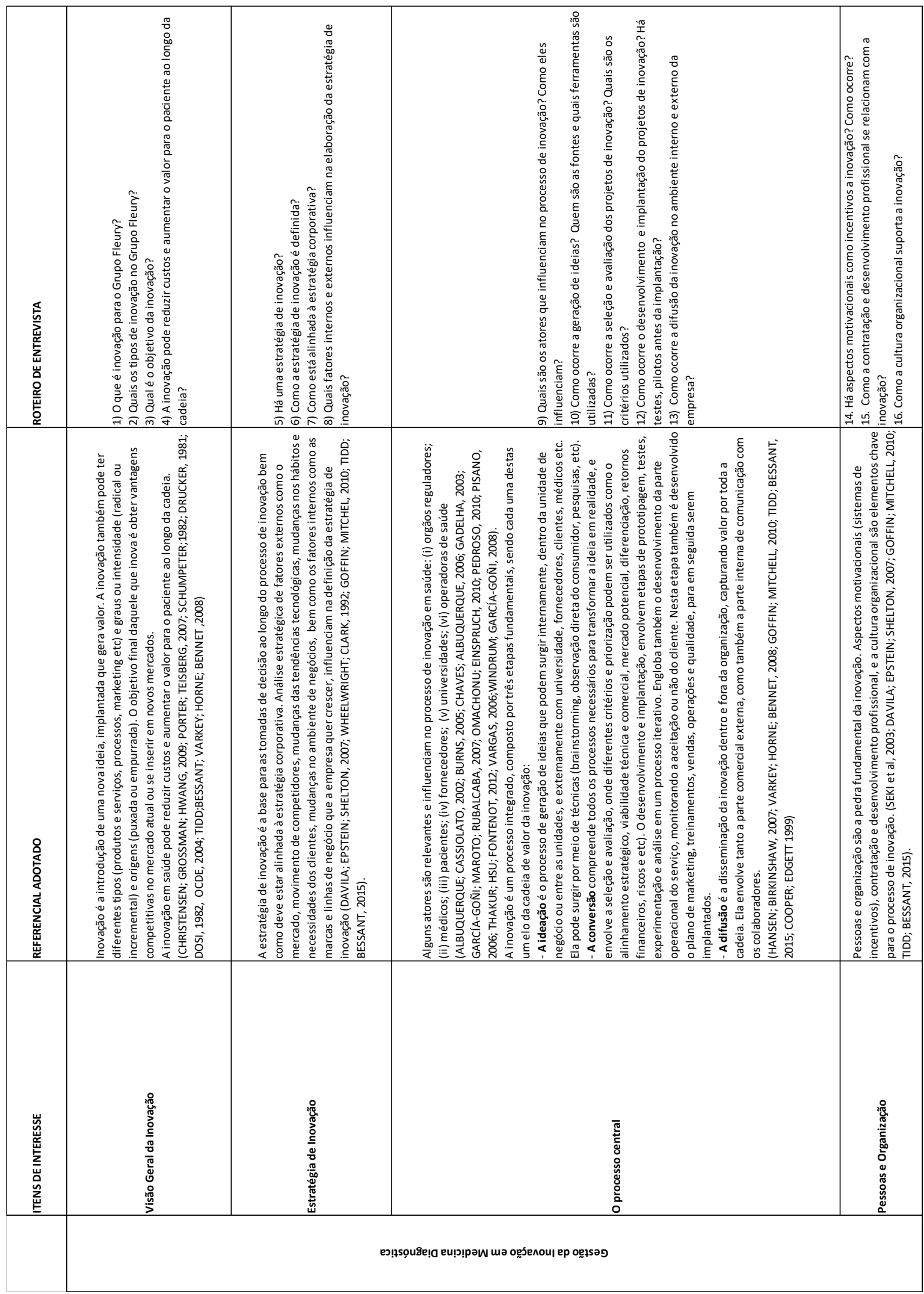




\section{APÊNDICE 2: CARTA CONVITE PARA A PESQUISA}

\section{STEAUSP}

Caro entrevistado,

Gostaria de convidá-lo a participar da pesquisa de campo da minha dissertação de mestrado, conduzida na Faculdade de Economia, Administração e Contabilidade da Universidade de São Paulo - USP, sob a orientação do Profo. Dro. Marcelo Caldeira Pedroso.

O estudo é de natureza exploratória e aborda a seguinte questão de pesquisa:

- Como ocorre a gestão da inovação em Medicina Diagnóstica?

Dada a questão de pesquisa, o objetivo deste projeto é aprofundar a compreensão sobre a gestão da inovação em uma empresa de medicina diagnóstica, buscando avançar no conhecimento de cada etapa do processo de gestão da inovação. Neste sentido, partindo de uma abordagem processual, tomando como base as etapas do processo de gestão da inovação encontrados na literatura, o estudo visa entender três objetivos específicos:

- $\quad$ Entender o processo de ideação, conversão e difusão da inovação em Medicina Diagnóstica

- $\quad$ Entender como a estratégia de inovação se insere no processo de gestão da inovação

- $\quad$ Entender como pessoas e organização se inserem no processo de gestão da inovação

Para isso, será realizada uma entrevista com duração de cerca de 60 minutos, em que gravarei o conteúdo para posterior análise.

O conteúdo será utilizado apenas para a realização do estudo, podendo ser publicado no meio acadêmico. É importante informar que será mantido absoluto sigilo quanto à sua identidade. A sua participação será totalmente voluntária, podendo deixá-la a qualquer momento.

Contamos com sua participação,

Att.,

Edgard Rasquini Arnas 


\section{APÊNDICE 3: TERMO DE CONCENTIMENTO DO ENTREVISTADO}

\section{TERMO DE CONSENTIMENTO LIVRE E ESCLARECIDO}

Você está sendo convidado(a) como voluntário(a) a participar da pesquisa para dissertação de mestrado com o tema em Gestão Da Inovação.

A JUSTIFICATIVA, OS OBJETIVOS E OS PROCEDIMENTOS: O motivo que nos leva a estudar a gestão da inovação em medicina diagnóstica é enriquecer a literatura sobre o tema. $O$ objetivo é compreender como ocorre o processo de geração, conversão e difusão da inovação, e também entender como a estratégia de inovação, pessoas e organização se inserem neste processo.

Para isso, será realizada uma entrevista com duração de cerca de 60 minutos, em que o conteúdo será gravado para posterior análise.

DESCONFORTOS E RISCOS E BENEFÍCIOS: Existe um desconforto e risco mínimo para a você que se submeter à coleta do dado sendo que se justifica por sua contribuição de conhecimento à sociedade.

GARANTIA DE ESCLARECIMENTO, LIBERDADE DE RECUSA E GARANTIA DE SIGILO: Você será esclarecido(a) sobre a pesquisa em qualquer aspecto que desejar. Você é livre para recusar-se a participar, retirar seu consentimento ou interromper a participação a qualquer momento. A sua participação é voluntária e a recusa em participar não irá acarretar qualquer penalidade ou perda de benefícios.

O(s) pesquisador(es) irá(ão) tratar a sua identidade com padrões profissionais de sigilo. Você não será identificado(a) nominalmente em nenhuma publicação que possa resultar deste estudo. Uma cópia deste consentimento informado será arquivada na plataforma educacional da Universidade Corporativa - Click Educação e outra será fornecida a você.

CUSTOS DA PARTICIPAÇÃO, RESSARCIMENTO E INDENIZAÇÃO POR EVENTUAIS DANOS: A participação no estudo não acarretará custos para você e não será disponível nenhuma compensação financeira adicional.

DECLARAÇÃo Eu, fui informada (o) dos objetivos da pesquisa acima de maneira clara e detalhada e esclareci minhas dúvidas. Sei que em qualquer momento poderei solicitar novas informações e motivar minha decisão se assim o desejar. $\mathrm{O}$ (a) colaborador (a) que está realizando a pesquisa Edgard Rasquini Arnas certificou-me de que todos os dados desta pesquisa serão confidenciais.

Declaro que concordo em participar desse estudo. Recebi uma cópia deste termo de consentimento livre e esclarecido e me foi dada a oportunidade de ler e esclarecer as minhas dúvidas.

\begin{tabular}{clc}
\hline Nome & Assinatura do Participante & Data \\
& & \\
\hline Nome & Assinatura do Pesquisador & \\
\hline Nome & Assinatura da Testemunha & Data
\end{tabular}

